\title{
Preparations of Sulfamates and Sulfamides Using a Selective Sulfamoylation Agent
}

Hai-Ming Wang, ${ }^{\mathrm{a}}$ Chao-Dong Xiong, ${ }^{\mathrm{c}, \mathrm{d}}$ Xiao-Qu Chen, ${ }^{\mathrm{b}}$ Chun $\mathrm{Hu}^{* \mathrm{a}}$ and Dong-Yu Wang*b

${ }^{a}$ Key Laboratory of Structure-based Drug Design \& Discovery, Ministry of Education; School of Pharmaceutical Engineering, Shenyang Pharmaceutical University, Shenyang 110016, China.

${ }^{\mathrm{b}}$ School of Pharmacy, Shanghai Jiao Tong University, 800 Dongchuan Road, Shanghai 200240, China.

${ }^{\mathrm{c}}$ CAS Key Laboratory of Receptor Research, Shanghai Institute of Materia Medica (SIMM), Chinese Academy of Sciences, Shanghai 201203, China.

d University of Chinese Academy of Sciences, Beijing 100049, China. 


\section{Table of Contents}

1. General Methods for Experiments

2. Procedure for the Preparation of Sulfamoylation Reagent $\mathbf{1}$ and Measurement of Saturated Solubility

3. Optimization for Reaction Conditions

4. General Procedure for the Sulfamoylation of Alcohols (Phenols).

5. General Procedure for the Sulfamoylation of Amines.

6. Procedure for the Sulfamoylation with Various Pharmaceuticals and Bioactive Molecules, or Their Derivatives Containing an $\mathrm{OH}$ or $\mathrm{NH}_{2}$ Moiety

7. Procedure for the Selective Sulfamoylation of Compounds with S4 Different Nucleophilic Groups.

8. Characterization of Products

9. Copies of NMR spectra data 


\section{General Methods for Experiments}

Solvents and chemical reagents were obtained from commercial sources and used without further purification. ${ }^{1} \mathrm{H}$ NMR spectral data were recorded in chloroform-d, DMSO-d6, or Methanol-d4 on Varian Mercury 400, 500 or 600 NMR spectrometer, and ${ }^{13} \mathrm{C}$ NMR was recorded in chloroform-d, DMSO-d6 or methanol-d4 on Varian Mercury 500, 600 NMR spectrometer. Low-resolution mass spectra (MS) and high-resolution mass spectra (HRMS) were recorded on a Thermo Fisher Finnigan LTQ or Agilent G6520 Q-TOF spectrometer. Column chromatography was carried out on silica gel (200-300 mesh). All reactions were monitored using thin layer chromatography (TLC) on silica gel plates $(15 \mathrm{~mm} \times 50 \mathrm{~mm})$.

\section{Procedure for the Preparation of Sulfamoylation Reagent 1 and Measurement of Saturated Solubility}

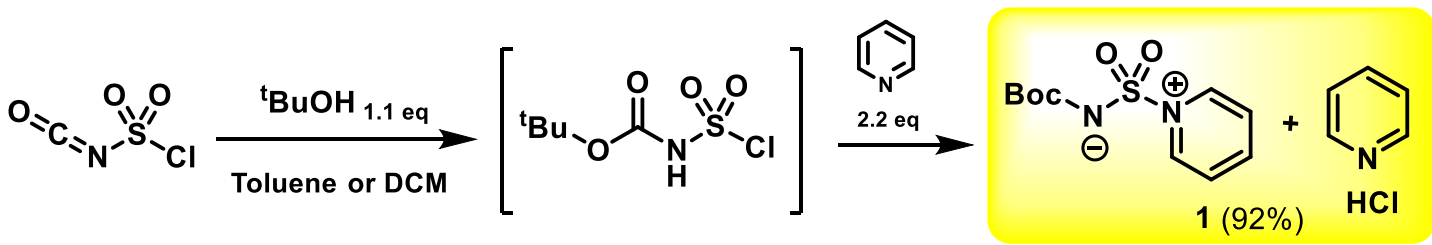

In order to prepare 1, Tert-butyl alcohol (1630 mg, $22 \mathrm{mmol}, 1.1$ equiv) and anhydrous toluene ( $400.0 \mathrm{~mL}, 3.76 \mathrm{~mol}, 16.3$ equiv) were added to a reaction vessel under nitrogen and the mixture was cooled to $0^{\circ} \mathrm{C}$. chlorosulfonyl isocyanate $(2830 \mathrm{mg}$, 20 mmol, 1.0 equiv) was added at a rate that kept the temperature below $0{ }^{\circ} \mathrm{C}$ and the mixture was stirred for 1 hour. Pyridine (3480 mg, $44 \mathrm{mmol}, 2.2$ equiv) was added while keeping the temperature below $0{ }^{\circ} \mathrm{C}$ and the mixture was then stirred for 4 hours at at room temperature. Sulfamoylating reagent 1 was collected by filtration and dried under vacuum giving a white solid (6863 mg, $18.4 \mathrm{mmol}, 92 \%$ yield).

To Measure the saturated solubility of sulfamoylation reagent $\mathbf{1}$, acetonitrile-d3 (1.0 $\mathrm{ml}), \mathbf{1}(1.0 \mathrm{mmol})$ were added to a vial at room temperature and the mixture was stirred for 5 min. After a filtration, the concentration of 1 was calculated based on ${ }^{1} \mathrm{H}-\mathrm{NMR}$ analysis with mesitylene as an internal standard. The saturated solubility of Burgesstype reagent $(\mathbf{C})$ was measured with the same procedure. 
3. Optimization for Reaction Conditions.<smiles>O=C(NS(=O)(=O)OC(=O)c1ccccc1)OCCc1ccc2ccccc2c1</smiles>

\begin{tabular}{ccccc}
\hline Entry & $\mathrm{n}$ & Additive & Solvent & 3a yield ${ }^{[\mathrm{b}]}$ \\
\hline 1 & 1.5 & - & $\mathrm{DCM}$ & $80 \%$ \\
2 & 2 & - & $\mathrm{DCM}$ & $82 \%$ \\
3 & 2.5 & - & $\mathrm{DCM}$ & $79 \%$ \\
4 & 1.5 & - & $\mathrm{THF}$ & $51 \%$ \\
5 & 1.5 & - & $\mathrm{DMF}$ & $43 \%$ \\
6 & 1.5 & - & $\mathrm{MeCN}$ & $79 \%$ \\
7 & 1.5 & & $\mathrm{DCE}$ & $71 \%$ \\
8 & 1.5 & $\mathrm{Cs}_{2} \mathrm{CO}_{3}$ & $\mathrm{DCM}$ & $77 \%$ \\
9 & 1.5 & $\mathrm{KO}^{\mathrm{t}} \mathrm{Bu}$ & $\mathrm{DCM}$ & $61 \%$ \\
10 & 1.5 & $\mathrm{DIPEA}$ & $\mathrm{DCM}$ & $53 \%$ \\
11 & 1.5 & $\mathrm{~K}_{2} \mathrm{CO} 3$ & $\mathrm{DCM}$ & $73 \%$ \\
12 & 1.5 & $\mathrm{CF}_{3} \mathrm{COOH}_{3}$ & $\mathrm{DCM}$ & $34 \%$ \\
13 & 1.5 & $\mathrm{AlCl}_{3}$ & $\mathrm{DCM}$ & $32 \%$ \\
14 & 1.5 & $\mathrm{CH}_{3} \mathrm{COOH}$ & $\mathrm{DCM}$ & $43 \%$ \\
\hline
\end{tabular}

[a] Reaction conditions: 2-(naphthalen-2-yl)ethan-1-ol (2a, $0.2 \mathrm{mmol}), \mathbf{1}$ (n eq.), additive ( $0.4 \mathrm{mmol})$, Ligand (0.024 mmol), Solvent $(1 \mathrm{ml})$, room temperature, $3 \mathrm{~h}$.

${ }^{[b]}$ Yields were calculated based on ${ }^{1} \mathrm{H}-\mathrm{NMR}$ analysis with mesitylene as an internal standard.

\section{General Procedure for the Reactions of Sulfamoylation Reagent 1 with}

\section{Alcohols (Phenol)}<smiles></smiles>

1 (2.0 eq.)
$+\mathrm{R}-\mathrm{OH}$ 2 (1.0 eq.)<smiles>[R]OS(=O)(=O)NC(C)(C)C</smiles>

3

Alcohol $(0.2 \mathrm{mmol}), 1(0.3 \mathrm{mmol})$ and dry dichloromethane $(3 \mathrm{~mL})$ were added to a reaction vessel at room temperature and the mixture was stirred for 3 hours. After the completion of the reaction as indicated by TLC, the mixture was concentrated under a reduced pressure. Saturated aqueous $\mathrm{Na}_{2} \mathrm{CO}_{3}(50 \mathrm{~mL})$ was added to the residue and the resulting mixture was extracted with EA. The organic layers were washed with $\mathrm{HCl}$ $(0.5 \mathrm{M})$ in water. The organic layer was dried over $\mathrm{Na}_{2} \mathrm{SO}_{4}$, concentrated under a 
reduced pressure. The residue was purified by flash column chromatography on silica gel

Phenol $(0.2 \mathrm{mmol}), 1(0.4 \mathrm{mmol})$ and dry dichloromethane $(3 \mathrm{~mL})$ were added to a reaction vessel at room temperature and the mixture was stirred for 3.5 hours. After the completion of the reaction as indicated by TLC, the mixture was concentrated under a reduced pressure. Saturated aqueous $\mathrm{Na}_{2} \mathrm{CO}_{3}(50 \mathrm{~mL})$ was added to the residue and the resulting mixture was extracted with EA. The organic layers were washed with $\mathrm{HCl}$ $(0.5 \mathrm{M})$ in water. The organic layer was dried over $\mathrm{Na}_{2} \mathrm{SO}_{4}$, concentrated under a reduced pressure. The residue was purified by flash column chromatography on silica gel.

\section{General Procedure for the Reactions of Sulfamoylation Reagent 1 with RNHR'(H).}<smiles></smiles>

1 (1.5 eq.)<smiles>[R]N[O]</smiles>

6 (1.0 eq.)<smiles>[R]N([R])S(=O)(=O)NC(C)(C)C</smiles>

7

Aniline (0.2 mmol), 1(0.3 mmol) and dry dichloromethane $(3 \mathrm{~mL})$ were added to a reaction vessel at room temperature and the mixture was stirred for 3 hours. After the completion of the reaction as indicated by TLC, the mixture was concentrated under a reduced pressure. Saturated aqueous $\mathrm{Na}_{2} \mathrm{CO}_{3}(50 \mathrm{~mL})$ was added to the residue and the resulting mixture was extracted with EA. The organic layers were washed with $\mathrm{HCl}$ $(0.5 \mathrm{M})$ in water. The organic layer was dried over $\mathrm{Na}_{2} \mathrm{SO}_{4}$, concentrated under a reduced pressure. The residue was purified by flash column chromatography on silica gel

6. General Procedure for the Reactions of Sulfamoylation Reagent 1 with Various Pharmaceuticals and Bioactive Molecules, or Their Derivatives Containing an OH or $\mathrm{NH}_{2}$ Moiety. 


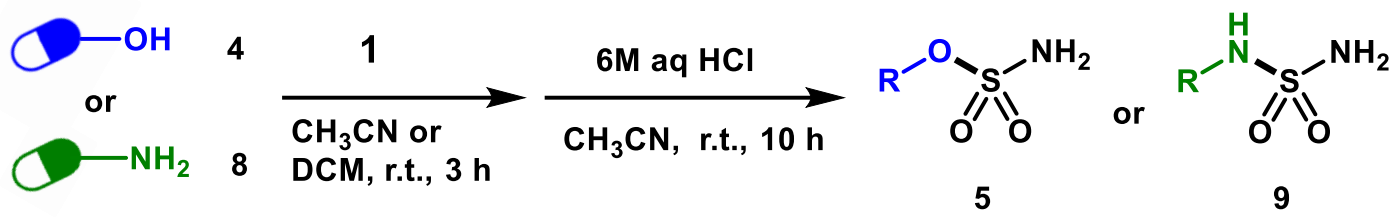

6 or $7(0.2 \mathrm{mmol}), 1(0.4 \mathrm{mmol})$ and dry acetonitrile $(3 \mathrm{~mL})$ were added to the reaction vessel at room temperature, and the mixture was stirred for 3 hours. After the completion of the reaction indicated by TLC, $\mathrm{HCl}(12 \mathrm{M})$ in water $(0.5 \mathrm{~mL})$ was added dropwise. and the mixture was stirred for 8 hours. After the completion of the reaction indicated by TLC, the mixture was concentrated under reduced pressure. Saturated aqueous $\mathrm{Na}_{2} \mathrm{CO}_{3}(50 \mathrm{~mL})$ was added to the residue, and the resulting mixture was extracted with EA. The organic layer was dried over $\mathrm{Na}_{2} \mathrm{SO}_{4}$ and concentrated under reduced pressure. The residue was purified by flash column chromatography on silica gel

7. General Procedure for the Reactions of Sulfamoylation Reagent 1with Compounds with Different Nucleophilic Groups.

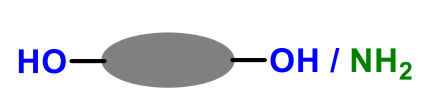

10
1) $1, \mathrm{MeCN}$ or DCM, r.t. $3 \mathrm{~h}$

2) $6 \mathrm{M} \mathrm{HCl}, \mathrm{MeCN}$, r.t., $8 \mathrm{~h}$

11

$10(0.2 \mathrm{mmol}), 1(0.3-0.4 \mathrm{mmol})$ and dry dichloromethane $(3 \mathrm{~mL})$ were added to the reaction vessel at room temperature, and the mixture was stirred for 3.3 hours. After the completion of the reaction was indicated by TLC, the solvent was evaporated, anhydrous acetonitrile $(3 \mathrm{~mL})$ was added, and $\mathrm{HCl}(12 \mathrm{M})$ in water $(0.5 \mathrm{~mL})$ was added dropwise at room temperature. The mixture was concentrated under reduced pressure. Saturated aqueous $\mathrm{Na}_{2} \mathrm{CO}_{3}(50 \mathrm{~mL})$ was added to the residue, and the resulting mixture was extracted with EA. The combined organic layer was dried over $\mathrm{Na}_{2} \mathrm{SO}_{4}$ and concentrated under reduced pressure. The residue was purified by flash column chromatography on silica gel. 


\section{Characterization of Products}<smiles>CC(C)(C)OC(=O)N([O-])S(=O)(=O)c1ccccc1</smiles>

white-solid (6863.2mg, 92\% yield). ${ }^{1} \mathbf{H}$ NMR (400 MHz, Chloroform- $d$ ) $\delta 8.92(\mathrm{dd}, J$ $=6.5,1.4 \mathrm{~Hz}, 4 \mathrm{H}), 8.54-8.47(\mathrm{~m}, 2 \mathrm{H}), 8.03(\mathrm{dd}, J=7.8,6.7 \mathrm{~Hz}, 4 \mathrm{H}), 7.65(\mathrm{~s}, 1 \mathrm{H})$, 1.36 (s, 9H). ${ }^{13}$ C NMR (101 MHz, Chloroform- $d$ ) $\delta$ 152.8, 145.9, 141.4, 127.1, 80.9, 27.9. HRMS (ESI): (tert-butoxycarbonyl) (pyridin-1-ium-1-ylsulfonyl) amide calc'd for $\mathrm{C}_{10} \mathrm{H}_{15} \mathrm{~N}_{2} \mathrm{O}_{4} \mathrm{~S}^{+}[\mathrm{M}+\mathrm{H}]^{+}:$259.0747, found: 259.0751 .<smiles>O=S(=O)(NS(=O)(=O)OCc1ccccc1)OCCc1ccc2ccccc2c1</smiles>

white-solid $(57.5 \mathrm{mg}, 82 \%$ yield). The product was purified by flash column chromatography on silica gel (eluent: dichloromethane/ammonia methanol $=10: 1){ }^{\mathbf{1}} \mathbf{H}$ NMR (400 MHz, Chloroform- $d) \delta 7.82-7.73(\mathrm{~m}, 3 \mathrm{H}), 7.68-7.63(\mathrm{~m}, 1 \mathrm{H}), 7.50-$ $7.40(\mathrm{~m}, 2 \mathrm{H}), 7.32(\mathrm{dd}, J=8.5,1.8 \mathrm{~Hz}, 1 \mathrm{H}), 4.57(\mathrm{t}, J=7.1 \mathrm{~Hz}, 2 \mathrm{H}), 3.20(\mathrm{t}, J=7.1$ Hz, 2H), 1.39 (s, 9H). ${ }^{13}$ C NMR (101 MHz, Chloroform- $d$ ) $\delta$ 133.6, 133.5, 132.4, 131.3, 128.4, 127.6, 127.6, 127.0, 126.2, 125.7, 84.2, 73.5, 35.4, 27.8. HRMS (ESI): calc'd for $\mathrm{C}_{17} \mathrm{H}_{25} \mathrm{~N}_{2} \mathrm{O}_{5} \mathrm{~S}^{+}\left[\mathrm{M}+\mathrm{NH}^{4}\right]^{+}:$369.1479, found: 369.1454 .

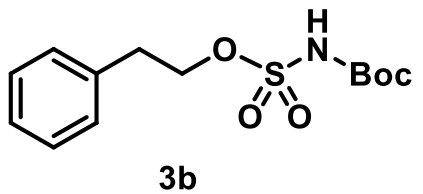

white-solid (50.58 $\mathrm{mg}, 84 \%$ yield) The product was purified by flash column chromatography on silica gel (eluent: dichloromethane/ammonia methanol $=8: 1$ ) ${ }^{1} \mathbf{H}$ NMR (400 MHz, Acetonitrile- $\left.d_{3}\right) \delta 7.38-7.24(\mathrm{~m}, 5 \mathrm{H}), 4.51-4.46(\mathrm{~m}, 2 \mathrm{H}), 3.05(\mathrm{t}$, $J=6.6 \mathrm{~Hz}, 2 \mathrm{H}), 1.46(\mathrm{~s}, 9 \mathrm{H}) .{ }^{13} \mathbf{C}$ NMR $\left(101 \mathrm{MHz}\right.$, Acetonitrile- $\left.d_{3}\right) \delta$ 149.1, 136.9, 128.9, 126.8, 117.3, 83.4, 73.3, 34.6, 27.1. HRMS (ESI): calc'd for $\mathrm{C}_{13} \mathrm{H}_{19} \mathrm{NNaO}_{5} \mathrm{~S}^{+}$ $[\mathrm{M}+\mathrm{Na}]^{+}:$324.0876, found: 324.0884 . 


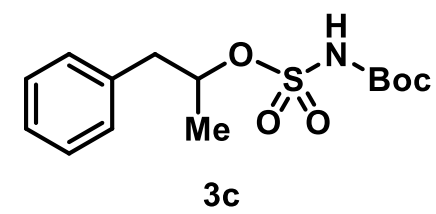

white-solid $(56.72 \mathrm{mg}, 90 \%$ yield) The product was purified by flash column chromatography on silica gel (eluent: dichloromethane/ammonia methanol $=8: 1)^{1} \mathbf{H}$ NMR (400 MHz, Acetonitrile- $\left.d_{3}\right) \delta 7.39-7.01$ (m, 5H), 4.97 (m, 1H), $3.04-2.86(\mathrm{~m}$, 2H), $1.42(\mathrm{~s}, 9 \mathrm{H}), 1.27(\mathrm{~d}, J=6.3 \mathrm{~Hz}, 3 \mathrm{H}) \cdot{ }^{13} \mathrm{C}$ NMR $\left(101 \mathrm{MHz}\right.$, Acetonitrile- $\left.d_{3}\right) \delta$ 149.3, 136.3, 129.7, 126.9, 117.3, 83.3, 83.3, 41.9, 27.2, 19.0 HRMS (ESI): calc'd for $\mathrm{C}_{14} \mathrm{H}_{25} \mathrm{~N}_{2} \mathrm{O}_{5} \mathrm{~S}^{+}\left[\mathrm{M}+\mathrm{NH}^{4}\right]^{+}: 333.1479$, found: 333.1470 .<smiles>CC(C)(C)OC(=O)NS(=O)(=O)Oc1ccc2ccccc2c1</smiles>
$3 d$

white-solid (48.46 mg, 75\% yield) The product was purified by flash column chromatography on silica gel (eluent: dichloromethane/ammonia methanol $=10: 1)^{1} \mathbf{H}$ NMR $\left(400 \mathrm{MHz}\right.$, Methanol- $\left.d_{4}\right) \delta 7.89-7.72(\mathrm{~m}, 4 \mathrm{H}), 7.54-7.38(\mathrm{~m}, 3 \mathrm{H}), 1.43(\mathrm{~s}$, 9H) ${ }^{13}$ C NMR (101 MHz, Methanol- $\left.d_{4}\right) \delta 158.5,149.3,133.8,131.6,128.8,127.3$, 127.3, 126.1, 125.3, 121.5, 118.7, 78.5, 27.3. HRMS (ESI): calc'd for $\mathrm{C}_{15} \mathrm{H}_{17} \mathrm{NNaO}_{5} \mathrm{~S}^{+}$ $[\mathrm{M}+\mathrm{Na}]^{+}: 346.0720$, found: 346.0719 .<smiles>CC(C)(C)NS(=O)(=O)Oc1ccc(Oc2ccccc2)cc1</smiles>

Colorless-oil (61.32 mg, 84\% yield) The product was purified by flash column chromatography on silica gel (eluent: dichloromethane/ammonia methanol $=10: 1)^{1} \mathbf{H}$ NMR (400 MHz, Chloroform- $d$ ) $\delta 7.33$ - $7.17(\mathrm{~m}, 4 \mathrm{H}), 7.11-7.04(\mathrm{~m}, 1 \mathrm{H}), 6.97-$ 6.85 (m, 4H), 1.40 (s, 9H). ${ }^{13}$ C NMR (101 MHz, Chloroform- $d$ ) $\delta 156.7,156.4,148.5$, 
144.9, 130.0, 124.1, 123.2, 119.4, 119.3, 85.1, 27.9. HRMS (ESI): calc'd for $\mathrm{C}_{17} \mathrm{H}_{23} \mathrm{~N}_{2} \mathrm{O}_{6} \mathrm{~S}^{+}\left[\mathrm{M}+\mathrm{NH}^{4}\right]^{+}:$383.1271, found: 383.1261 .<smiles>CC(C)(C)NS(=O)(=O)Oc1ccc(C(C)(C)C)cc1</smiles>

$3 f$

white-solid (56.59 $\mathrm{mg}, 86 \%$ yield) The product was purified by flash column chromatography on silica gel (eluent: dichloromethane/ammonia methanol $=7: 1$ ) ${ }^{\mathbf{1}} \mathbf{H}$ NMR $\left(400 \mathrm{MHz}\right.$, Methanol- $\left.d_{4}\right) \delta 7.38(\mathrm{~d}, J=8.8 \mathrm{~Hz}, 2 \mathrm{H}), 7.21(\mathrm{~d}, J=8.8 \mathrm{~Hz}, 2 \mathrm{H})$, 1.45 (s, 9H), 1.31 (s, 9H). ${ }^{13}$ C NMR (101 MHz, Methanol- $\left.d_{4}\right) \delta$ 158.3, 149.3, 148.6, 125.8, 121.4 78.6, 33.9, 30.5, 27.3. HRMS (ESI): calc'd for $\mathrm{C}_{15} \mathrm{H}_{23} \mathrm{NNaO}_{5} \mathrm{~S}^{+}[\mathrm{M}+\mathrm{Na}]^{+}$: 352.1189, found: 352.1192 .<smiles>COc1ccc(OS(=O)(=O)NC(C)(C)C)c2ccccc12</smiles>

Brown-oil (57.89 mg, 82\% yield) The product was purified by flash column chromatography on silica gel (eluent: dichloromethane/ammonia methanol $=8: 1$ ) ${ }^{1} \mathbf{H}$ NMR (400 MHz, Methanol- $\left.d_{4}\right) \delta 8.33-8.14(\mathrm{~m}, 2 \mathrm{H}), 7.59-7.40(\mathrm{~m}, 3 \mathrm{H}), 6.89-6.82$ (m, 1H), 3.99 (s, 3H), $1.40(\mathrm{~s}, 9 \mathrm{H}) .{ }^{13} \mathbf{C}$ NMR (101 MHz, Methanol- $\left.d_{4}\right) \delta$ 153.7, 140.3, $128.3,126.4,126.0,125.4,121.9,121.5,118.0,102.6,68.1,54.9,29.8$. HRMS (ESI): calc'd for $\mathrm{C}_{16} \mathrm{H}_{23} \mathrm{~N}_{2} \mathrm{O}_{6} \mathrm{~S}^{+}\left[\mathrm{M}+\mathrm{NH}^{4}\right]^{+}$: 371.1271 , found: 371.1253 .<smiles>CC(C)(C)OC(=O)NS(=O)(=O)Oc1ccc(Br)cc1</smiles>

$3 \mathrm{~h}$

white-solid (49.14 mg, 70\% yield) The product was purified by flash column chromatography on silica gel (eluent: dichloromethane/ammonia methanol $=8: 1)^{1} \mathbf{H}$ 
NMR (400 MHz, Methanol- $\left.d_{4}\right) \delta 7.54-7.50(\mathrm{~m}, 2 \mathrm{H}), 7.24-7.20(\mathrm{~m}, 2 \mathrm{H}), 1.45(\mathrm{~s}$, 9H).${ }^{13}$ C NMR (101 MHz, Chloroform- $\left.d\right) \delta$ 154.5, 136.5, 136.1, 127.6, 122.6, 72.0, 33.7. HRMS (ESI): calc'd for $\mathrm{C}_{11} \mathrm{H}_{13} \mathrm{BrNO}_{5} \mathrm{~S}^{-}[\mathrm{M}-\mathrm{H}]^{-}: 349.9703$, found: 349.9702 .<smiles>COC(=O)c1ccc(OS(=O)(=O)NC(=O)OC(C)(C)C)cc1</smiles>

white-solid (50.31 mg, 76\% yield) The product was purified by flash column chromatography on silica gel (eluent: dichloromethane/ammonia methanol $=7: 1)^{\mathbf{1}} \mathbf{H}$ NMR $\left(400 \mathrm{MHz}\right.$, Acetonitrile- $\left.d_{3}\right) \delta 8.08-7.99(\mathrm{~m}, 2 \mathrm{H}), 7.40-7.32(\mathrm{~m}, 2 \mathrm{H}), 3.87$ (s, 3H), 1.41 (s, 9H). ${ }^{13} \mathbf{C}$ NMR (101 MHz, Acetonitrile- $\left.d_{3}\right) \delta 166.0,158.9,130.9,121.7$, 51.8, 27.3. HRMS (ESI): calc'd for $\mathrm{C}_{13} \mathrm{H}_{16} \mathrm{NO}_{7} \mathrm{~S}^{-}[\mathrm{M}-\mathrm{H}]^{-}: 330.0653$, found: 330.0653 .<smiles>CC(C)(C)OC(=O)NS(=O)(=O)Oc1ccc(C(=O)c2ccccc2)cc1</smiles>

Yellow-oil (49.02 mg, 65\% yield) The product was purified by flash column chromatography on silica gel (eluent: dichloromethane/ammonia methanol $=8: 1$ ). ${ }^{1} \mathbf{H}$ NMR (400 MHz, Chloroform- $d$ ) $\delta 7.85$ - 7.64 (m, 4H), 7.58 - 7.51 (m, 1H), 7.49 7.33 (m, 4H), 1.41 (s, 9H). ${ }^{13}$ C NMR (101 MHz, Chloroform-d) $\delta$ 195.5, 153.2, 137.0, 136.1, 132.8, 131.8, 130.0, 128.4, 121.8, 27.9. HRMS (ESI): calc'd for $\mathrm{C}_{18} \mathrm{H}_{20} \mathrm{NO}_{6} \mathrm{~S}^{+}$ $[\mathrm{M}+\mathrm{H}]^{+}:$378.1006, found: 378.0478 .<smiles>COC1=C(OC)C(=O)C(CCCCCCCCCCOS(N)(=O)=O)=C(C)C1=O</smiles> 
yellow-solid $(67.55,77 \%$ yield) The product was purified by flash column chromatography on silica gel (eluent: dichloromethane/ammonia methanol $=8: 1$ ) ${ }^{1} \mathbf{H}$ NMR $\left(400 \mathrm{MHz}\right.$, Methanol- $\left.d_{4}\right) \delta 4.11(\mathrm{t}, J=6.5 \mathrm{~Hz}, 2 \mathrm{H}), 3.96-3.95(\mathrm{~m}, 6 \mathrm{H}), 2.49-$ $2.43(\mathrm{~m}, 2 \mathrm{H}), 1.99(\mathrm{~s}, 3 \mathrm{H}), 1.75-1.66(\mathrm{~m}, 2 \mathrm{H}), 1.43-1.30(\mathrm{~m}, 14 \mathrm{H}) .{ }^{\mathbf{1 3}} \mathbf{C}$ NMR $(101$ MHz, Methanol- $\left.d_{4}\right) \delta 184.6,184.2,144.4,144.4,142.7,138.7,69.7,60.2,60.2,29.4$, 29.1, 29.0, 28.9, 28.7, 28.6, 28.2, 25.7, 25.2, 10.5. HRMS calc'd for $\mathrm{C}_{19} \mathrm{H}_{32} \mathrm{NO}_{7} \mathrm{~S}^{+}[\mathrm{M}$ $+\mathrm{H}]^{+}$418.1894, found 418.1898 .

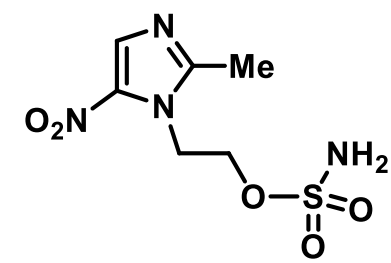

$5 \mathbf{b}$

white-solid (40 mg, $80 \%$ yield) The product was purified by flash column chromatography on silica gel (eluent: dichloromethane/ammonia methanol $=8: 1$ ). ${ }^{1} \mathbf{H}$ NMR (400 MHz, Methanol-d $\left.d_{4}\right) \delta 7.96(\mathrm{~s}, 1 \mathrm{H}), 4.72-4.69(\mathrm{~m}, 2 \mathrm{H}), 4.48-4.44(\mathrm{~m}$, 2H), 2.53 (s, 3H). ${ }^{13}$ C NMR (101 MHz, Methanol- $\left.d_{4}\right) \delta 151.8,131.4,67.4,45.2,12.8$. HRMS calc'd for $\mathrm{C}_{6} \mathrm{H}_{11} \mathrm{~N}_{4} \mathrm{O}_{5} \mathrm{~S}[\mathrm{M}+\mathrm{H}]^{+} 251.0445$, found 251.0421 .

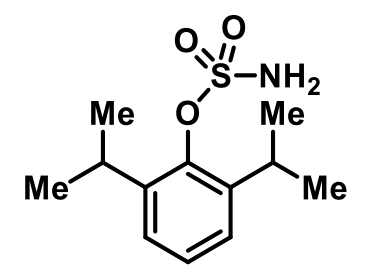

$5 c$

white-solid (38.57 mg, 75\% yield) The product was purified by flash column chromatography on silica gel (eluent: dichloromethane/ammonia methanol $=9: 1$ ) ${ }^{\mathbf{1}} \mathbf{H}$ NMR (400 MHz, Methanol- $\left.d_{4}\right) \delta 7.23-7.16(\mathrm{~m}, 3 \mathrm{H}), 3.64-3.55(\mathrm{~m}, 2 \mathrm{H}), 1.21(\mathrm{~d}$, 12H). ${ }^{13}$ C NMR (101 MHz, Methanol- $\left.d_{4}\right) \delta$ 145.3, 142.6, 126.7, 124.0, 26.9, 22.7. HRMS calc'd for $\mathrm{C}_{12} \mathrm{H}_{19} \mathrm{NO}_{3} \mathrm{~S}^{+}[\mathrm{M}+\mathrm{Na}]^{+} 280.0978$, found 280.0994 . 


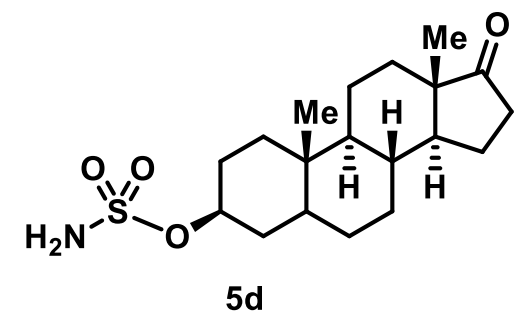

white-solid (54.64 mg, 74\% yield) The product was purified by flash column chromatography on silica gel (eluent: dichloromethane/ammonia methanol $=10: 1){ }^{1} \mathbf{H}$ NMR (400 MHz, Methanol-d $\left.d_{4}\right) \delta 4.47-4.37$ (m, 1H), 2.49 - 2.38 (m, 1H), $2.11-1.91$ (m, 3H), $1.86-1.49(\mathrm{~m}, 9 \mathrm{H}), 1.39-1.17(\mathrm{~m}, 6 \mathrm{H}), 1.13-0.99(\mathrm{~m}, 2 \mathrm{H}), 0.89(\mathrm{~d}, J=9.5$ $\mathrm{Hz}, 6 \mathrm{H}), 0.81-0.72(\mathrm{~m}, 1 \mathrm{H}) .{ }^{13} \mathrm{C}$ NMR $\left(101 \mathrm{MHz}\right.$, Methanol- $\left.d_{4}\right) \delta$ 80.8, 54.3, 51.3, 44.7, 36.6, 35.3, 35.2, 34.9, 34.6, 31.4, 30.6, 28.1, 28.1, 21.3, 20.2, 12.8, 11.1. HRMS calc'd for $\mathrm{C}_{19} \mathrm{H}_{32} \mathrm{NO}_{4} \mathrm{~S}[\mathrm{M}+\mathrm{H}]^{+} 370.2047$, found 370.2038.

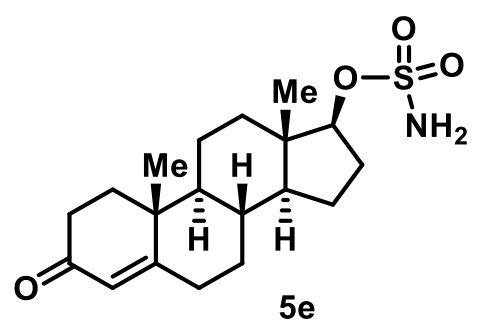

white-solid (59.48 mg, $81 \%$ yield) The product was purified by flash column chromatography on silica gel (eluent: dichloromethane/ammonia methanol $=10: 1){ }^{\mathbf{1}} \mathbf{H}$ NMR (400 MHz, Methanol- $\left.d_{4}\right) \delta 5.74-5.71(\mathrm{~m}, 1 \mathrm{H}), 4.39-4.30(\mathrm{~m}, 1 \mathrm{H}), 2.55-2.43$ $(\mathrm{m}, 2 \mathrm{H}), 2.36-2.17(\mathrm{~m}, 3 \mathrm{H}), 2.13-2.05(\mathrm{~m}, 1 \mathrm{H}), 2.00-1.62(\mathrm{~m}, 7 \mathrm{H}), 1.56-1.37(\mathrm{~m}$, 2H), $1.36-1.26(\mathrm{~m}, 2 \mathrm{H}), 1.25$ (s, 3H), $1.13-0.96(\mathrm{~m}, 3 \mathrm{H}), 0.89$ (s, 3H). ${ }^{13} \mathbf{C}$ NMR (101 MHz, Methanol- $\left.d_{4}\right) \delta 200.9,173.4,122.8,88.5,53.8,49.6,42.5,38.6,36.0,35.3,35.2$, 33.3, 32.4, 31.3, 27.4, 22.8, 20.1, 16.3, 10.6. HRMS calc'd for $\mathrm{C}_{19} \mathrm{H}_{30} \mathrm{NO}_{4} \mathrm{~S}^{+}[\mathrm{M}+\mathrm{H}]^{+}$ 368.1890 , found 368.1862 . 
<smiles>COc1ccccc1OCC(COC(N)=O)OS(N)(=O)=O</smiles>

$5 f$

white-solid (47.37 mg, 74\% yield) The product was purified by flash column chromatography on silica gel (eluent: dichloromethane/ammonia methanol $=10: 1) .{ }^{1} \mathbf{H}$ NMR (400 MHz, Methanol-d $\left.)_{4}\right) \quad 7.03-6.84(\mathrm{~m}, 4 \mathrm{H}), 5.06-4.94(\mathrm{~m}, 1 \mathrm{H}), 4.42$ (dd, $J$ $=12.0,4.0 \mathrm{~Hz}, 1 \mathrm{H}), 4.35-4.26(\mathrm{~m}, 2 \mathrm{H}), 4.18(\mathrm{dd}, J=10.6,6.3 \mathrm{~Hz}, 1 \mathrm{H}), 3.82(\mathrm{~s}$, 3H). ${ }^{13}$ C NMR (101 MHz, Methanol- $\left.d_{4}\right) \delta$ 157.8, 149.6, 147.8, 122.0, 120.8, 114.2, 112.2, 77.4, 67.7, 62.7, 55.1. HRMS calc'd for $\mathrm{C}_{11} \mathrm{H}_{16} \mathrm{~N}_{2} \mathrm{NaO}_{7} \mathrm{~S}^{+}[\mathrm{M}+\mathrm{Na}]^{+}$343.0570, found 343.0572.<smiles>NS(=O)(=O)Oc1ccc(C2CC(=O)c3ccccc3O2)cc1</smiles>

white-solid (48.50 mg, $76 \%$ yield) The product was purified by flash column chromatography on silica gel (eluent: dichloromethane/ammonia methanol $=10: 1$ ). ${ }^{1} \mathbf{H}$ NMR (400 MHz, Methanol- $\left.d_{4}\right) \delta 7.92-7.80(\mathrm{~m}, 1 \mathrm{H}), 7.67-7.52(\mathrm{~m}, 3 \mathrm{H}), 7.38$ (d, $J$ $=8.3 \mathrm{~Hz}, 2 \mathrm{H}), 7.15-7.02(\mathrm{~m}, 2 \mathrm{H}), 5.63-5.55(\mathrm{~m}, 1 \mathrm{H}), 3.18-3.05(\mathrm{~m}, 1 \mathrm{H}), 2.87(\mathrm{dd}$, $J=16.9,3.1 \mathrm{~Hz}, 1 \mathrm{H}) .{ }^{13} \mathbf{C}$ NMR $\left(101 \mathrm{MHz}\right.$, Methanol- $\left.d_{4}\right) \delta 192.4,161.6,150.7,137.6$, $136.2,127.4,126.3,122.2,121.3,120.7,117.8,78.8,43.9$. HRMS calc'd for $\mathrm{C}_{15} \mathrm{H}_{14} \mathrm{NO}_{5} \mathrm{~S}^{+}[\mathrm{M}+\mathrm{H}]^{+}$320.0587, found 320.0570.<smiles>COC(=O)[C@H](Cc1ccc(OS(N)(=O)=O)cc1)NC(C)(C)C</smiles>

$5 h$ 
white-solid (57.13 mg, 70\% yield) The product was purified by flash column chromatography on silica gel (eluent: dichloromethane/ammonia methanol $=10: 1$ ) ${ }^{\mathbf{1}} \mathbf{H}$ NMR (400 MHz, Methanol-d $\left.d_{4}\right) \delta 7.55-7.07(\mathrm{~m}, 9 \mathrm{H}), 5.03(\mathrm{~s}, 2 \mathrm{H}), 4.48$ - 4.39 (m, 1H), $3.71(\mathrm{~s}, 3 \mathrm{H}), 3.24-3.12(\mathrm{~m}, 1 \mathrm{H}), 3.01-2.88(\mathrm{~m}, 1 \mathrm{H}) .{ }^{13} \mathrm{C}$ NMR (101 MHz, Methanol- $\left.d_{4}\right) \delta 172.3,157.0,149.6,136.7,135.7,130.1,128.1,127.6,127.3,121.9$, 66.2, 55.5, 51.4, 36.5. HRMS calc'd for $\mathrm{C}_{18} \mathrm{H}_{21} \mathrm{~N}_{2} \mathrm{O}_{7} \mathrm{~S}^{+}[\mathrm{M}+\mathrm{H}]^{+}$409.1064, found 409.1046.

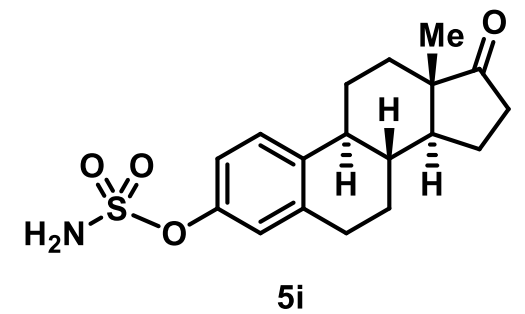

white-solid (56.54 mg, $81 \%$ yield) The product was purified by flash column chromatography on silica gel (eluent: dichloromethane/ammonia methanol $=10: 1$ ) ${ }^{1} \mathbf{H}$ NMR (400 MHz, Methanol- $\left.d_{4}\right) \delta 7.37-7.29(\mathrm{~m}, 1 \mathrm{H}), 7.10-6.99(\mathrm{~m}, 2 \mathrm{H}), 2.98-2.86$ $(\mathrm{m}, 2 \mathrm{H}), 2.55-2.39(\mathrm{~m}, 2 \mathrm{H}), 2.35-2.24(\mathrm{~m}, 1 \mathrm{H}), 2.21-1.99(\mathrm{~m}, 3 \mathrm{H}), 1.93-1.83(\mathrm{~m}$, 1H), $1.68-1.41(\mathrm{~m}, 6 \mathrm{H}), 0.91(\mathrm{~s}, 3 \mathrm{H}) .{ }^{\mathbf{1 3}} \mathrm{C}$ NMR (101 MHz, Methanol- $\left.d_{4}\right) \delta$ 222.1, 148.6, 138.2, 138.2, 126.1, 121.8, 119.0, 50.2, 44.0, 38.1, 35.3, 31.3, 28.9, 26.0, 25.5, 21.1, 12.8. HRMS calc'd for $\mathrm{C}_{18} \mathrm{H}_{24} \mathrm{NO}_{4} \mathrm{~S}^{+}[\mathrm{M}+\mathrm{H}]^{+} 409.1064$, found 409.1046 .

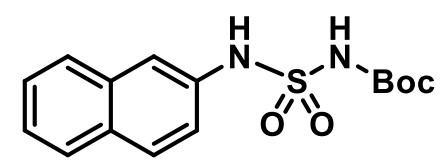

$7 a$

white-solid (54.76 $\mathrm{mg}, 85 \%$ yield) The product was purified by flash column chromatography on silica gel (eluent: dichloromethane/ammonia methanol $=8: 1$ ) ${ }^{1} \mathbf{H}$ NMR (400 MHz, Methanol- $\left.d_{4}\right) \delta 7.84-7.74(\mathrm{~m}, 3 \mathrm{H}), 7.71-7.67(\mathrm{~m}, 1 \mathrm{H}), 7.50-7.35$ $(\mathrm{m}, 3 \mathrm{H}), 1.34(\mathrm{~s}, 9 \mathrm{H}) .{ }^{13} \mathbf{C}$ NMR $\left(101 \mathrm{MHz}\right.$, Methanol- $\left.d_{4}\right) \delta 150.7,135.0,133.8,131.0$, 
128.6, 127.3, 127.0, 126.3, 124.9, 120.4, 117.1, 82.0, 26.8.HRMS (ESI): calc'd for $\mathrm{C}_{15} \mathrm{H}_{17} \mathrm{~N}_{2} \mathrm{O}_{4} \mathrm{~S}^{-}[\mathrm{M}-\mathrm{H}]^{-}$321.0915, found: 321.0917.<smiles>CN(C)c1ccc(NS(=O)(=O)NC(C)(C)C)cc1</smiles>

Yellow-solid (51.66 mg, 82\% yield) The product was purified by flash column chromatography on silica gel (eluent: dichloromethane/ammonia methanol $=7: 1$ ) ${ }^{\mathbf{1}} \mathbf{H}$ NMR (400 MHz, Methanol-d $\left.d_{4}\right) \delta 7.10(\mathrm{~d}, J=9.0 \mathrm{~Hz}, 2 \mathrm{H}), 6.73(\mathrm{~d}, J=9.0 \mathrm{~Hz}, 2 \mathrm{H})$, $2.90(\mathrm{~s}, 6 \mathrm{H}), 1.45$ (s, 9H). ${ }^{13} \mathrm{C}$ NMR (101 MHz, Methanol- $\left.d_{4}\right) \delta$ 151.1, 149.3, 126.3, 124.4, 113.0, 81.8, 39.8, 26.9. HRMS (ESI): calc'd for $\mathrm{C}_{13} \mathrm{H}_{22} \mathrm{~N}_{3} \mathrm{O}_{4} \mathrm{~S}^{+}[\mathrm{M}+\mathrm{H}]^{+}$: 316.1326, found: 316.1303 .<smiles>CC(=O)c1cccc(NS(=O)(=O)NC(=O)OC(C)(C)C)c1</smiles>

$7 c$

white-solid (47.1 mg, 75\% yield) The product was purified by flash column chromatography on silica gel (eluent: dichloromethane/ammonia methanol $=7: 1$ ). ${ }^{1} \mathbf{H}$ NMR (400 MHz, Methanol- $\left.d_{4}\right) \delta 7.84(\mathrm{~m}, 1 \mathrm{H}), 7.77(\mathrm{~m}, 1 \mathrm{H}), 7.49-7.43(\mathrm{~m}, 2 \mathrm{H}), 2.59$ (s, 3H), $1.38(\mathrm{~s}, 9 \mathrm{H}) .{ }^{\mathbf{1 3}} \mathbf{C}$ NMR (101 MHz, Methanol-d 4 ) $\delta$ 198.4, 138.2, 137.9, 129.2, 124.9, 124.2, 119.7, 81.9, 26.8, 25.4. HRMS (ESI): calc'd for $\mathrm{C}_{13} \mathrm{H}_{22} \mathrm{~N}_{3} \mathrm{O}_{5} \mathrm{~S}^{+}\left[\mathrm{M}+\mathrm{HH}^{4}\right]^{+}$: 332.1275, found: 332.1260 .<smiles>CC(C)(C)OC(=O)NS(=O)(=O)Nc1ccc(C(F)(F)F)cc1</smiles>

yellow-solid (53.4 mg, 78\% yield) The product was purified by flash column chromatography on silica gel (eluent: dichloromethane/ammonia methanol $=8: 1$ ) ${ }^{1} \mathbf{H}$ 
NMR (400 MHz, Methanol- $\left.d_{4}\right) \delta 7.62-7.58(\mathrm{~m}, 2 \mathrm{H}), 7.38-7.34(\mathrm{~m}, 2 \mathrm{H}), 1.36(\mathrm{~s}$, 9H). ${ }^{13}$ C NMR (101 MHz, Methanol- $\left.d_{4}\right) \delta 150.4,141.2,126.0$ (q, $\left.J=3.8 \mathrm{~Hz}\right), 125.4$ (q, $J=33.33 \mathrm{~Hz}), 124.3(\mathrm{q}, J=271.69 \mathrm{~Hz}), 118.0,82.2,26.7$. HRMS (ESI): calc'd for $\mathrm{C}_{12} \mathrm{H}_{14} \mathrm{~F}_{3} \mathrm{~N}_{2} \mathrm{O}_{4} \mathrm{~S}^{-}[\mathrm{M}-\mathrm{H}]^{-}: 339.0632$, found: 339.0627.<smiles>CN(c1ccccc1)S(=O)(=O)NC(=O)OC(C)(C)C</smiles>

white-solid (50.35 mg, 88\% yield) The product was purified by flash column chromatography on silica gel (eluent: dichloromethane/ammonia methanol $=7: 1$ ) ${ }^{\mathbf{1}} \mathbf{H}$ NMR (400 MHz, Methanol-d $\left.d_{4}\right) \delta 7.45-7.35(\mathrm{~m}, 4 \mathrm{H}), 7.34-7.27(\mathrm{~m}, 1 \mathrm{H}), 3.43(\mathrm{~s}$, 3H), $1.46(\mathrm{~s}, 9 \mathrm{H}) .{ }^{13} \mathrm{C}$ NMR (101 MHz, Methanol- $\left.d_{4}\right) \delta 151.2,141.4,128.9,127.0$, 126.0, 82.1, 39.6, 26.9. HRMS (ESI): calc'd for $\mathrm{C}_{12} \mathrm{H}_{18} \mathrm{~N}_{2} \mathrm{NaO}_{4} \mathrm{~S}^{+}[\mathrm{M}+\mathrm{Na}]^{+}:$309.0879, found: 309.0863 .<smiles>CC(C)(C)OC(=O)NS(=O)(=O)N(c1ccccc1)c1ccccc1</smiles>

white-solid (63.36 mg, 91\% yield) The product was purified by flash column chromatography on silica gel (eluent: dichloromethane/ammonia methanol $=8: 1$ ) ${ }^{\mathbf{1}} \mathbf{H}$ NMR (400 MHz, Methanol-d $\left.d_{4}\right) \delta 7.56-7.49$ (m, 4H), 7.40 - 7.32 (m, 4H), 7.30 - 7.23 (m, 2H), 1.44 (s, 9H). ${ }^{13}$ C NMR (101 MHz, Methanol-d 4$) \delta 150.7,141.8,128.9,128.0$, 127.0, 82.0, 26.9. HRMS (ESI): calc'd for $\mathrm{C}_{17} \mathrm{H}_{20} \mathrm{~N}_{2} \mathrm{NaO}_{4} \mathrm{~S}^{+}[\mathrm{M}+\mathrm{Na}]^{+}: 371.1036$, found: 371.1040 . 


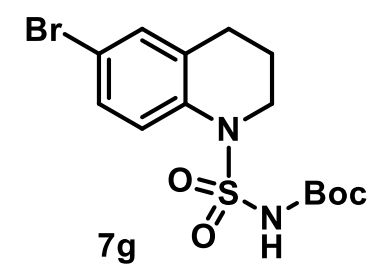

white-solid (62.4 $\mathrm{mg}, 80 \%$ yield) The product was purified by flash column chromatography on silica gel (eluent: dichloromethane/ammonia methanol $=8: 1$ ). ${ }^{1} \mathbf{H}$ NMR (400 MHz, Methanol- $\left.d_{4}\right) \delta 7.56-7.47$ (m, 1H), $7.29-7.22$ (m, 2H), $3.91-3.77$ (m, 2H), $2.77(\mathrm{t}, J=6.5 \mathrm{~Hz}, 2 \mathrm{H}), 2.04-1.91(\mathrm{~m}, 2 \mathrm{H}), 1.34(\mathrm{~s}, 9 \mathrm{H}) \cdot{ }^{13} \mathbf{C}$ NMR (101 MHz, Methanol- $\left.d_{4}\right) \delta$ 136.2, 131.6, 131.4, 128.9, 122.9, 116.0, 82.1, 26.7,26.7 21.9. HRMS (ESI): calc'd for $\mathrm{C}_{14} \mathrm{H}_{18} \mathrm{BrN}_{2} \mathrm{O}_{4} \mathrm{~S}^{-}$[M-H] $: 389.0176$, found: 339.0177 .

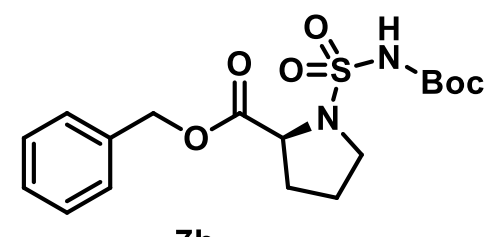

$7 \mathrm{~h}$

Colorless oil (57.6 mg, 75\% yield) The product was purified by flash column chromatography on silica gel (eluent: dichloromethane/ammonia methanol $=8: 1$ ). ${ }^{1} \mathbf{H}$ NMR (400 MHz, Chloroform- $d$ ) $\delta 7.39-7.29$ (m, 5H), $5.23-5.13(\mathrm{~m}, 2 \mathrm{H}), 4.79-$ $4.70(\mathrm{~m}, 1 \mathrm{H}), 3.68-3.58(\mathrm{~m}, 1 \mathrm{H}), 3.56-3.45(\mathrm{~m}, 1 \mathrm{H}), 2.29-2.20(\mathrm{~m}, 1 \mathrm{H}), 2.08-$ $1.94(\mathrm{~m}, 3 \mathrm{H}), 1.48$ (s, 9H). ${ }^{13} \mathbf{C}$ NMR (101 MHz, Chloroform- $d$ ) $\delta$ 172.0, 150.1, 135.5, 128.6, 128.4, 128.1, 83.5, 67.1, 61.9, 49.0, 30.8, 28.0, 24.7. HRMS (ESI): calc'd for $\mathrm{C}_{17} \mathrm{H}_{28} \mathrm{~N}_{3} \mathrm{O}_{6} \mathrm{~S}^{+}\left[\mathrm{M}+\mathrm{NH}_{4}\right]^{+}: 402.1693$, found: 402.1691 .

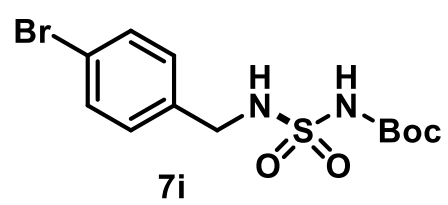

Yellow solid (48.0 mg, 66\% yield) The product was purified by flash column chromatography on silica gel (eluent: dichloromethane/ammonia methanol $=10: 1) .{ }^{1} \mathbf{H}$ NMR (400 MHz, Methanol- $\left.d_{4}\right) \delta 7.50-7.43(\mathrm{~m}, 2 \mathrm{H}), 7.32-7.25(\mathrm{~m}, 2 \mathrm{H}), 4.17(\mathrm{~s}$, 2H), 1.43 (s, 9H). ${ }^{13} \mathbf{C}$ NMR (101 MHz, Methanol- $\left.d_{4}\right) \delta 151.0,136.7,131.2,129.7$, 120.9, 81.8, 46.0, 26.9. HRMS (ESI): calc'd for $\mathrm{C}_{12} \mathrm{H}_{16} \mathrm{BrN}_{2} \mathrm{O}_{4} \mathrm{~S}^{-}[\mathrm{M}-\mathrm{H}]^{-:}: 363.0020$, found: 363.0006 . 


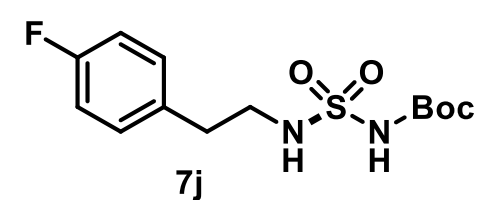

Yellow solid (44.5 mg, 70\% yield) The product was purified by flash column chromatography on silica gel (eluent: dichloromethane/ammonia methanol $=10: 1$ ). ${ }^{1} \mathbf{H}$ NMR (400 MHz, Methanol-d $\left.d_{4}\right) \delta 7.29-7.18(\mathrm{~m}, 2 \mathrm{H}), 7.07-6.95(\mathrm{~m}, 2 \mathrm{H}), 3.21(\mathrm{t}, J=$ $7.5 \mathrm{~Hz}, 2 \mathrm{H}), 2.83$ (t, $J=7.5 \mathrm{~Hz}, 2 \mathrm{H}), 1.48(\mathrm{~s}, 9 \mathrm{H}) .{ }^{13} \mathbf{C}$ NMR (101 MHz, Methanol- $\left.d_{4}\right)$ $\delta 161.7(\mathrm{~d}, J=243.1 \mathrm{~Hz}), 151.3,134.6(\mathrm{~d}, J=3.2 \mathrm{~Hz}), 130.1(\mathrm{~d}, J=8.0 \mathrm{~Hz}), 114.8(\mathrm{~d}$, $J=21.5 \mathrm{~Hz}), 81.9,44.6,34.5$, 27.0. HRMS (ESI): calc'd for $\mathrm{C}_{13} \mathrm{H}_{18} \mathrm{FN}_{2} \mathrm{O}_{4} \mathrm{~S}^{-}[\mathrm{M}-\mathrm{H}]^{-}$: 317.0977, found: 317.0980 .<smiles>CCN(CC)CCOC(=O)c1ccc(NS(N)(=O)=O)cc1</smiles>

$9 a$

white-solid (42.75 mg, 75\% yield) The product was purified by flash column chromatography on silica gel (eluent: dichloromethane/ammonia methanol $=6: 1$ ). ${ }^{1} \mathbf{H}$ NMR (400 MHz, Methanol- $\left.d_{4}\right) \delta 8.02-7.86(\mathrm{~m}, 2 \mathrm{H}), 7.29-7.19$ (m, 2H), 4.40 (t, $J=$ $5.9 \mathrm{~Hz}, 2 \mathrm{H}), 2.90(\mathrm{t}, J=5.9 \mathrm{~Hz}, 2 \mathrm{H}), 2.69(\mathrm{q}, J=7.2 \mathrm{~Hz}, 4 \mathrm{H}), 1.10(\mathrm{t}, J=7.2 \mathrm{~Hz}$, 6H). ${ }^{13}$ C NMR (101 MHz, Methanol- $\left.d_{4}\right) \delta 166.4,144.0,130.5,123.3,116.6,62.2,50.5$, 10.2. HRMS calc'd for $\mathrm{C}_{13} \mathrm{H}_{22} \mathrm{~N}_{3} \mathrm{O}_{4} \mathrm{~S}^{+}[\mathrm{M}+\mathrm{H}]^{+} 316.1326$, found 316.1317.<smiles>CCOC(=O)c1ccc(NS(N)(=O)=O)cc1</smiles>

$9 b$

white-solid (40.50 mg, 83\% yield) The product was purified by flash column chromatography on silica gel (eluent: dichloromethane/ammonia methanol $=10: 1){ }^{\mathbf{1}} \mathbf{H}$ 
NMR (400 MHz, Methanol- $\left.d_{4}\right) \delta 7.96-7.87(\mathrm{~m}, 2 \mathrm{H}), 7.27-7.17$ (m, 2H), 4.31 (q, $J$ $=7.1 \mathrm{~Hz}, 2 \mathrm{H}), 1.35(\mathrm{t}, J=7.1 \mathrm{~Hz}, 3 \mathrm{H}) .{ }^{13} \mathrm{C}$ NMR $\left(101 \mathrm{MHz}\right.$, Methanol- $\left.d_{4}\right) \delta 166.6$, 143.8, 130.4, 123.7, 116.6, 60.5, 13.2. HRMS calc'd for $\mathrm{C}_{9} \mathrm{H}_{13} \mathrm{~N}_{2} \mathrm{O}_{4} \mathrm{~S}^{+}[\mathrm{M}+\mathrm{H}]^{+}$ 245.0591, found 245.0581 .<smiles>CCN(CC)CCNC(=O)c1ccc(NS(N)(=O)=O)cc1</smiles>

$9 c$

white-solid (50.24 mg, $80 \%$ yield). The product was purified by flash column chromatography on silica gel (eluent: dichloromethane/ammonia methanol $=6: 1$ ). ${ }^{1} \mathbf{H}$ NMR (400 MHz, Methanol-d $\left.d_{4}\right) \delta 7.90-7.74(\mathrm{~m}, 2 \mathrm{H}), 7.42-7.07(\mathrm{~m}, 2 \mathrm{H}), 3.72(\mathrm{t}, J=$ $6.1 \mathrm{~Hz}, 2 \mathrm{H}), 3.39-3.31(\mathrm{~m}, 2 \mathrm{H}), 3.29(\mathrm{q}, J=1.8 \mathrm{~Hz}, 4 \mathrm{H}), 1.33(\mathrm{t}, J=7.3 \mathrm{~Hz}, 6 \mathrm{H}) .{ }^{13} \mathrm{C}$ NMR (151 MHz, Methanol- $\left.d_{4}\right) \delta 169.5,143.1,128.3,126.4,116.9,51.9,35.1,7.8$. HRMS calc'd for $\mathrm{C}_{13} \mathrm{H}_{23} \mathrm{~N}_{4} \mathrm{O}_{3} \mathrm{~S}^{+}[\mathrm{M}+\mathrm{H}]^{+} 315.1485$, found 315.1479 .

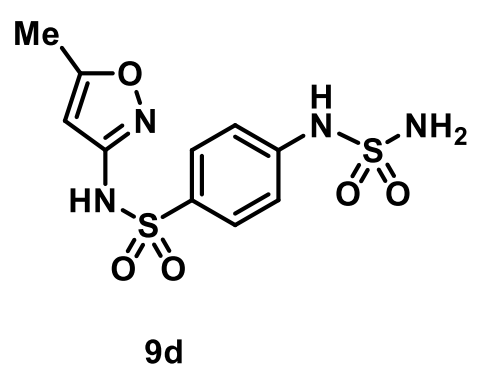

white-solid (42.50 mg, 64\% yield). The product was purified by preparative HPLC. ${ }^{1} \mathbf{H}$ NMR (400 MHz, Methanol-d $\left.d_{4}\right) \delta 7.83-7.77$ (m, 2H), 7.30 - 7.25 (m, 2H), $6.14-6.12$ (m, 1H), $2.32-2.31(\mathrm{~m}, 3 \mathrm{H}) .{ }^{\mathbf{1 3}} \mathbf{C}$ NMR (101 MHz, Methanol-d $\left.d_{4}\right) \delta 170.6,157.9,144.0$, 132.3, 128.3, 116.8, 95.0, 10.9. HRMS calc'd for $\mathrm{C}_{10} \mathrm{H}_{13} \mathrm{~N}_{4} \mathrm{O}_{5} \mathrm{~S}_{2}{ }^{+}[\mathrm{M}+\mathrm{H}]^{+} 333.0322$, found 333.0313 . 
<smiles>[M]C(NS(N)(=O)=O)C(=O)OCc1ccccc1</smiles>

$9 e$

white-solid (32.00 mg, 62\% yield) The product was purified by flash column chromatography on silica gel (eluent: dichloromethane/ammonia methanol $=10: 1)$. ${ }^{1} \mathbf{H}$ NMR $\left(400 \mathrm{MHz}\right.$, Methanol- $\left.d_{4}\right) \delta 7.54-7.17(\mathrm{~m}, 5 \mathrm{H}), 5.22-5.15(\mathrm{~m}, 2 \mathrm{H}), 4.10(\mathrm{q}, J$ $=7.2 \mathrm{~Hz}, 1 \mathrm{H}), 1.39(\mathrm{~d}, J=7.2 \mathrm{~Hz}, 3 \mathrm{H}) \cdot{ }^{\mathbf{1 3}} \mathbf{C}$ NMR $\left(101 \mathrm{MHz}\right.$, Methanol- $\left.d_{4}\right) \delta$ 173.4, 135.9, 128.2, 127.9, 127.9, 66.6, 51.7, 17.7. HRMS calc'd for $\mathrm{C}_{10} \mathrm{H}_{15} \mathrm{~N}_{2} \mathrm{O}_{4} \mathrm{~S}^{+}[\mathrm{M}+\mathrm{H}]^{+}$ 259.0747 , found 259.0737<smiles>COC(=O)C(Cc1ccccc1)NS(N)(=O)=O</smiles>

9f

white-solid (35.61 mg, 69\% yield) The product was purified by flash column chromatography on silica gel (eluent: dichloromethane/ammonia methanol $=10: 1)^{1} \mathbf{H}$ NMR (400 MHz, Methanol-d $\left.d_{4}\right) \delta 7.35-7.17(\mathrm{~m}, 5 \mathrm{H}), 4.23(\mathrm{t}, J=7.0 \mathrm{~Hz}, 1 \mathrm{H}), 3.65(\mathrm{~s}$, 3H), $3.03(\mathrm{~d}, J=7.0 \mathrm{~Hz}, 2 \mathrm{H}) .{ }^{\mathbf{1 3}} \mathbf{C}$ NMR (101 MHz, Methanol- $\left.d_{4}\right) \delta 172.8,136.4,129.1$, 128.1, 126.6, 57.4, 51.3, 38.5. HRMS calc'd for $\mathrm{C}_{10} \mathrm{H}_{13} \mathrm{~N}_{2} \mathrm{O}_{4} \mathrm{~S}^{-}[\mathrm{M}-\mathrm{H}]^{-}$257.0602, found 257.0602 .<smiles>NS(=O)(=O)OCCc1ccc(O)cc1</smiles>

10a $(0.2 \mathrm{mmol}), 1(0.4 \mathrm{mmol})$ and dry dichloromethane $(3 \mathrm{~mL})$ were added to the reaction vessel at room temperature, and the mixture was stirred for 3.2 hours. After the completion of the reaction was indicated by TLC, the solvent was evaporated, anhydrous acetonitrile $(3 \mathrm{~mL})$ was added, and $\mathrm{HCl}(12 \mathrm{M})$ in water $(0.5 \mathrm{~mL})$ was added 
dropwise at room temperature. The mixture was concentrated under reduced pressure. Saturated aqueous $\mathrm{Na}_{2} \mathrm{CO}_{3}(50 \mathrm{~mL})$ was added to the residue, and the resulting mixture was extracted with EA. The combined organic layer was dried over $\mathrm{Na}_{2} \mathrm{SO}_{4}$ and concentrated under reduced pressure. By comparing with the raw material NMR data and mass spectrum data, the correctness of the structure is proved. white-solid (34.72 $\mathrm{mg}, 80 \%$ yield). The product was purified by flash column chromatography on silica gel (eluent: dichloromethane/ammonia methanol =6:1). ${ }^{1} \mathbf{H}$ NMR $(400 \mathrm{MHz}$, Methanol- $\left.d_{4}\right) \delta 7.11-7.02(\mathrm{~m}, 2 \mathrm{H}), 6.75-6.70(\mathrm{~m}, 2 \mathrm{H}), 4.24(\mathrm{t}, J=7.1 \mathrm{~Hz}, 2 \mathrm{H}), 2.91$ $(\mathrm{t}, J=7.1 \mathrm{~Hz}, 2 \mathrm{H}) .{ }^{13} \mathrm{C}$ NMR $\left(101 \mathrm{MHz}\right.$, Methanol- $\left.d_{4}\right) \delta 155.8,129.6,127.8,114.9$, 70.3, 34.1 HRMS calc'd for $\mathrm{C}_{8} \mathrm{H}_{10} \mathrm{NO}_{4} \mathrm{~S}^{-}[\mathrm{M}-\mathrm{H}]^{-} 216.0336$, found 216.0338.<smiles>NS(=O)(=O)Nc1cccc(O)c1</smiles>

$10 \mathrm{~b}(0.2 \mathrm{mmol}), 1(0.3 \mathrm{mmol})$ and dry dichloromethane $(3 \mathrm{~mL})$ were added to the reaction vessel at room temperature, and the mixture was stirred for 3.4 hours. After the completion of the reaction was indicated by TLC, the solvent was evaporated, anhydrous acetonitrile $(3 \mathrm{~mL})$ was added, and $\mathrm{HCl}(12 \mathrm{M})$ in water $(0.5 \mathrm{~mL})$ was added dropwise at room temperature. The mixture was concentrated under reduced pressure. Saturated aqueous $\mathrm{Na}_{2} \mathrm{CO}_{3}(50 \mathrm{~mL})$ was added to the residue, and the resulting mixture was extracted with EA. The combined organic layer was dried over $\mathrm{Na}_{2} \mathrm{SO}_{4}$ and concentrated under reduced pressure. By comparing with the raw material NMR data and mass spectrum data, the correctness of the structure is proved white-solid (28.20 mg, $75 \%$ yield) The product was purified by flash column chromatography on silica gel (eluent: dichloromethane/ammonia methanol = 7:1). ${ }^{1} \mathbf{H}$ NMR $(400 \mathrm{MHz}$, Methanol$\left.d_{4}\right) \delta 7.08(\mathrm{t}, J=8.1 \mathrm{~Hz}, 1 \mathrm{H}), 6.75-6.72(\mathrm{~m}, 1 \mathrm{H}), 6.70-6.65(\mathrm{~m}, 1 \mathrm{H}), 6.53-6.44(\mathrm{~m}$, 1H). ${ }^{13}$ C NMR (101 MHz, Methanol- $\left.d_{4}\right) \delta 157.7,140.0,129.4,110.4,110.0,106.3$. HRMS calc'd for $\mathrm{C}_{6} \mathrm{H}_{9} \mathrm{~N}_{2} \mathrm{O}_{3} \mathrm{~S}^{+}[\mathrm{M}+\mathrm{H}]^{+} 189.0328$, found 189.0328 . 


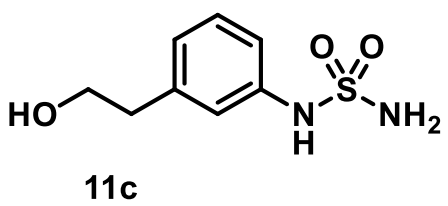

$10 \mathrm{c}(0.2 \mathrm{mmol}), 1(0.2 \mathrm{mmol})$ and dry dichloromethane $(3 \mathrm{~mL})$ were added to the reaction vessel at room temperature, and the mixture was stirred for 1.5 hours, $1(0.1$ mmol) was added. After the completion of the reaction was indicated by TLC, the solvent was evaporated, anhydrous acetonitrile $(3 \mathrm{~mL})$ was added, and $\mathrm{HCl}(12 \mathrm{M})$ in water $(0.5 \mathrm{~mL})$ was added dropwise at room temperature. The mixture was concentrated under reduced pressure. Saturated aqueous $\mathrm{Na}_{2} \mathrm{CO}_{3}(50 \mathrm{~mL})$ was added to the residue, and the resulting mixture was extracted with EA. The combined organic layer was dried over $\mathrm{Na}_{2} \mathrm{SO}_{4}$ and concentrated under reduced pressure. By comparing with the raw material NMR data and mass spectrum data, the correctness of the structure is proved .white-solid (33.70 mg, 78\% yield) The product was purified by flash column chromatography on silica gel (eluent: dichloromethane/ammonia methanol $=7: 1$ ) ${ }^{\mathbf{1}} \mathbf{H}$ NMR (400 MHz, Methanol-d $\left.d_{4}\right) \delta 7.25$ - $7.18(\mathrm{~m}, 1 \mathrm{H}), 7.13$ - $7.04(\mathrm{~m}, 2 \mathrm{H}), 6.97-6.91$ $(\mathrm{m}, 1 \mathrm{H}), 3.76(\mathrm{t}, J=7.0 \mathrm{~Hz}, 2 \mathrm{H}), 2.80(\mathrm{t}, J=7.0 \mathrm{~Hz}, 2 \mathrm{H}) .{ }^{13} \mathbf{C}$ NMR $(101 \mathrm{MHz}$, Methanol- $\left.d_{4}\right) \delta 140.1,138.9,128.6,123.7,119.9,117.2,62.7,38.8$. HRMS calc'd for $\mathrm{C}_{8} \mathrm{H}_{16} \mathrm{~N}_{3} \mathrm{O}_{3} \mathrm{~S}^{+}\left[\mathrm{M}+\mathrm{NH}^{4}\right]^{+} 234.0907$, found 234.0908.

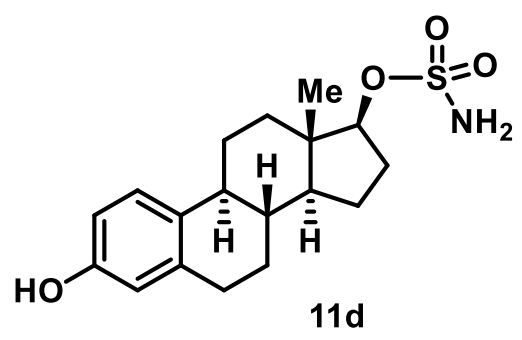

$10 \mathrm{~d}(0.2 \mathrm{mmol}), 1(0.3 \mathrm{mmol})$ and dry dichloromethane $(3 \mathrm{~mL})$ were added to the reaction vessel at room temperature, and the mixture was stirred for 3 hours. After the completion of the reaction was indicated by TLC, the solvent was evaporated, anhydrous acetonitrile $(3 \mathrm{~mL})$ was added, and $\mathrm{HCl}(12 \mathrm{M})$ in water $(0.5 \mathrm{~mL})$ was added dropwise at room temperature. The mixture was concentrated under reduced pressure. Saturated aqueous $\mathrm{Na}_{2} \mathrm{CO}_{3}(50 \mathrm{~mL})$ was added to the residue, and the resulting mixture 
was extracted with EA. The combined organic layer was dried over $\mathrm{Na}_{2} \mathrm{SO}_{4}$ and concentrated under reduced pressure. By comparing with the raw material NMR data and mass spectrum data, the correctness of the structure is proved .white-solid (49.16 $\mathrm{mg}, 70 \%$ yield) The product was purified by flash column chromatography on silica gel (eluent: dichloromethane/ammonia methanol $=10: 1){ }^{\mathbf{1}} \mathbf{H}$ NMR (400 MHz, Methanol$\left.d_{4}\right) \delta 7.06(\mathrm{~d}, J=8.5 \mathrm{~Hz}, 1 \mathrm{H}), 6.54(\mathrm{dd}, J=8.4,2.7 \mathrm{~Hz}, 1 \mathrm{H}), 6.47(\mathrm{~d}, J=2.7 \mathrm{~Hz}, 1 \mathrm{H})$, $4.44-4.38(\mathrm{~m}, 1 \mathrm{H}), 2.83-2.70(\mathrm{~m}, 2 \mathrm{H}), 2.32-2.20(\mathrm{~m}, 2 \mathrm{H}), 2.16-2.00(\mathrm{~m}, 2 \mathrm{H})$, $1.88-1.71(\mathrm{~m}, 3 \mathrm{H}), 1.46-1.24(\mathrm{~m}, 6 \mathrm{H}), 0.84(\mathrm{~s}, 3 \mathrm{H}) .{ }^{13} \mathrm{C}$ NMR $(101 \mathrm{MHz}$, Methanol$\left.d_{4}\right) \delta 154.6,137.4,130.9,125.9,114.7,112.4,88.8,49.1,43.7,43.0,38.8,36.3,29.2$, 27.5, 27.0, 26.0, 22.6, 10.8. HRMS calc'd for $\mathrm{C}_{18} \mathrm{H}_{26} \mathrm{NO}_{4} \mathrm{~S}^{+}[\mathrm{M}+\mathrm{H}]^{+} 352.1577$, found 352.1572 .

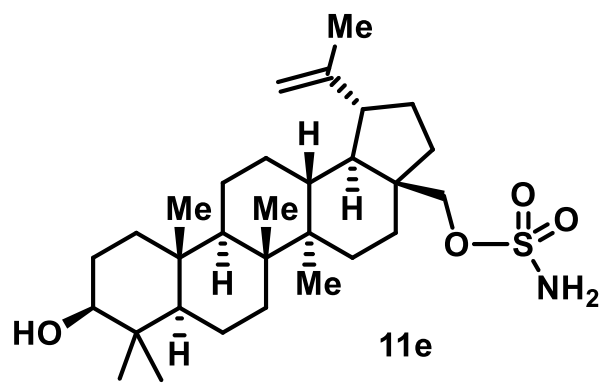

10e $(0.2 \mathrm{mmol}), 1(0.4 \mathrm{mmol})$ and dry dichloromethane $(3 \mathrm{~mL})$ were added to the reaction vessel at room temperature, and the mixture was stirred for 3 hours. After the completion of the reaction was indicated by TLC, the solvent was evaporated, anhydrous acetonitrile $(3 \mathrm{~mL})$ was added, and $\mathrm{HCl}(12 \mathrm{M})$ in water $(0.5 \mathrm{~mL})$ was added dropwise at room temperature. The mixture was concentrated under reduced pressure. Saturated aqueous $\mathrm{Na}_{2} \mathrm{CO}_{3}(50 \mathrm{~mL})$ was added to the residue, and the resulting mixture was extracted with EA. The combined organic layer was dried over $\mathrm{Na}_{2} \mathrm{SO}_{4}$ and concentrated under reduced pressure. By comparing with the raw material NMR data and mass spectrum data, the correctness of the structure is proved . white-solid (64.60 $\mathrm{mg}, 62 \%$ yield) The product was purified by flash column chromatography on silica gel (eluent: dichloromethane/ammonia methanol = 10:1) ${ }^{\mathbf{1}} \mathbf{H}$ NMR $\left(400 \mathrm{MHz}, \mathrm{DMSO}-d_{6}\right)$ 
$\delta 7.43(\mathrm{~s}, 2 \mathrm{H}), 4.73-4.68(\mathrm{~m}, 1 \mathrm{H}), 4.60-4.55(\mathrm{~m}, 1 \mathrm{H}), 4.28(\mathrm{~d}, J=5.1 \mathrm{~Hz}, 1 \mathrm{H}), 4.12$ $(\mathrm{d}, J=9.6 \mathrm{~Hz}, 1 \mathrm{H}), 3.75(\mathrm{~d}, J=9.6 \mathrm{~Hz}, 1 \mathrm{H}), 3.02-2.89(\mathrm{~m}, 1 \mathrm{H}), 2.45-2.37(\mathrm{~m}, 1 \mathrm{H})$, $2.03-1.85(\mathrm{~m}, 1 \mathrm{H}), 1.84-1.53(\mathrm{~m}, 10 \mathrm{H}), 1.48-1.22(\mathrm{~m}, 10 \mathrm{H}), 1.19-0.94(\mathrm{~m}, 10 \mathrm{H})$, $0.88-0.75(\mathrm{~m}, 7 \mathrm{H}), 0.70-0.60(\mathrm{~m}, 4 \mathrm{H}) .{ }^{13} \mathbf{C}$ NMR $\left(151 \mathrm{MHz}, \mathrm{DMSO}-d_{6}\right) \delta 149.1$, 109.5, 76.2, 66.7, 54.2, 49.1, 47.5, 46.6, 45.4, 41.6, 39.8, 37.9, 37.6, 36.6, 36.1, 33.1, 33.0, 28.2, 28.2, 27.5, 26.6, 25.8, 24.1, 19.7, 18.1, 17.3, 15.3, 15.2, 15.1, 13.9. HRMS calc'd for $\mathrm{C}_{30} \mathrm{H}_{51} \mathrm{ClNO}_{4} \mathrm{~S}^{-}[\mathrm{M}+\mathrm{Cl}]^{-} 556.3233$, found 556.3243 .

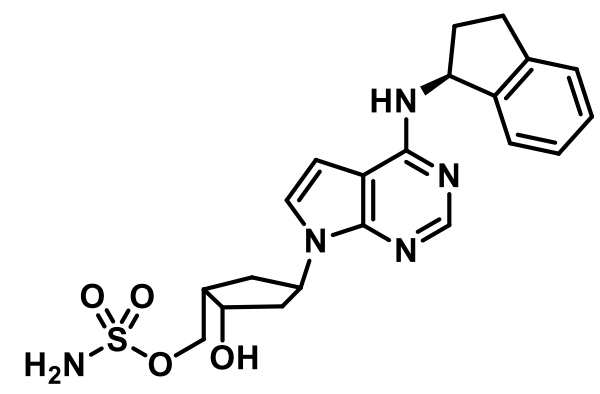

$11 f$

10f $(0.2 \mathrm{mmol}), 1(0.4 \mathrm{mmol})$ and dry acetonitrile $(3 \mathrm{~mL})$ were added to the reaction vessel at room temperature, and the mixture was stirred for 3 hours. After the completion of the reaction indicated by TLC, $\mathrm{HCl}(12 \mathrm{M})$ in water $(0.5 \mathrm{~mL})$ was added dropwise and the mixture was stirred for 8 hours. After the completion of the reaction indicated by TLC, the mixture was concentrated under reduced pressure. Saturated aqueous $\mathrm{Na}_{2} \mathrm{CO}_{3}(50 \mathrm{~mL})$ was added to the residue, and the resulting mixture was extracted with EA. The organic layer was dried over $\mathrm{Na}_{2} \mathrm{SO}_{4}$ and concentrated under reduced pressure. The residue was purified by flash column chromatography on silica gel. By comparing with the raw material NMR data and mass spectrum data, the correctness of the structure is proved. white-solid (34.72 mg, $80 \%$ yield). The product was purified by flash column chromatography on silica gel (eluent: dichloromethane/ammonia methanol $=10: 1)$. colorless-solid $(80 \%$ yield $) .{ }^{1} \mathbf{H}$ NMR $\left(400 \mathrm{MHz}\right.$, Methanol- $\left.d_{4}\right) \delta 8.18(\mathrm{~s}, 1 \mathrm{H}), 7.29-7.01(\mathrm{~m}, 5 \mathrm{H}), 6.64(\mathrm{~d}, J=3.6 \mathrm{~Hz}, 1 \mathrm{H})$, $5.85(\mathrm{t}, J=7.7 \mathrm{~Hz}, 1 \mathrm{H}), 5.53-5.35(\mathrm{~m}, 1 \mathrm{H}), 4.54-4.45(\mathrm{~m}, 1 \mathrm{H}), 4.43-4.33(\mathrm{~m}, 1 \mathrm{H})$, $4.29-4.15(\mathrm{~m}, 1 \mathrm{H}), 3.10-2.97(\mathrm{~m}, 1 \mathrm{H}), 2.96-2.73(\mathrm{~m}, 2 \mathrm{H}), 2.68-2.57(\mathrm{~m}, 1 \mathrm{H})$, $2.42-2.14(\mathrm{~m}, 3 \mathrm{H}), 2.09-1.92(\mathrm{~m}, 2 \mathrm{H}) .{ }^{13} \mathrm{C}$ NMR (101 MHz, Methanol-d 4 ) $\delta$ 156.4, 
150.6, 148.6, 143.8, 143.2, 127.4, 126.2, 124.3, 123.8, 121.2, 103.4, 99.1, 71.6, 69.4, 55.5, 52.6, 43.3, 42.1, 33.5, 33.2, 29.7. ESI: $\mathrm{m} / \mathrm{z}[\mathrm{M}+\mathrm{H}]^{+}: 444.2$ The characterization data were consistent with the literature ${ }^{1}$. 
9. Copies of NMR spectra data

${ }^{1} \mathrm{H}(400 \mathrm{MHz}$, Chloroform- $d)$ and ${ }^{13} \mathrm{C}(101 \mathrm{MHz}$, Chloroform- $d)$ spectra of

compound 1
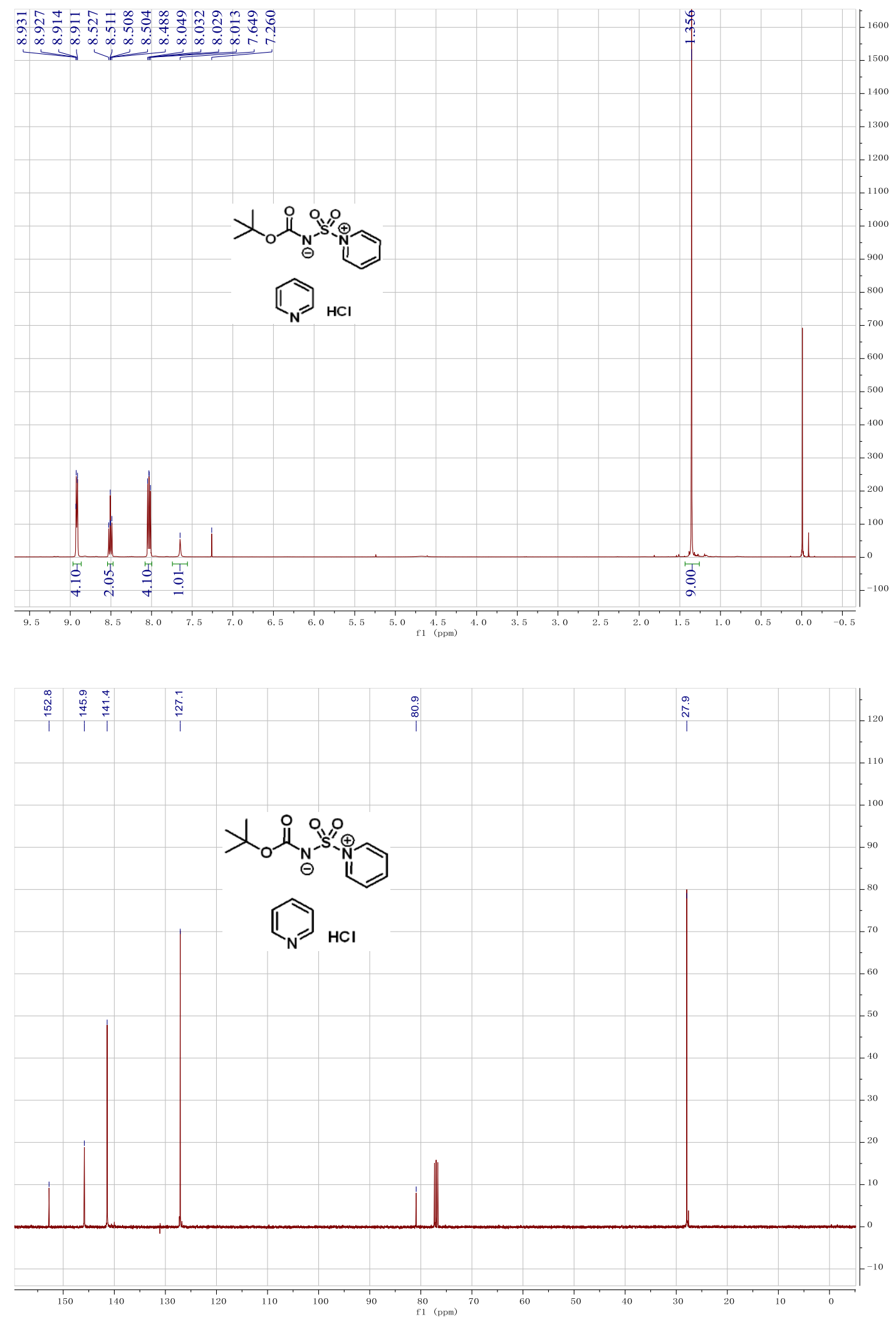

$\mathrm{S} 24$ 
${ }^{1} \mathrm{H}\left(400 \mathrm{MHz}\right.$, Chloroform-d) and ${ }^{13} \mathrm{C}(101 \mathrm{MHz}$, Chloroform-d) spectra of compound 3a
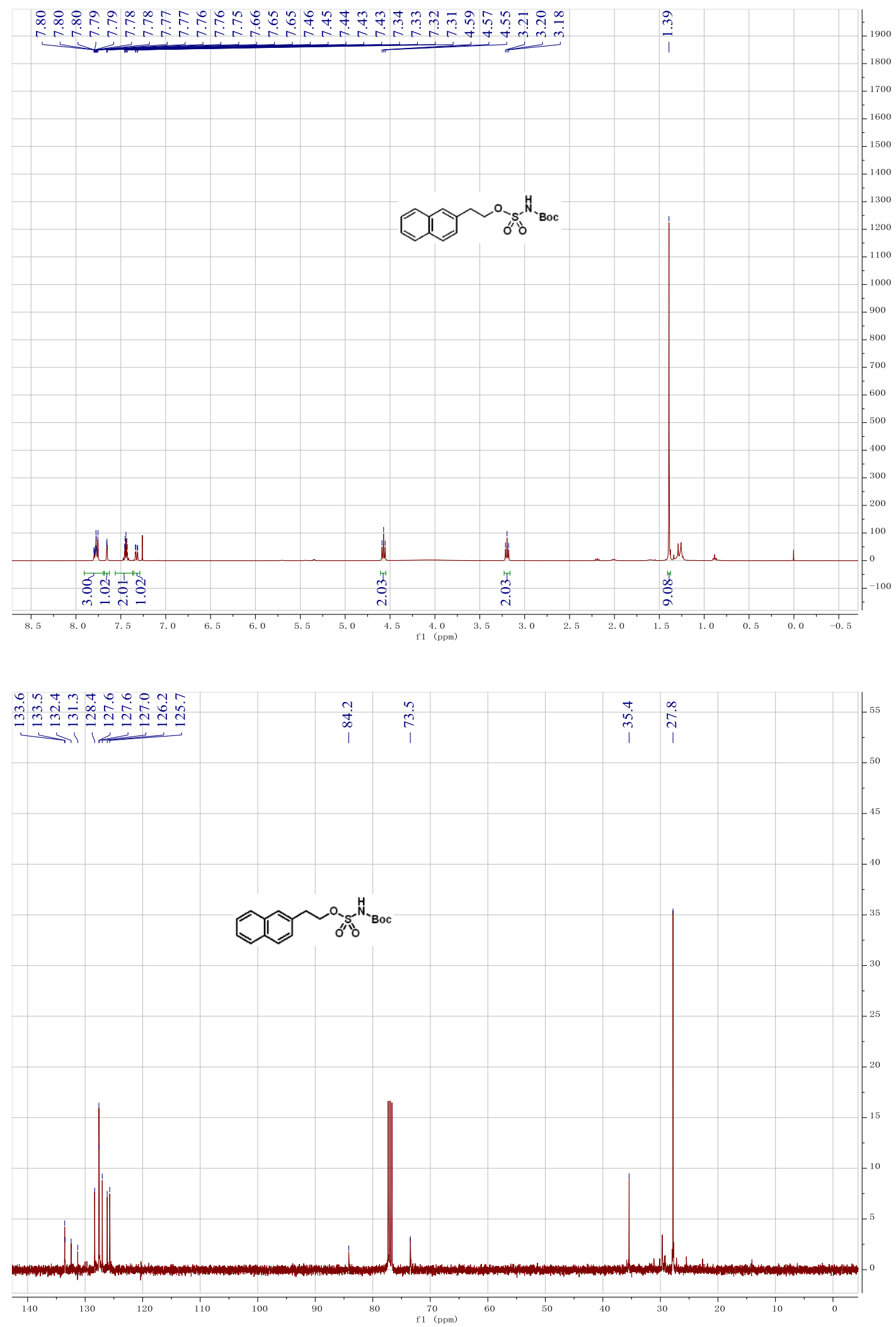
${ }^{1} \mathrm{H}\left(400 \mathrm{MHz}\right.$, Acetonitrile-d $\left.d_{3}\right)$ and ${ }^{13} \mathrm{C}(101 \mathrm{MHz}$, Acetonitrile-d3) spectra of compound 3b

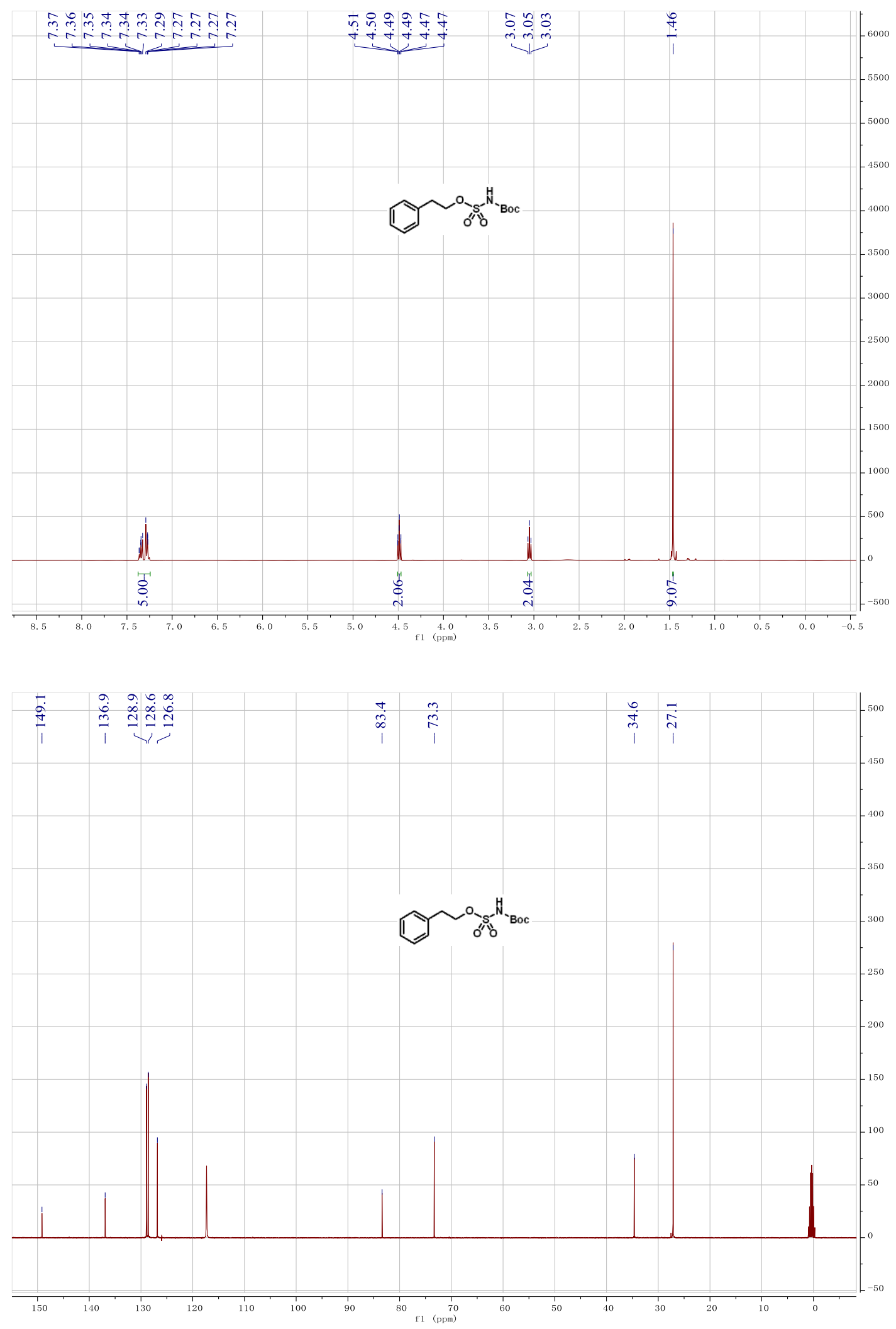


${ }^{1} \mathrm{H}\left(400 \mathrm{MHz}\right.$, Acetonitrile-d $\left.d_{3}\right)$ and ${ }^{13} \mathrm{C}\left(400 \mathrm{MHz}\right.$, Acetonitrile-d $\left.d_{3}\right)$ spectra of compound $3 \mathrm{c}$

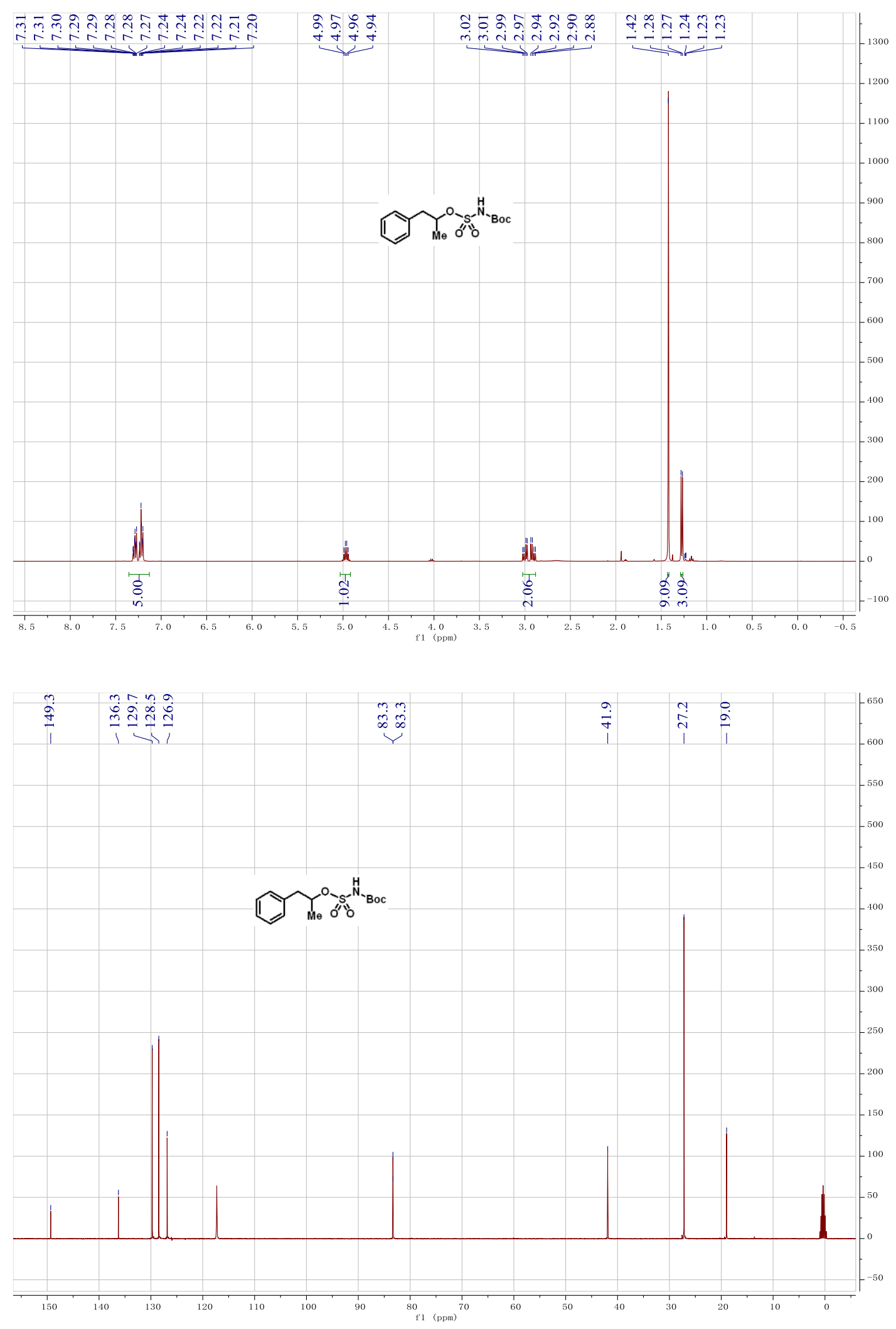


${ }^{1} \mathrm{H}\left(400 \mathrm{MHz}\right.$, Methanol- $\left.d_{4}\right)$ and ${ }^{13} \mathrm{C}\left(101 \mathrm{MHz}\right.$, Methanol- $\left.d_{4}\right)$ spectra of compound 3d

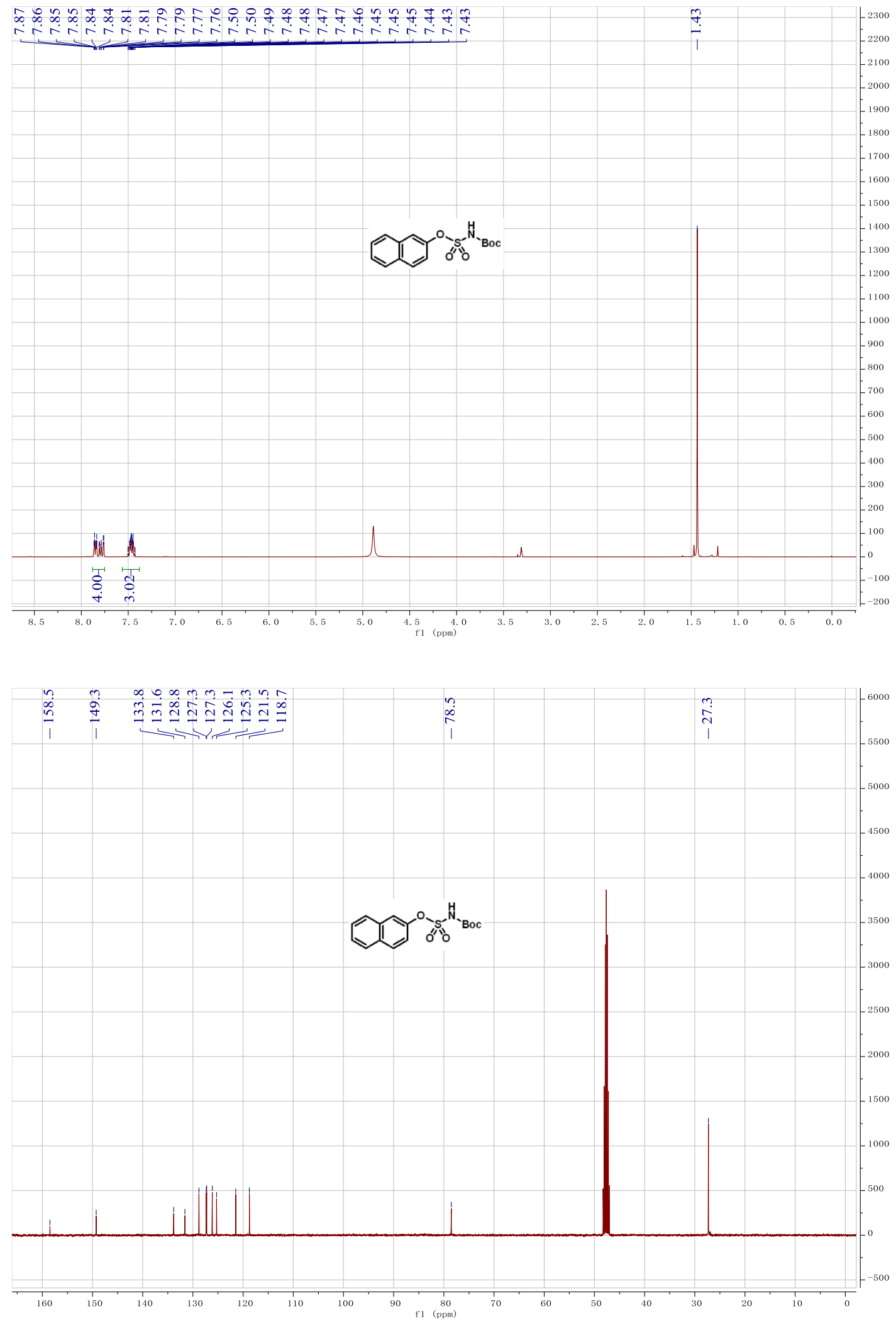


${ }^{1} \mathrm{H}(400 \mathrm{MHz}$, Chloroform- $d)$ and ${ }^{13} \mathrm{C}(101 \mathrm{MHz}$, Chloroform- $d)$ spectra of compound $3 \mathrm{e}$

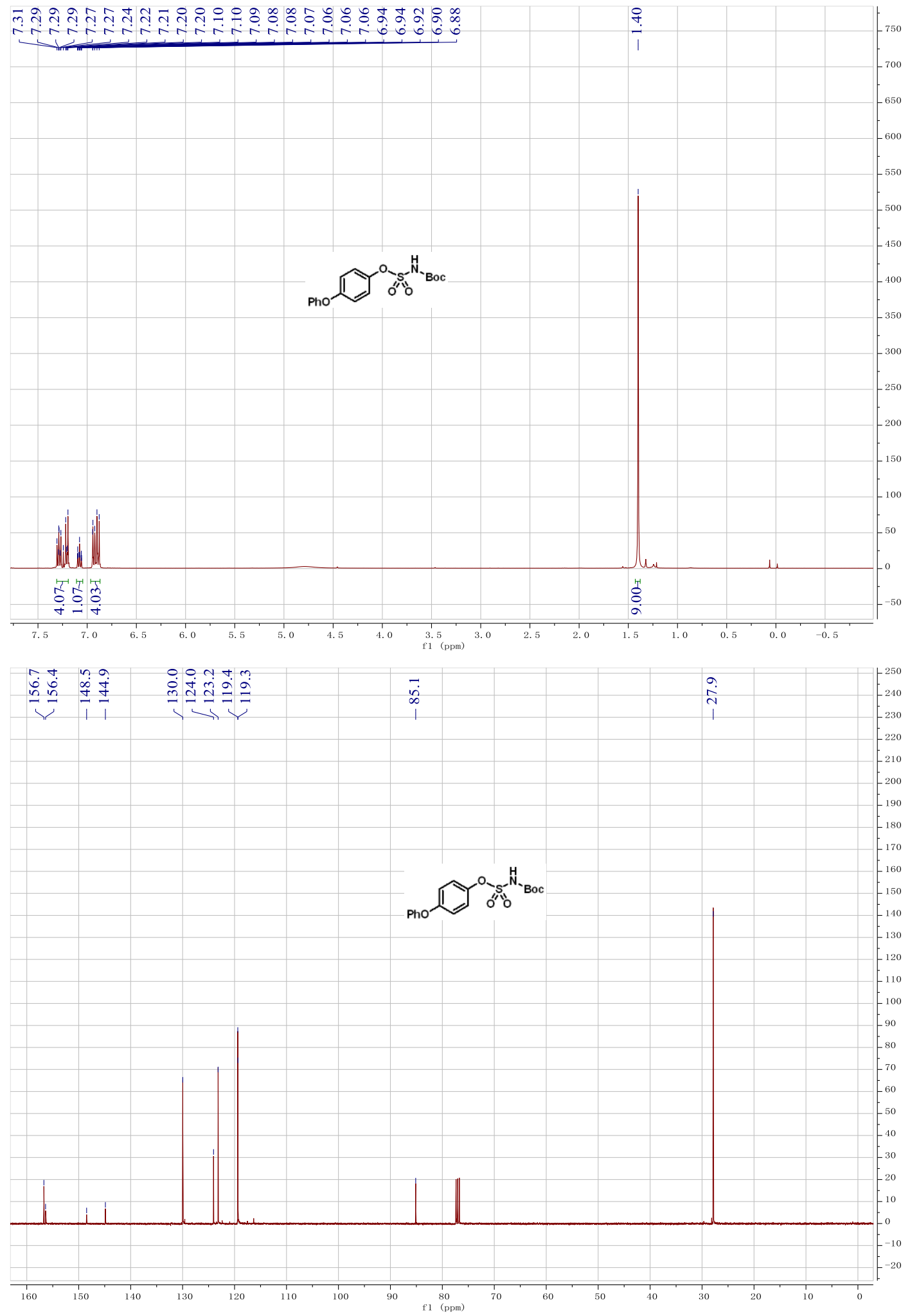


${ }^{1} \mathrm{H}\left(400 \mathrm{MHz}\right.$, Methanol- $\left.d_{4}\right)$ and ${ }^{13} \mathrm{C}\left(101 \mathrm{MHz}\right.$, Methanol- $\left.d_{4}\right)$ spectra of compound Bf
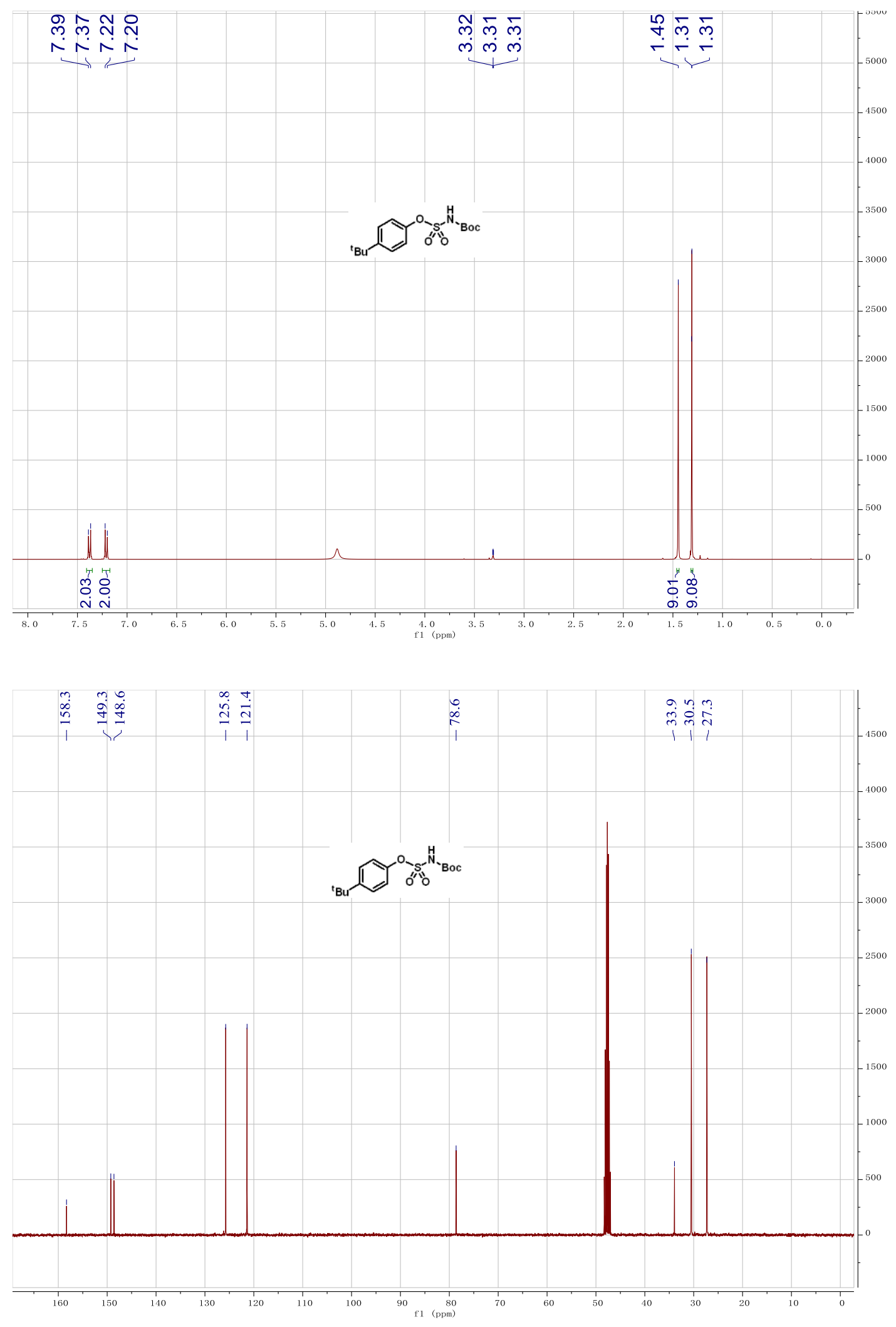

S30 
${ }^{1} \mathrm{H}\left(400 \mathrm{MHz}\right.$, Methanol- $\left.d_{4}\right)$ and ${ }^{13} \mathrm{C}\left(101 \mathrm{MHz}\right.$, Methanol- $\left.d_{4}\right)$ spectra of compound $3 g$
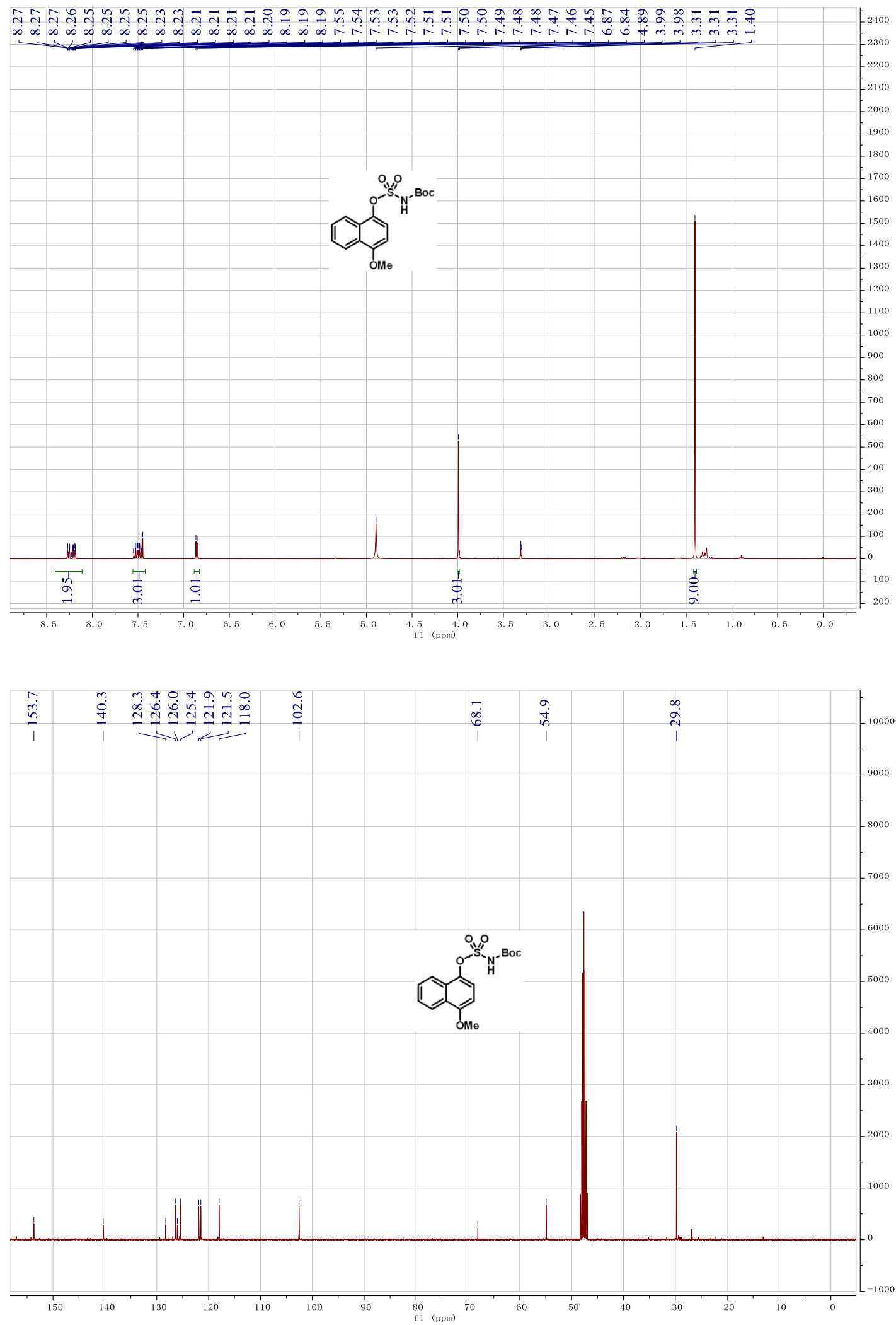
${ }^{1} \mathrm{H}\left(400 \mathrm{MHz}\right.$, Methanol- $\left.d_{4}\right)$ and ${ }^{13} \mathrm{C}\left(400 \mathrm{MHz}\right.$, Methanol- $\left.d_{4}\right)$ spectra of compound $3 \mathrm{~h}$
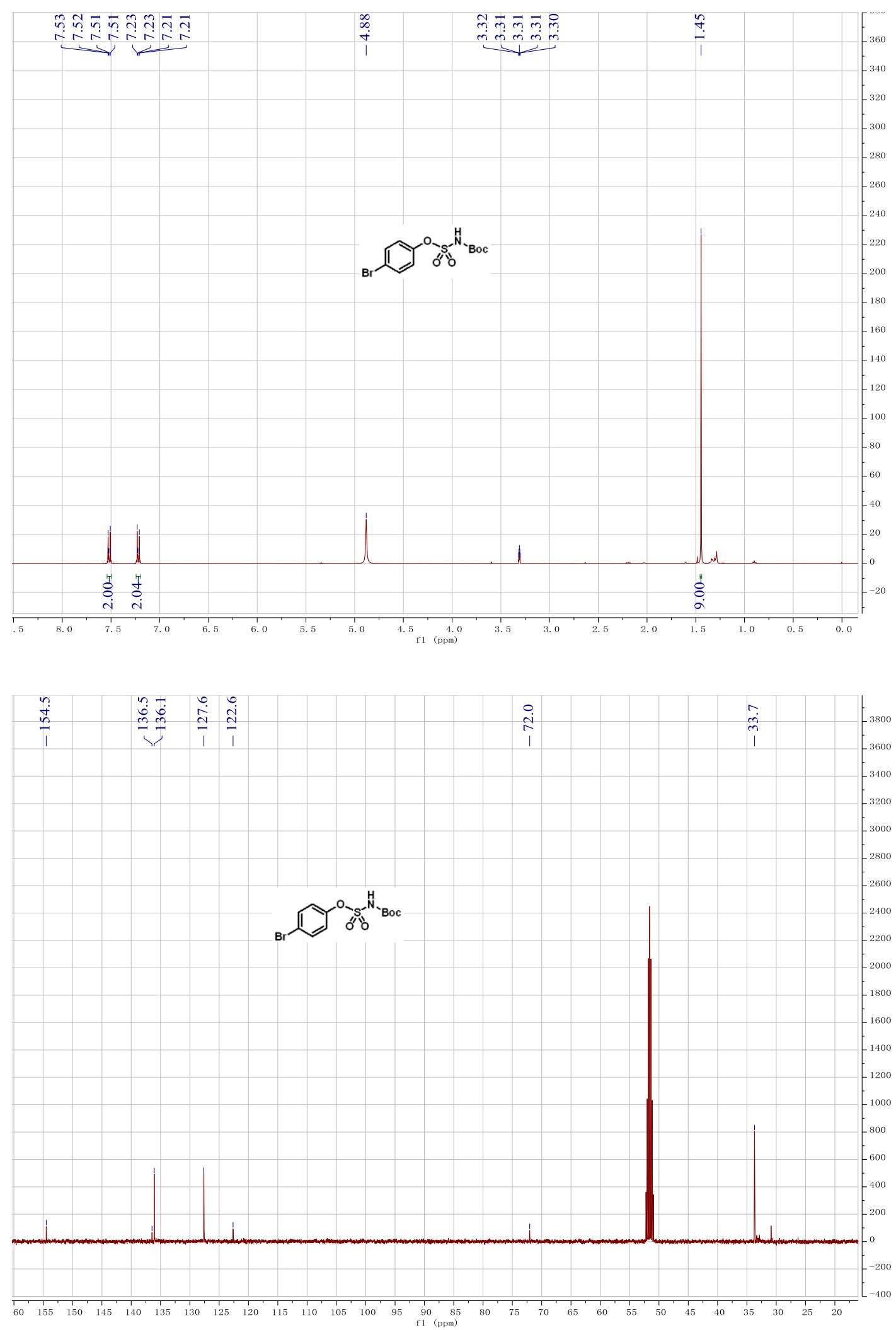
${ }^{1} \mathrm{H}\left(400 \mathrm{MHz}\right.$, Acetonitrile-d $\left.d_{3}\right)$ and ${ }^{13} \mathrm{C}\left(101 \mathrm{MHz}\right.$, Acetonitrile-d $\left.d_{3}\right)$ spectra of compound $3 \mathbf{i}$
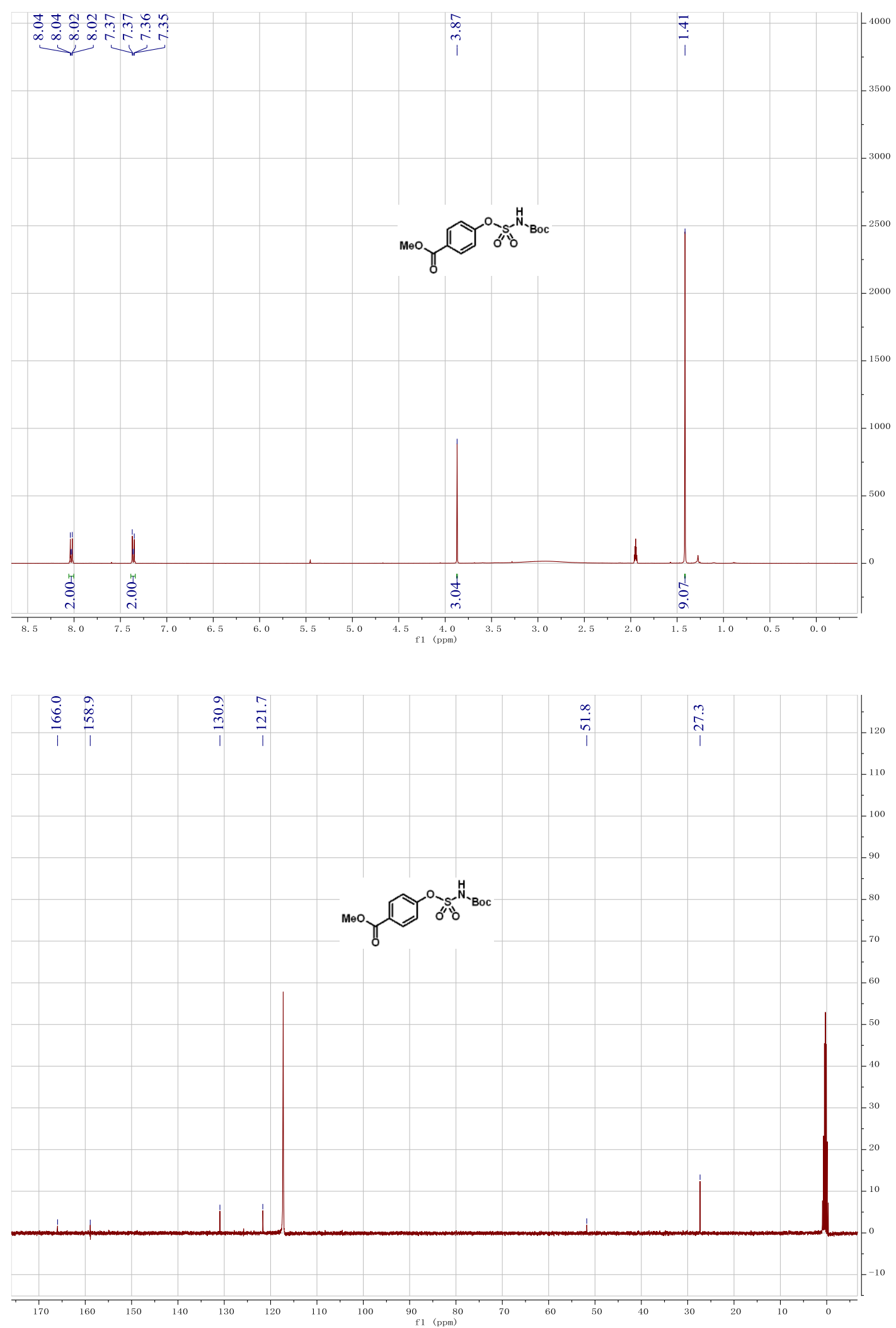
${ }^{1} \mathrm{H}(400 \mathrm{MHz}$, Chloroform- $d)$ and ${ }^{13} \mathrm{C}(101 \mathrm{MHz}$, Chloroform- $d)$ spectra of compound $3 \mathbf{j}$
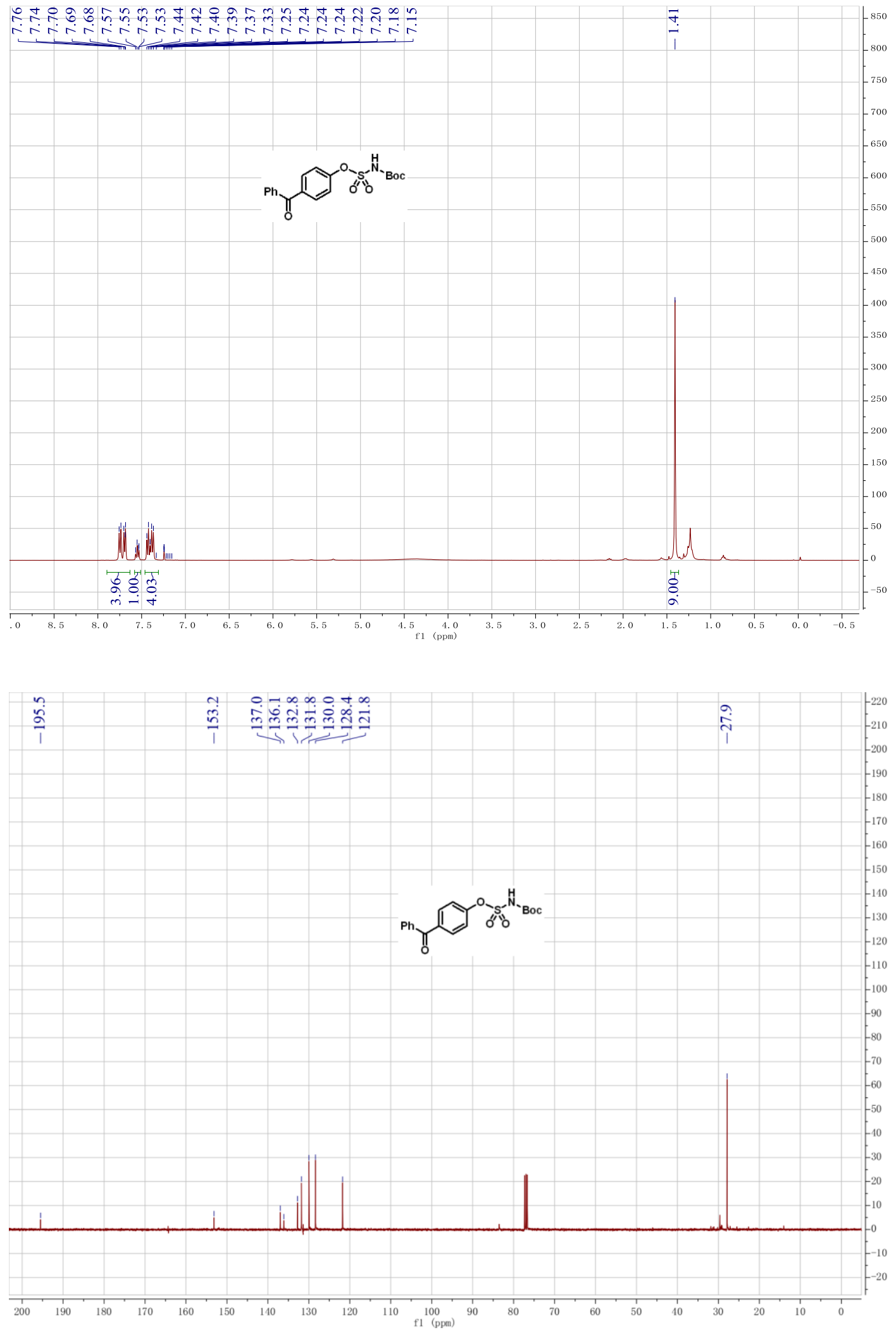
${ }^{1} \mathrm{H}\left(400 \mathrm{MHz}\right.$, Methanol- $\left.d_{4}\right)$ and ${ }^{13} \mathrm{C}\left(101 \mathrm{MHz}\right.$, Methanol- $\left.d_{4}\right)$ spectra of compound 5 a
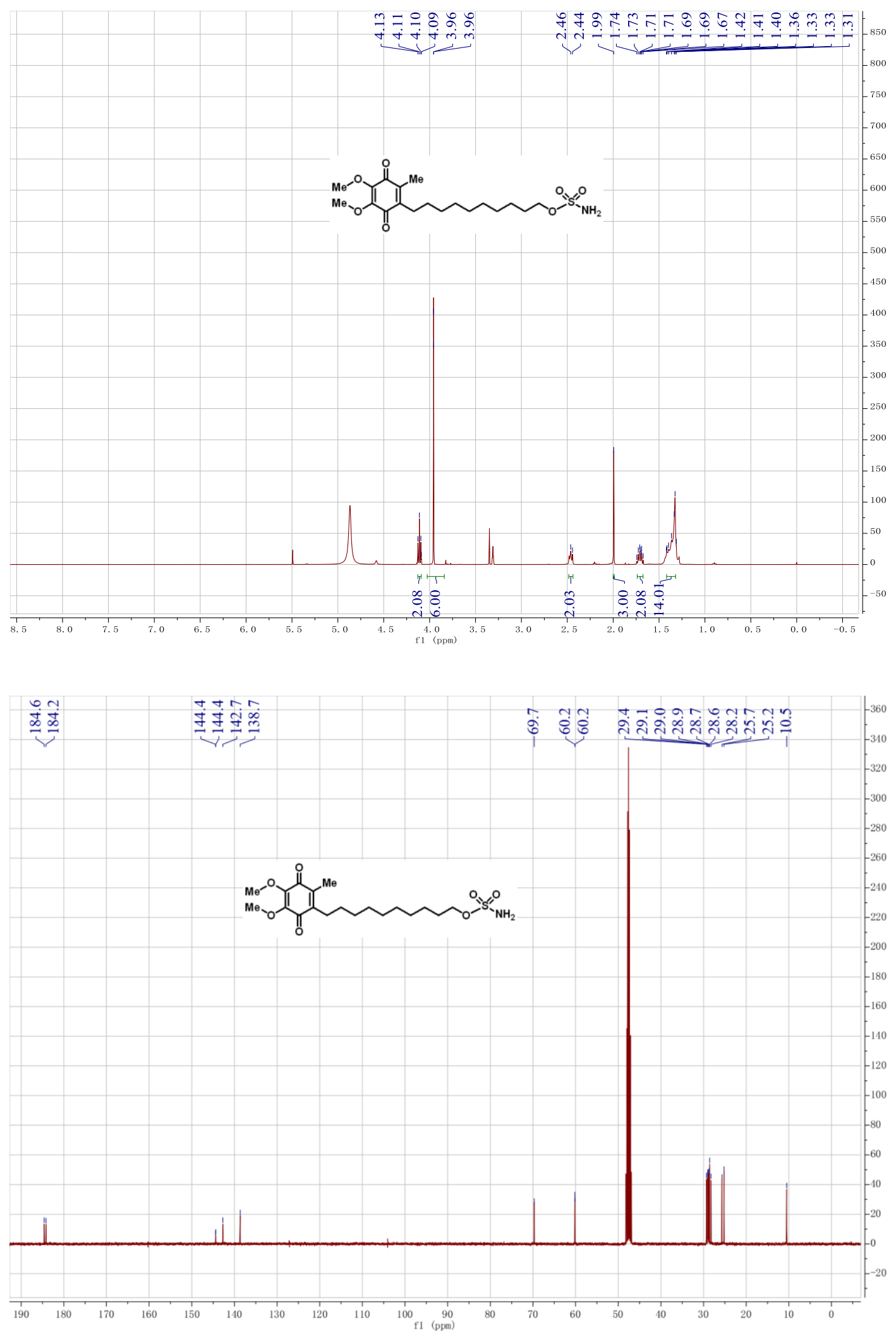
${ }^{1} \mathrm{H}\left(400 \mathrm{MHz}\right.$, Methanol- $\left.d_{4}\right)$ and ${ }^{13} \mathrm{C}\left(101 \mathrm{MHz}\right.$, Methanol- $\left.d_{4}\right)$ spectra of compound 5b
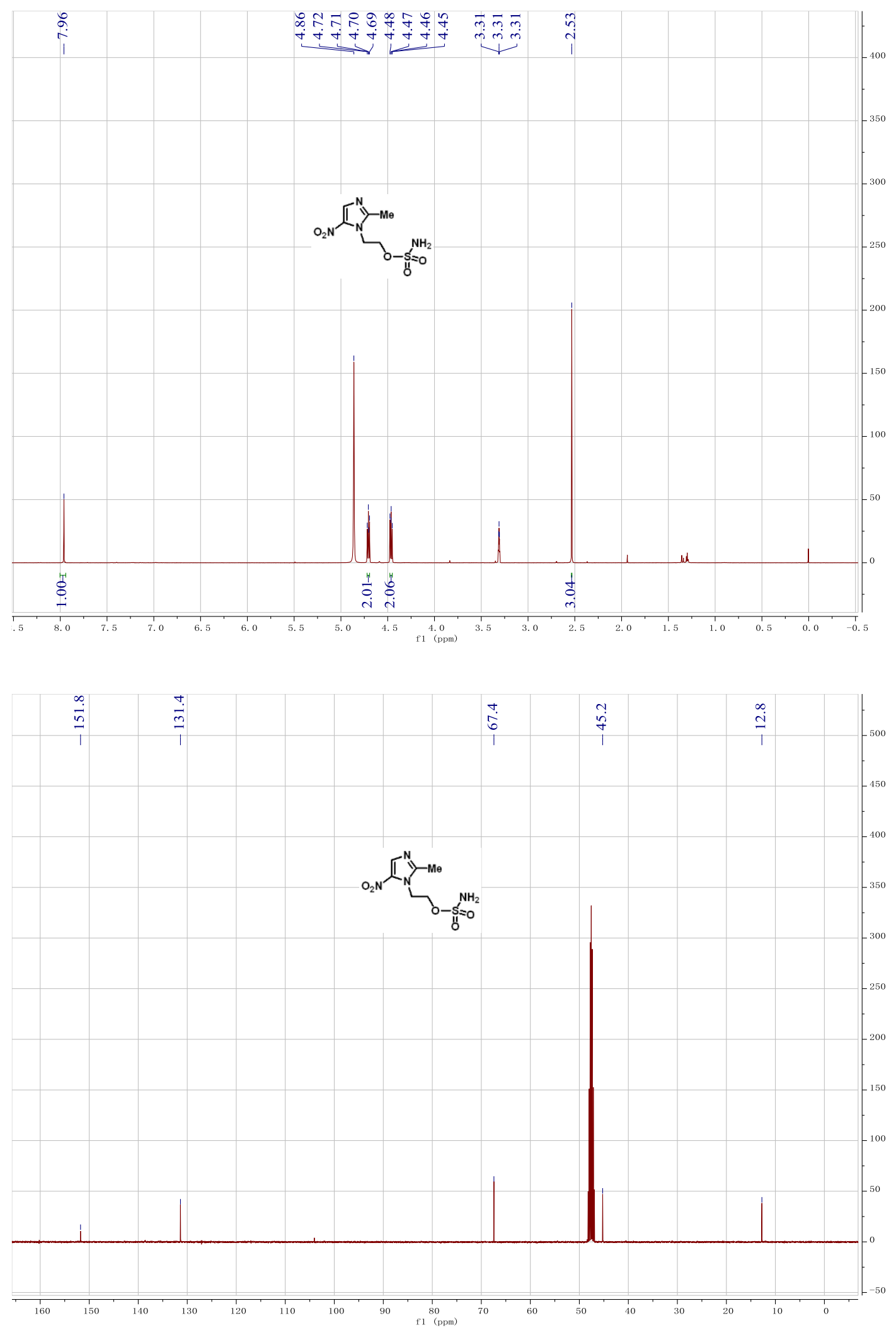
${ }^{1} \mathrm{H}\left(400 \mathrm{MHz}\right.$, Methanol- $\left.d_{4}\right)$ and ${ }^{13} \mathrm{C}\left(101 \mathrm{MHz}\right.$, Methanol- $\left.d_{4}\right)$ spectra of compound 5c
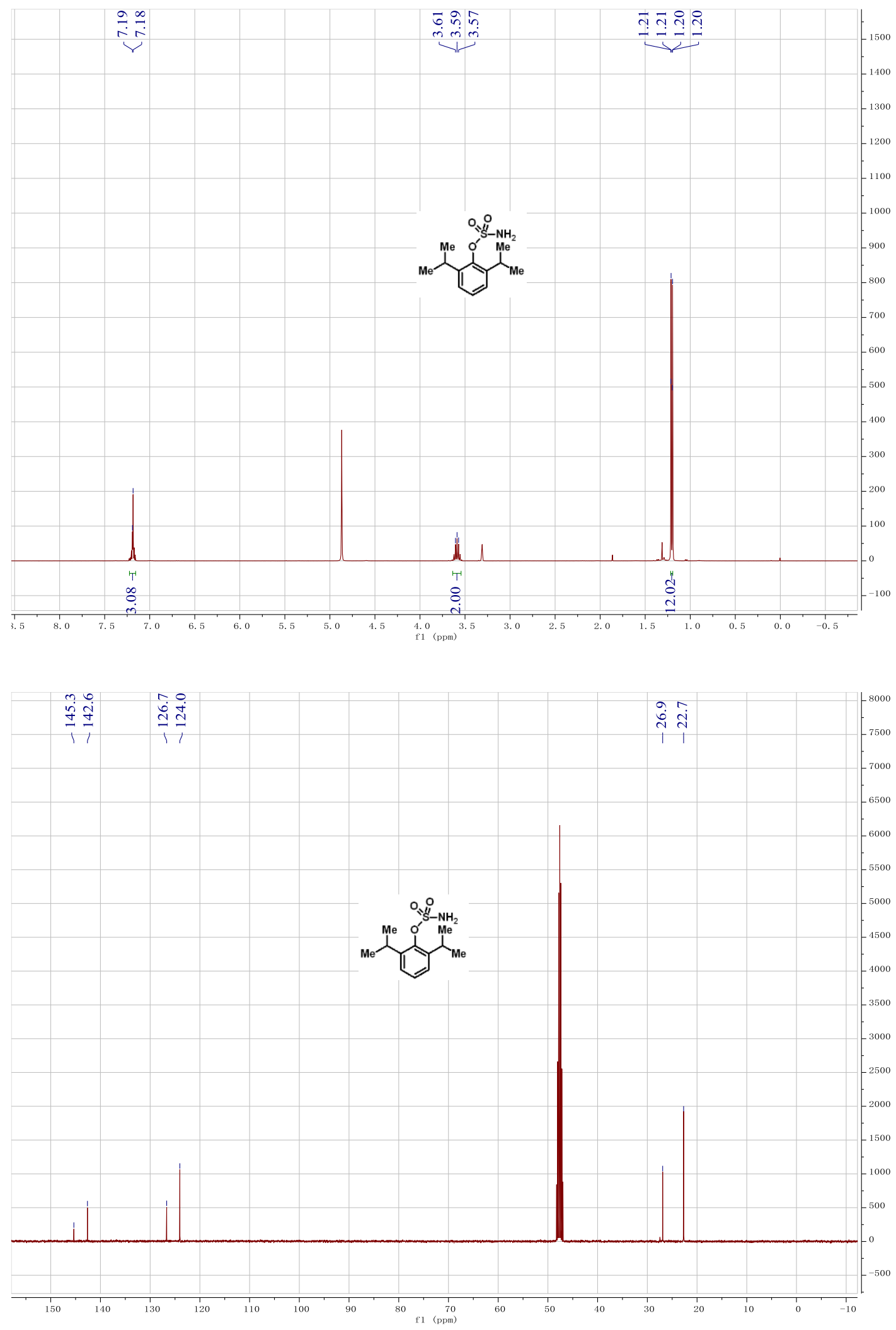
${ }^{1} \mathrm{H}\left(400 \mathrm{MHz}\right.$, Methanol- $\left.d_{4}\right)$ and ${ }^{13} \mathrm{C}\left(101 \mathrm{MHz}\right.$, Methanol- $\left.d_{4}\right)$ spectra of compound 5d
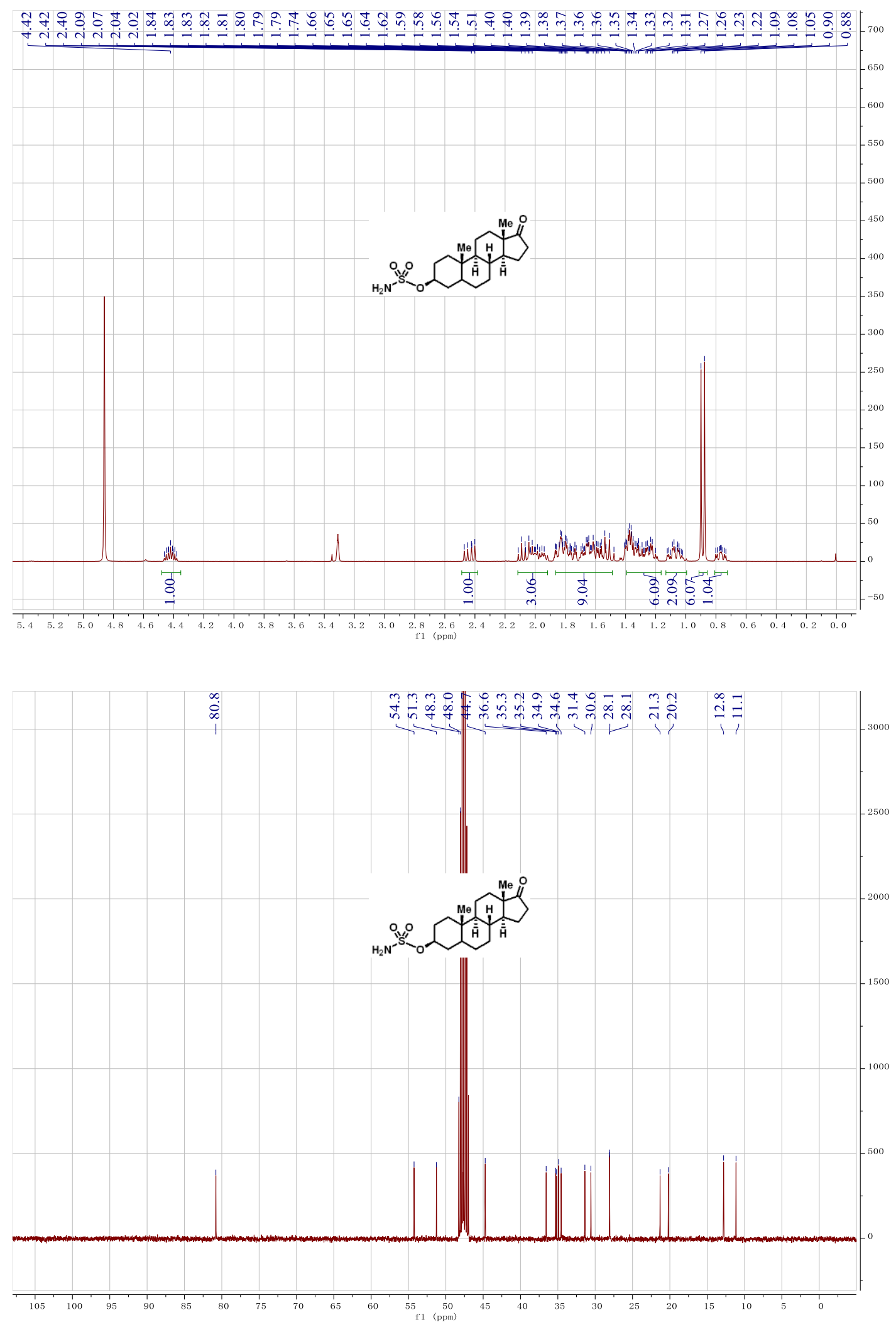
${ }^{1} \mathrm{H}\left(400 \mathrm{MHz}\right.$, Methanol- $\left.d_{4}\right)$ and ${ }^{13} \mathrm{C}\left(101 \mathrm{MHz}\right.$, Methanol- $\left.d_{4}\right)$ spectra of compound 5e
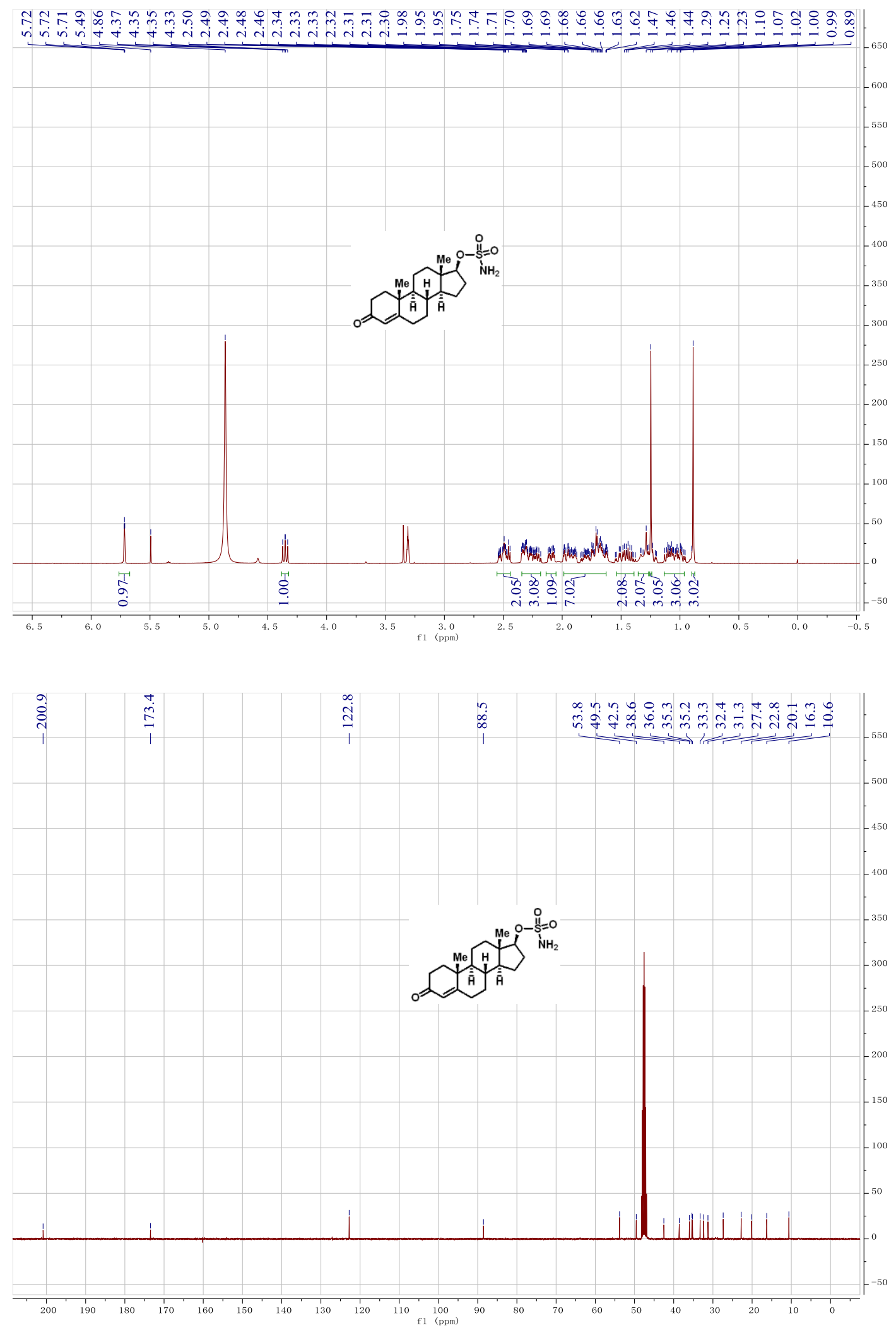
${ }^{1} \mathrm{H}\left(400 \mathrm{MHz}\right.$, Methanol- $\left.d_{4}\right)$ and ${ }^{13} \mathrm{C}\left(101 \mathrm{MHz}\right.$, Methanol- $\left.d_{4}\right)$ spectra of compound $5 f$
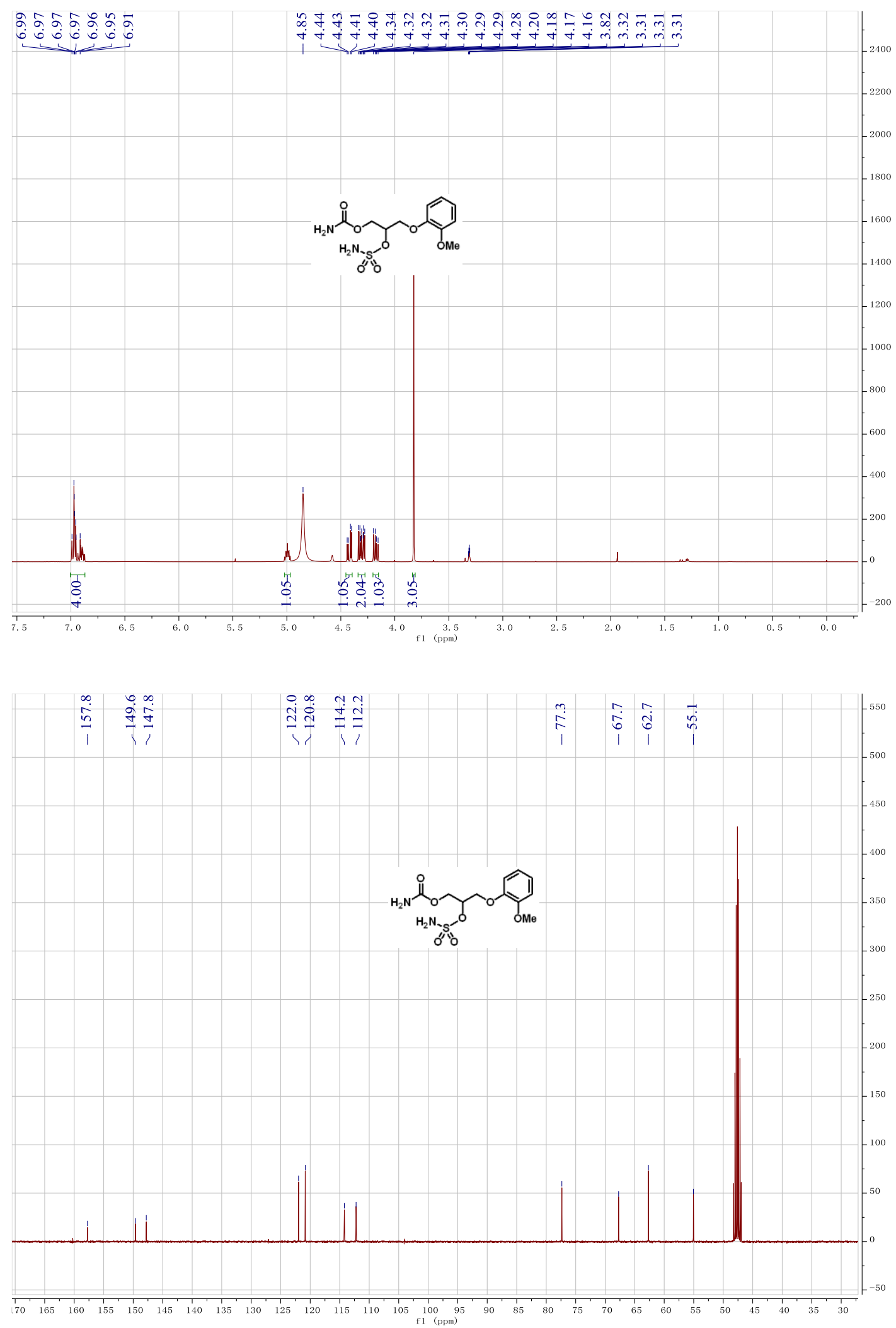
${ }^{1} \mathrm{H}\left(400 \mathrm{MHz}\right.$, Methanol- $\left.d_{4}\right)$ and ${ }^{13} \mathrm{C}\left(101 \mathrm{MHz}\right.$, Methanol- $\left.d_{4}\right)$ spectra of compound sg
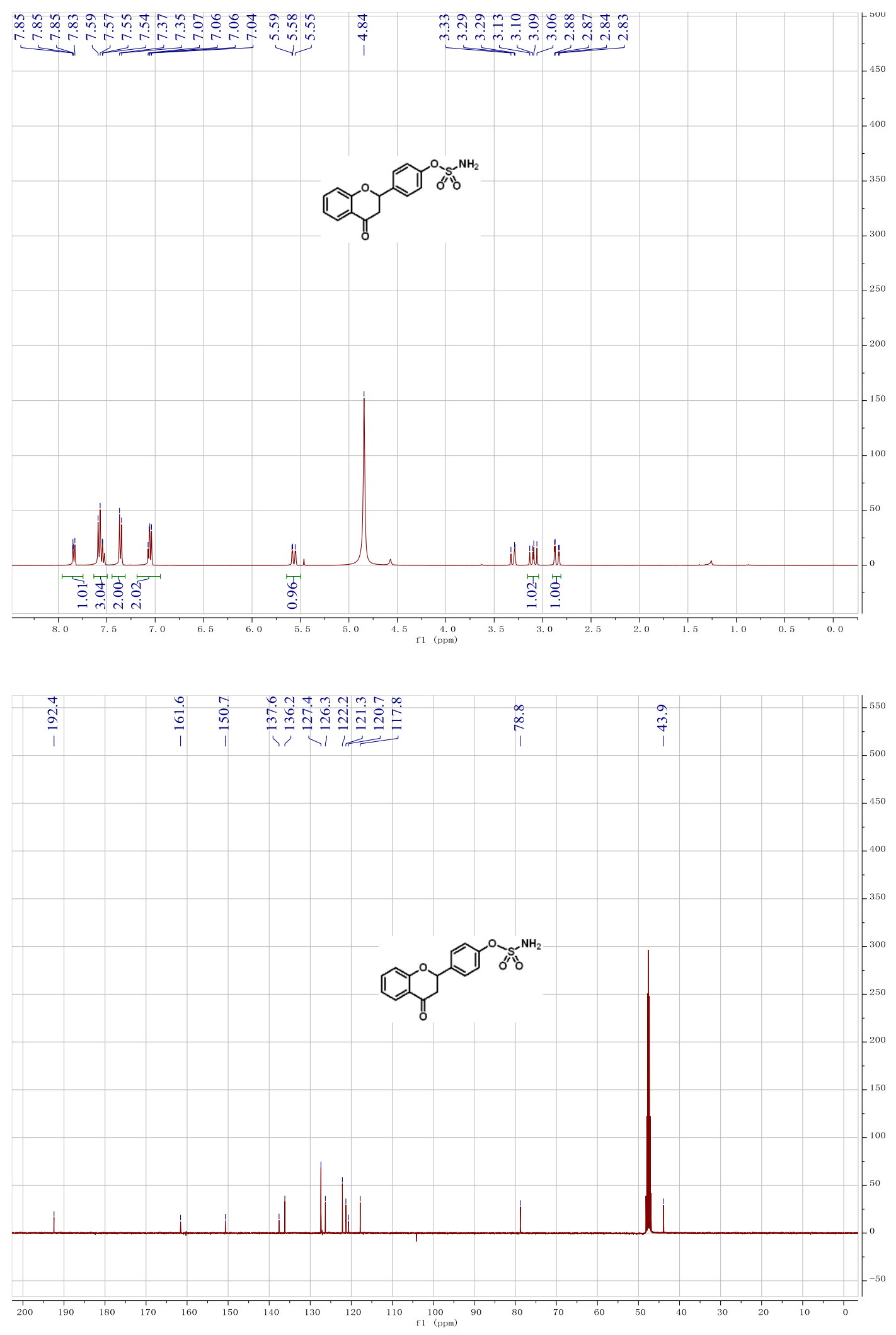

S41 
${ }^{1} \mathrm{H}\left(400 \mathrm{MHz}\right.$, Methanol- $\left.d_{4}\right)$ and ${ }^{13} \mathrm{C}\left(101 \mathrm{MHz}\right.$, Methanol- $\left.d_{4}\right)$ spectra of compound $5 h$
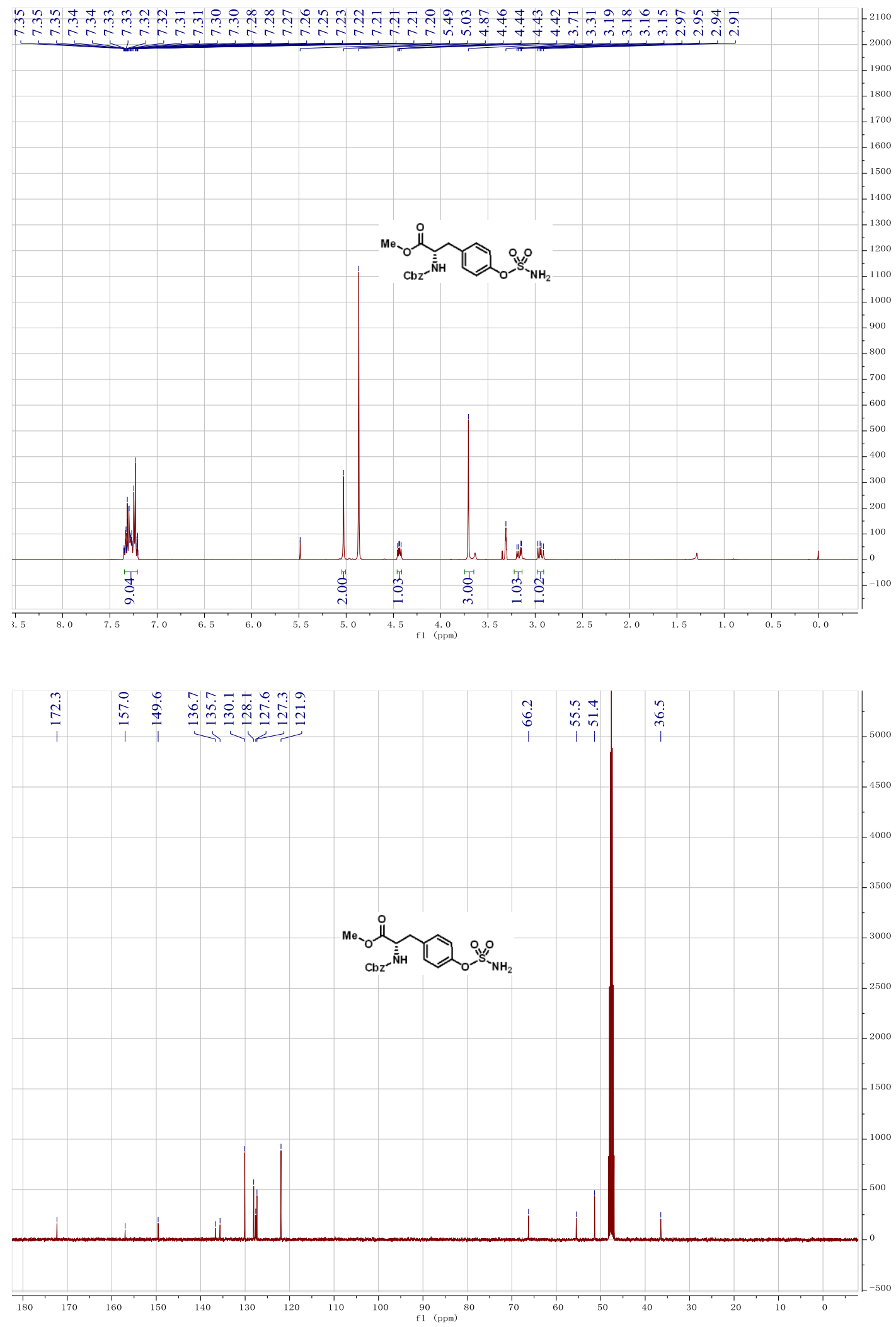
${ }^{1} \mathrm{H}\left(400 \mathrm{MHz}\right.$, Methanol- $\left.d_{4}\right)$ and ${ }^{13} \mathrm{C}\left(101 \mathrm{MHz}\right.$, Methanol- $\left.d_{4}\right)$ spectra of compound $5 \mathbf{i}$
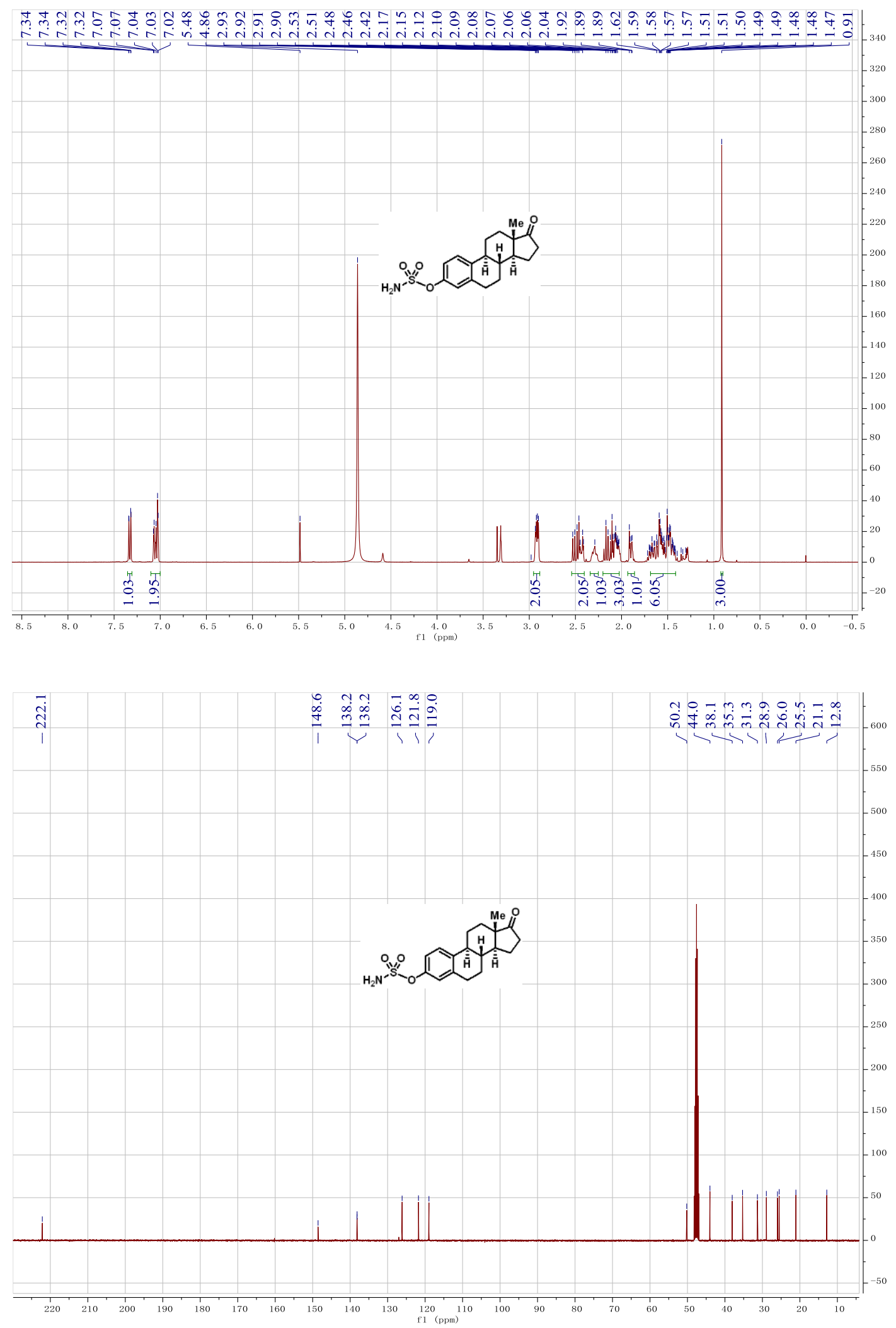
${ }^{1} \mathrm{H}\left(400 \mathrm{MHz}\right.$, Methanol- $\left.d_{4}\right)$ and ${ }^{13} \mathrm{C}\left(101 \mathrm{MHz}\right.$, Methanol- $\left.d_{4}\right)$ spectra of compound 7 a
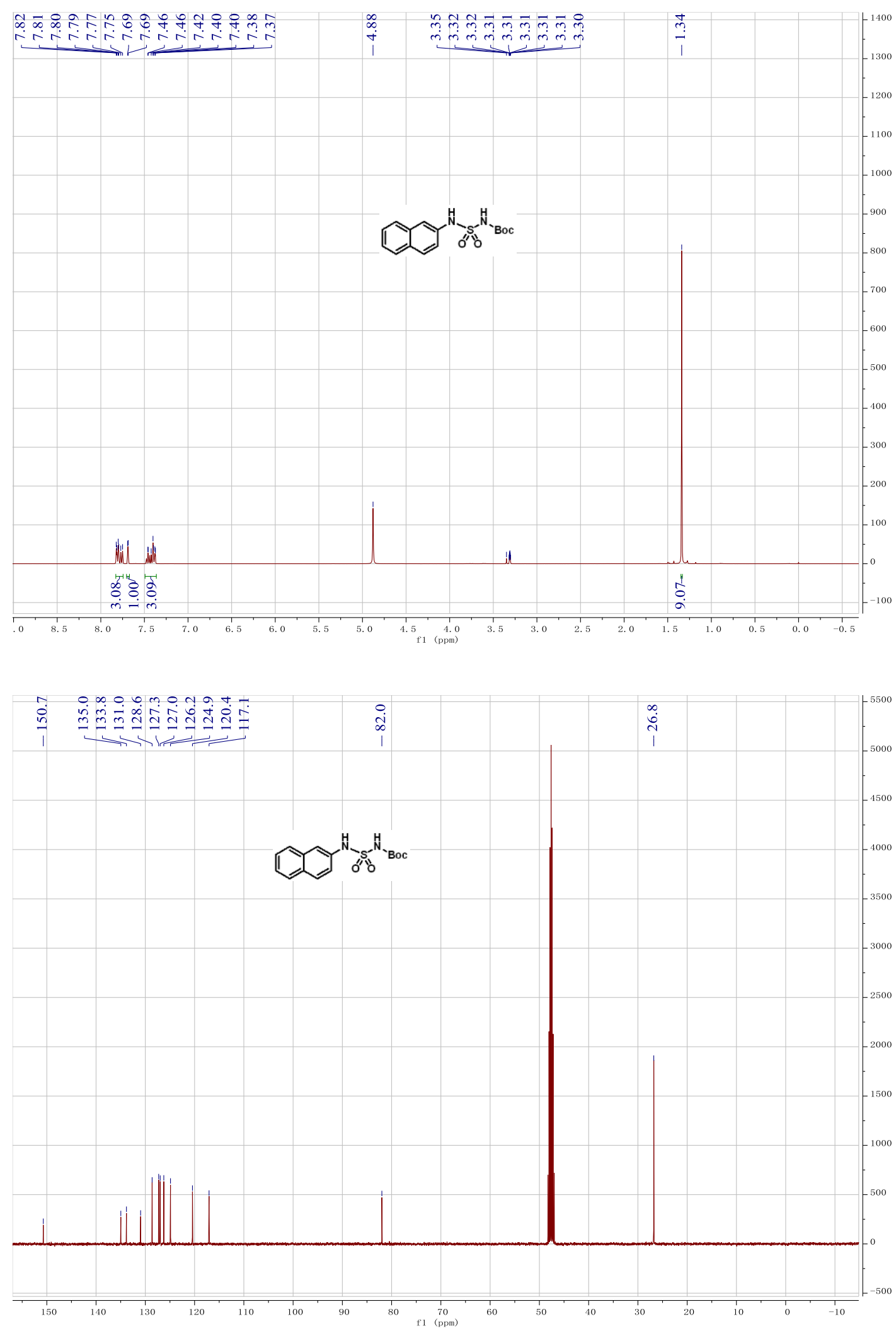
${ }^{1} \mathrm{H}\left(400 \mathrm{MHz}\right.$, Methanol- $\left.d_{4}\right)$ and ${ }^{13} \mathrm{C}\left(101 \mathrm{MHz}\right.$, Methanol- $\left.d_{4}\right)$ spectra of compound $7 \mathrm{~b}$
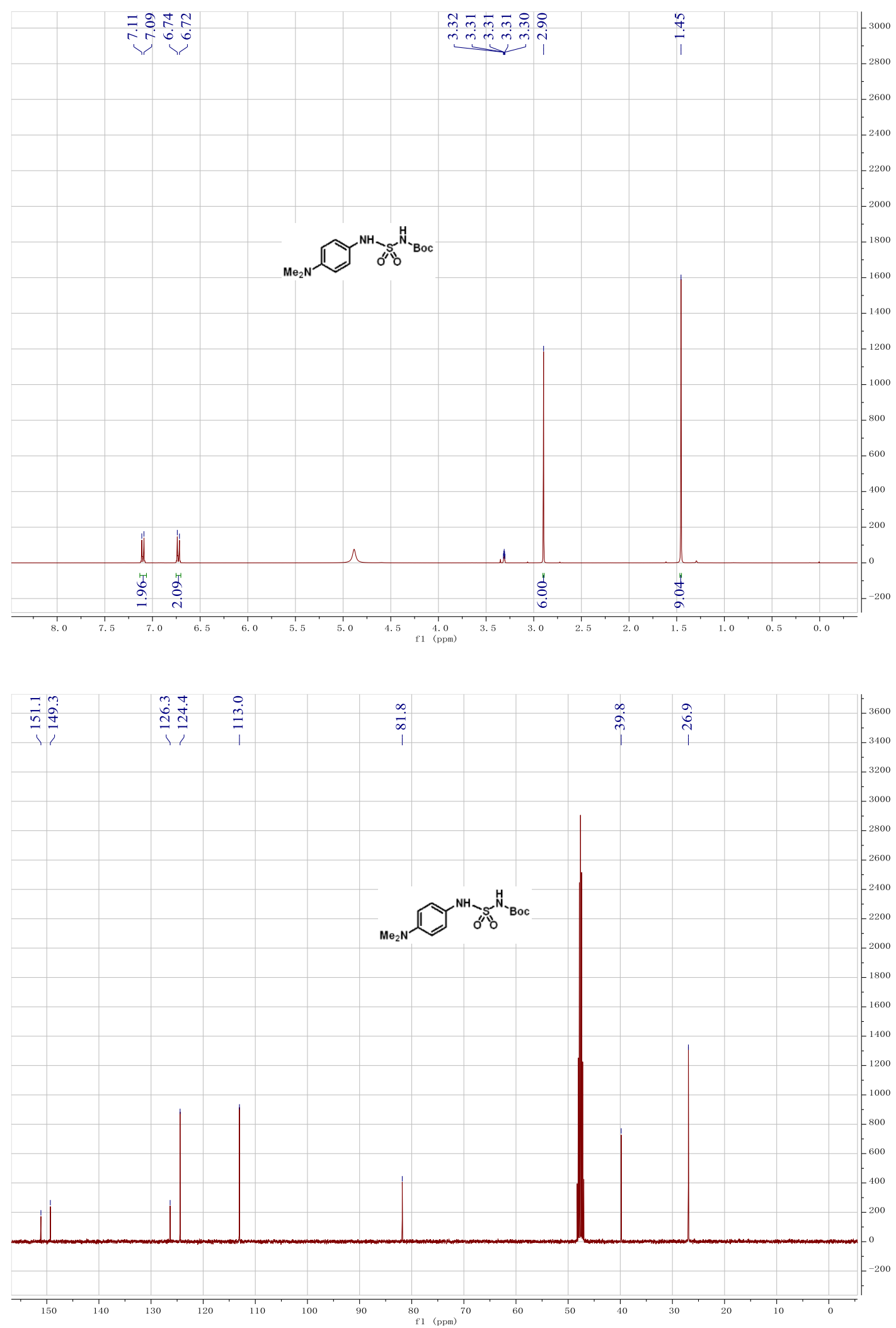
${ }^{1} \mathrm{H}\left(400 \mathrm{MHz}\right.$, Methanol- $\left.d_{4}\right)$ and ${ }^{13} \mathrm{C}\left(101 \mathrm{MHz}\right.$, Methanol- $\left.d_{4}\right)$ spectra of compound 7c
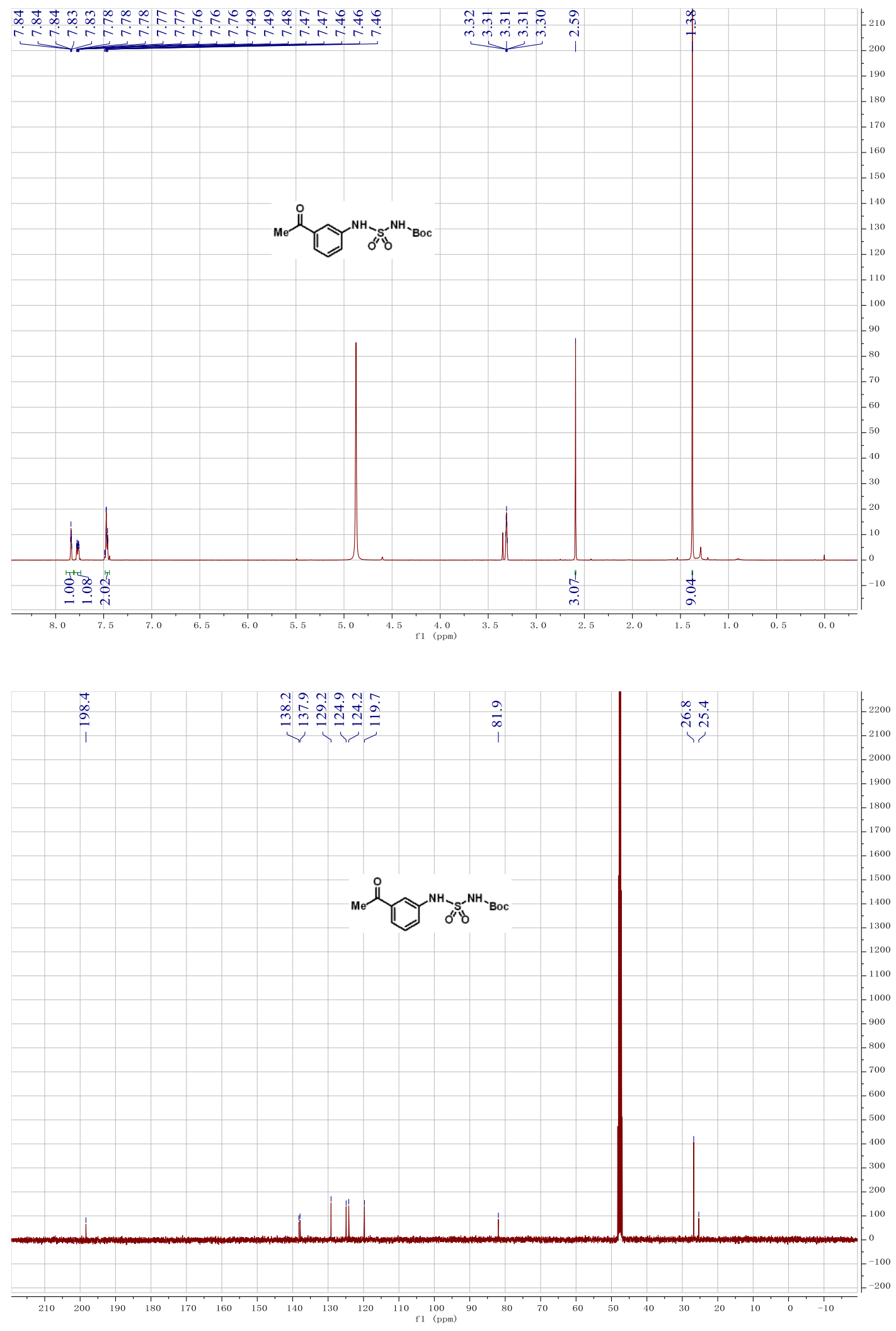
${ }^{1} \mathrm{H}\left(400 \mathrm{MHz}\right.$, Methanol- $\left.d_{4}\right)$ and ${ }^{13} \mathrm{C}\left(101 \mathrm{MHz}\right.$, Methanol- $\left.d_{4}\right)$ spectra of compound 7d
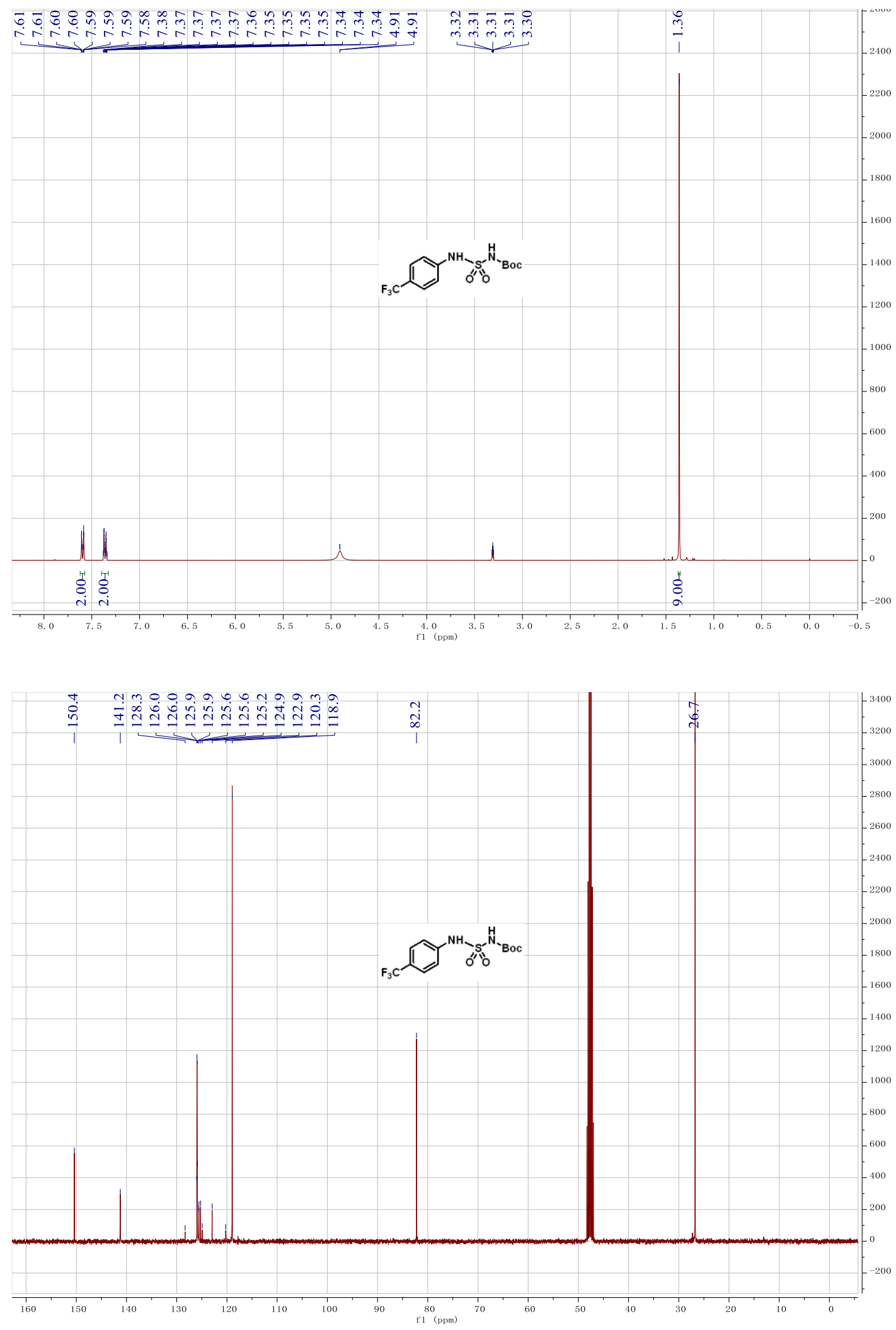
${ }^{1} \mathrm{H}\left(400 \mathrm{MHz}\right.$, Methanol- $\left.d_{4}\right)$ and ${ }^{13} \mathrm{C}\left(101 \mathrm{MHz}\right.$, Methanol- $\left.d_{4}\right)$ spectra of compound 7 e

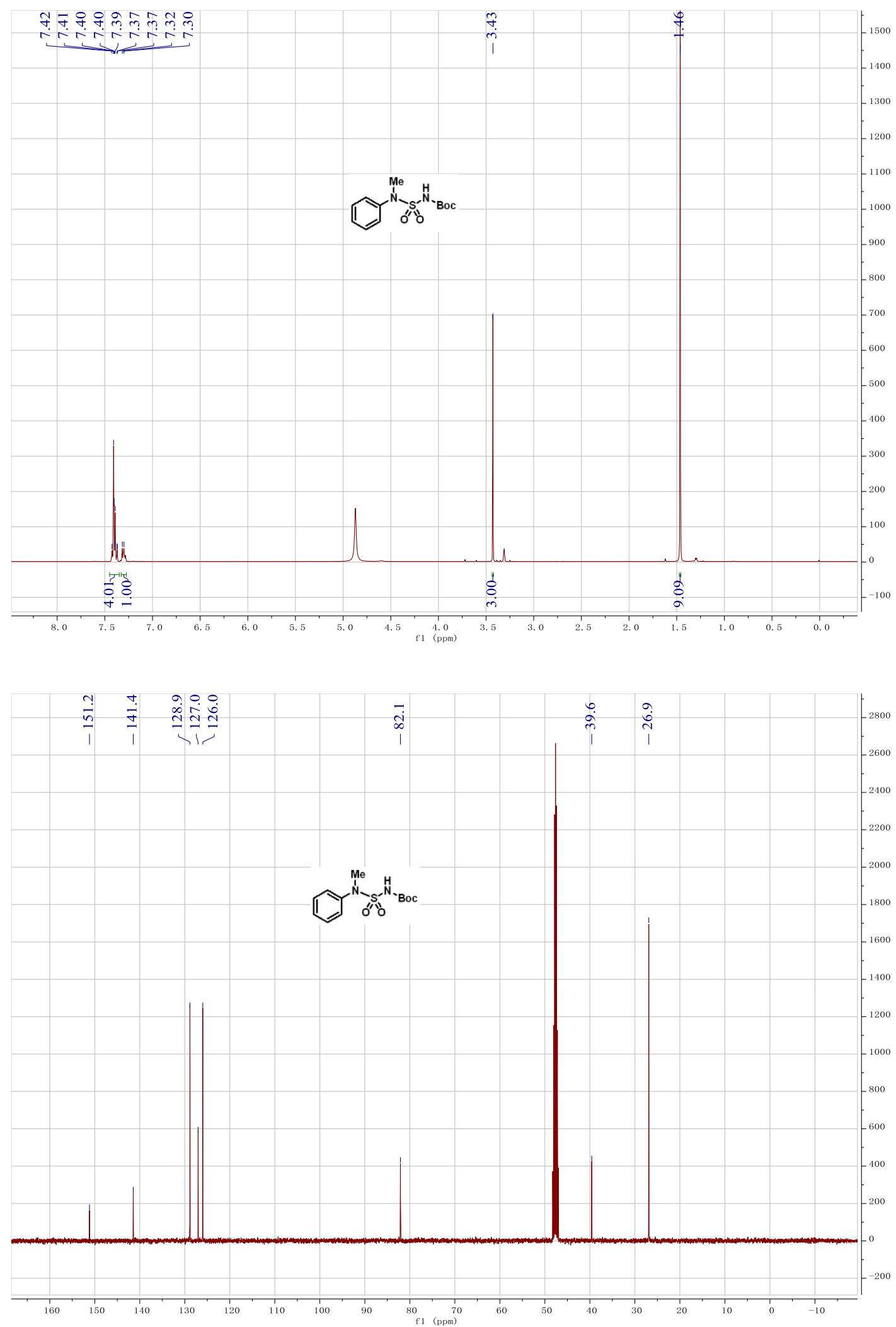


${ }^{1} \mathrm{H}\left(400 \mathrm{MHz}\right.$, Methanol- $\left.d_{4}\right)$ and ${ }^{13} \mathrm{C}\left(101 \mathrm{MHz}\right.$, Methanol- $\left.d_{4}\right)$ spectra of compound $7 f$
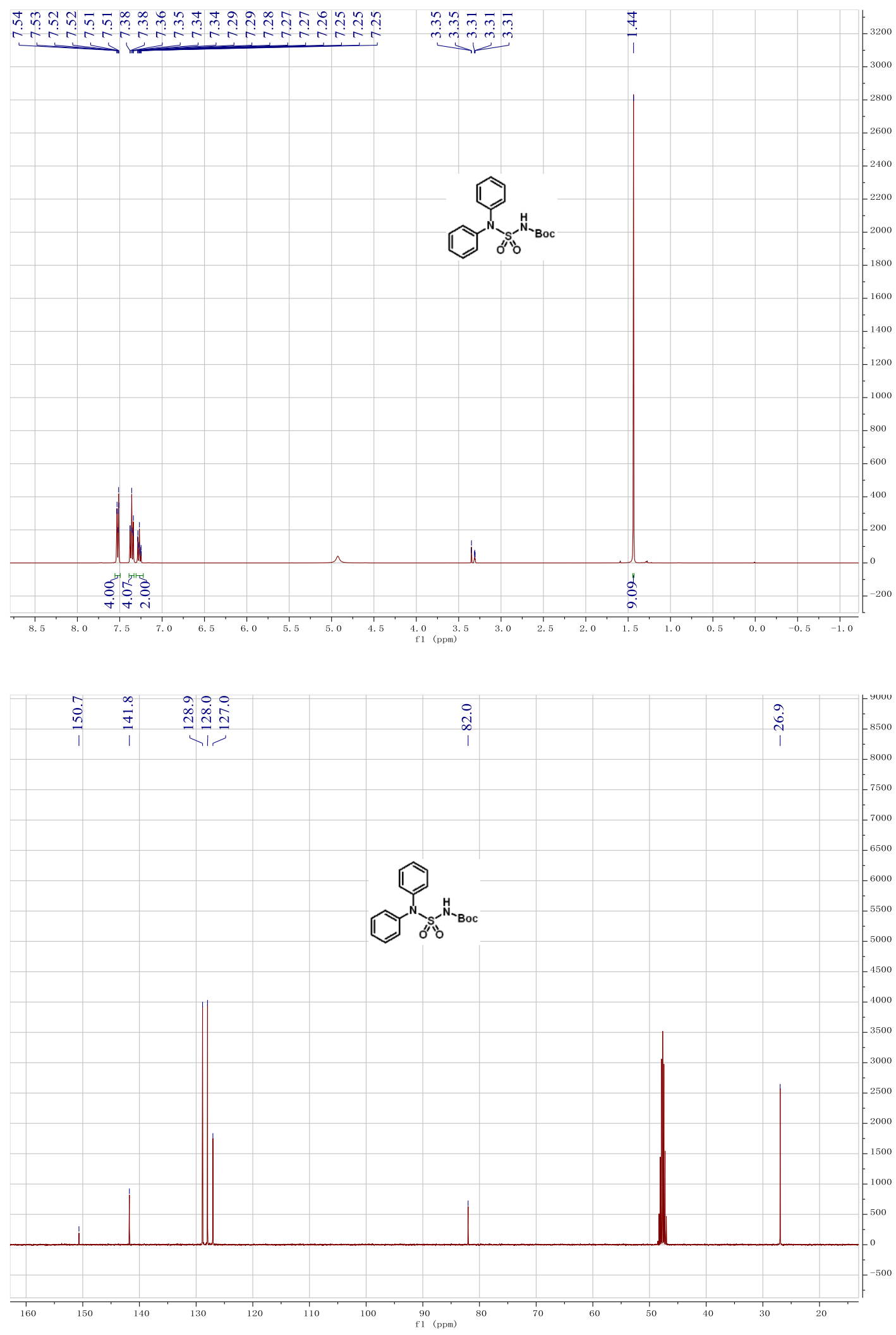
${ }^{1} \mathrm{H}\left(400 \mathrm{MHz}\right.$, Methanol- $\left.d_{4}\right)$ and ${ }^{13} \mathrm{C}\left(101 \mathrm{MHz}\right.$, Methanol- $\left.d_{4}\right)$ spectra of compound $7 \mathrm{~g}$
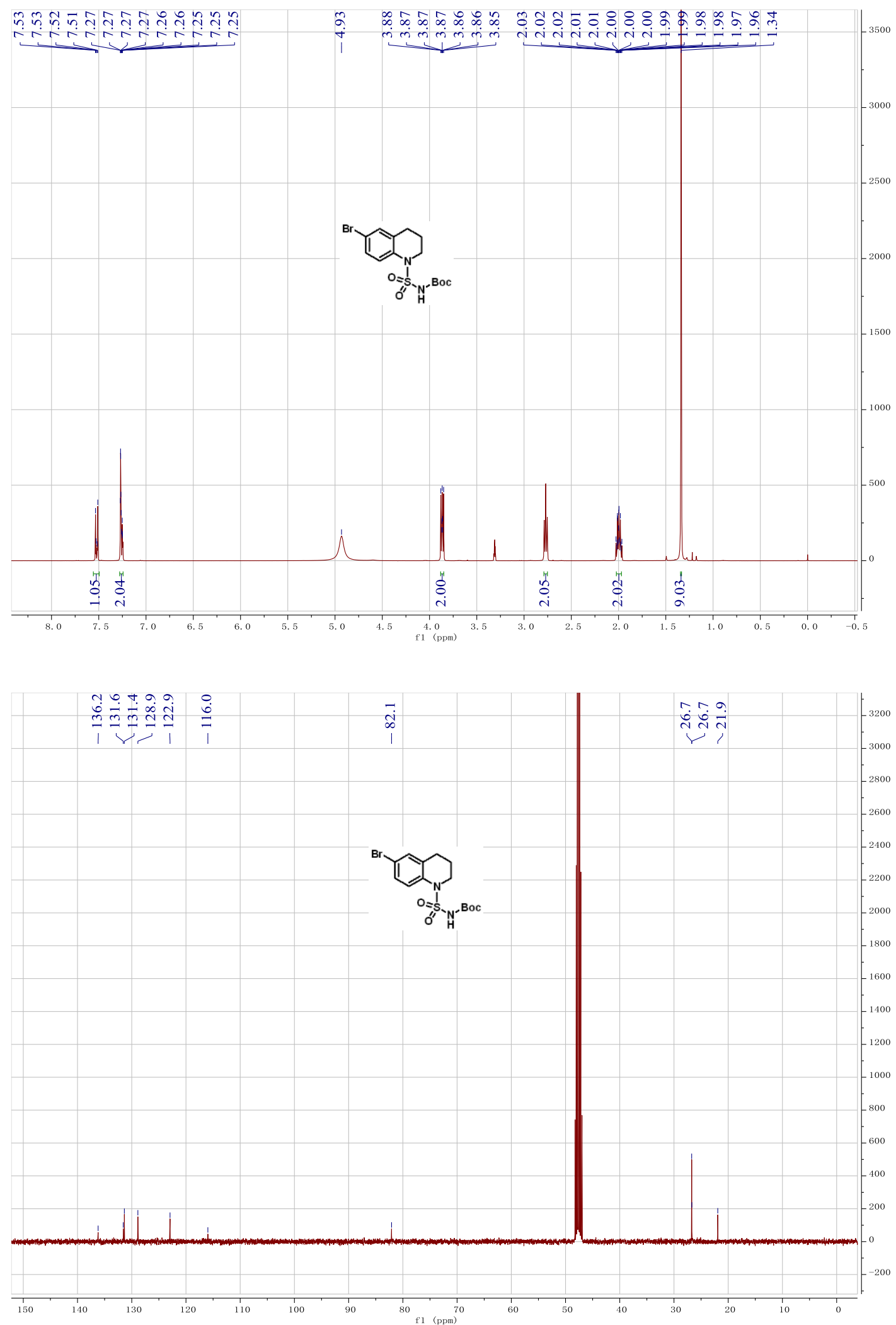
${ }^{1} \mathrm{H}\left(400 \mathrm{MHz}\right.$, Chloroform-d) and ${ }^{13} \mathrm{C}(101 \mathrm{MHz}$, Chloroform-d) spectra of compound $7 \mathrm{~h}$
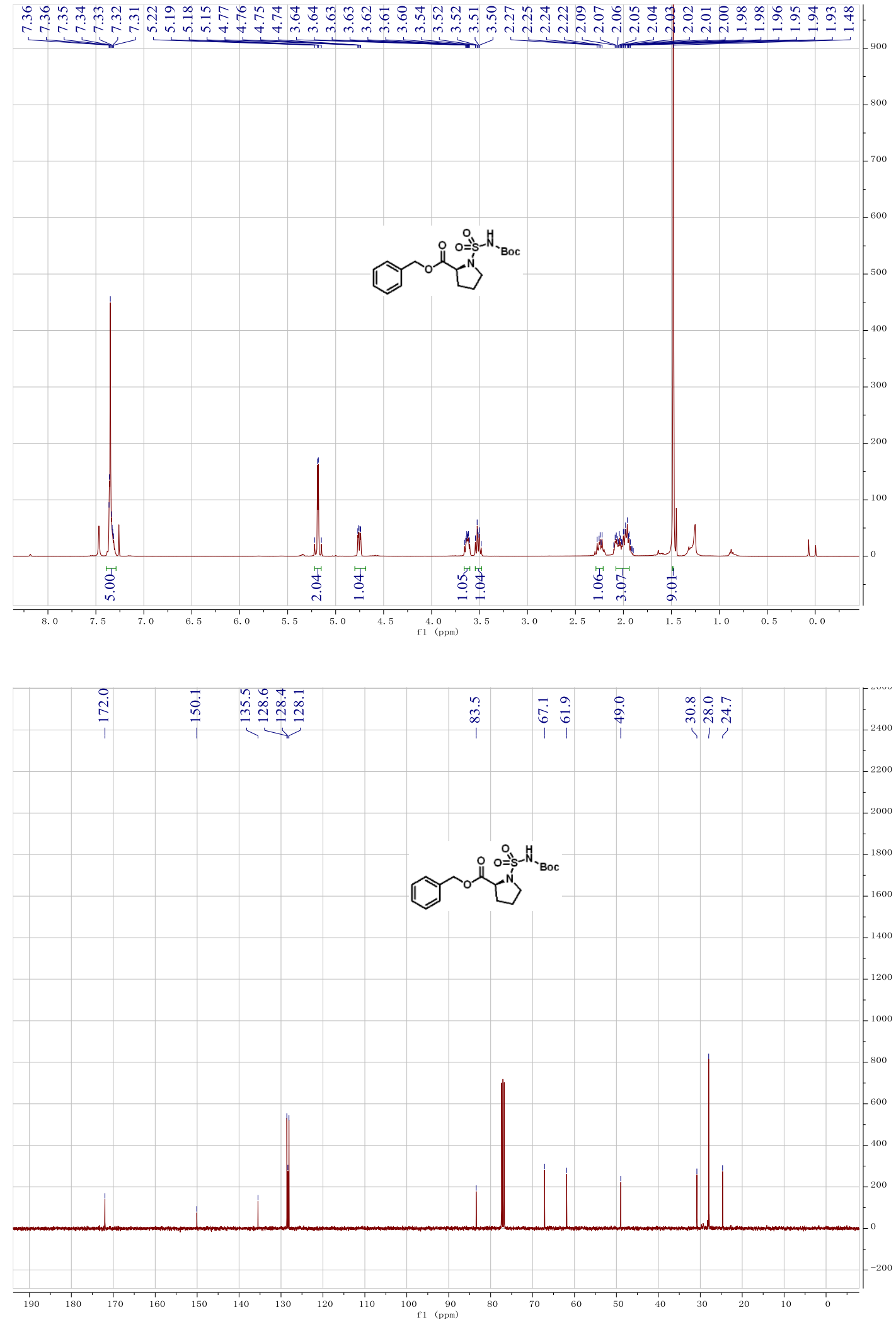
${ }^{1} \mathrm{H}\left(400 \mathrm{MHz}\right.$, Methanol- $\left.d_{4}\right)$ and ${ }^{13} \mathrm{C}\left(101 \mathrm{MHz}\right.$, Methanol- $\left.d_{4}\right)$ spectra of compound $7 \mathbf{i}$
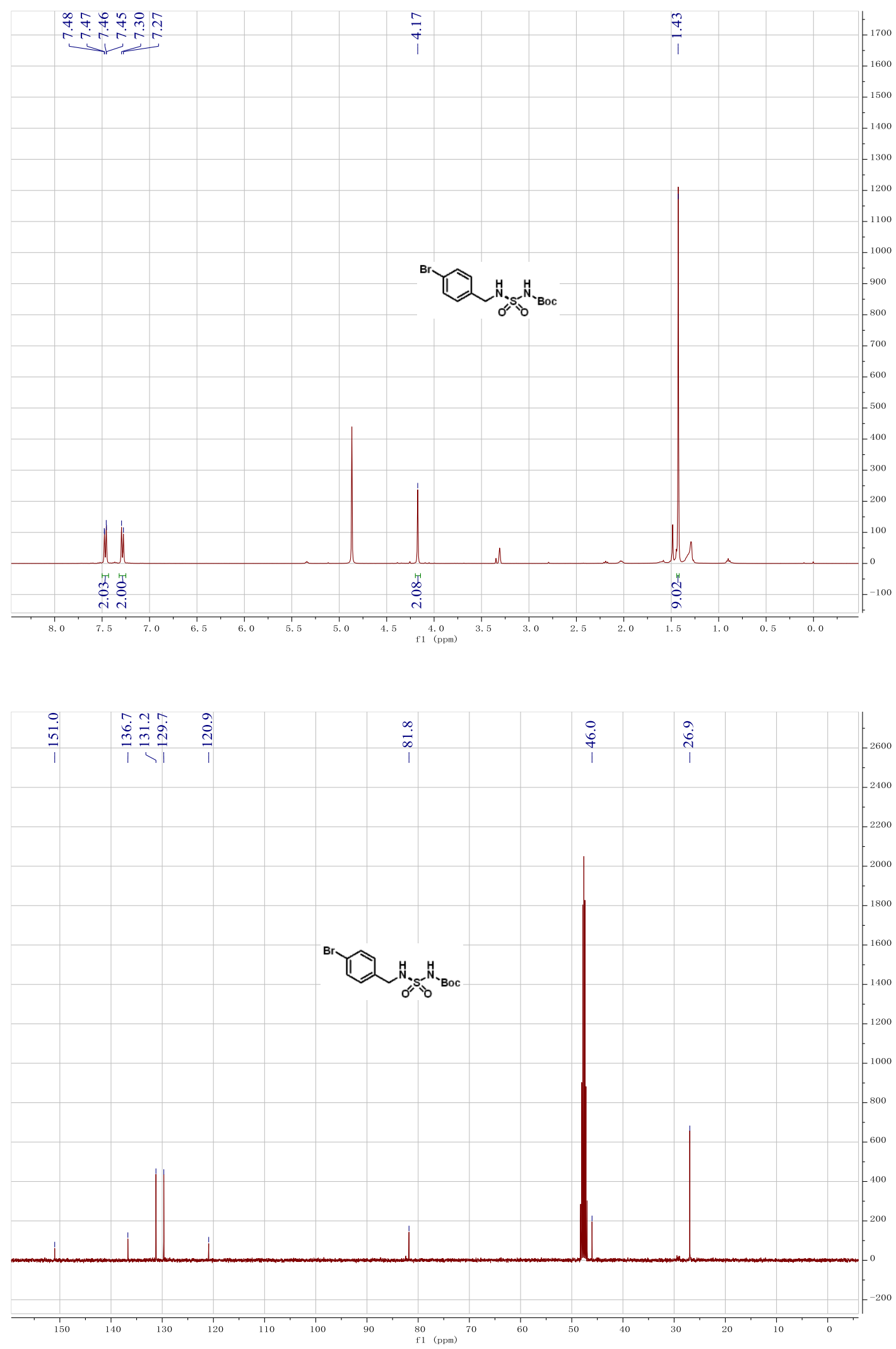
${ }^{1} \mathrm{H}\left(400 \mathrm{MHz}\right.$, Methanol- $\left.d_{4}\right)$ and ${ }^{13} \mathrm{C}\left(101 \mathrm{MHz}\right.$, Methanol- $\left.d_{4}\right)$ spectra of compound $7 \mathbf{j}$
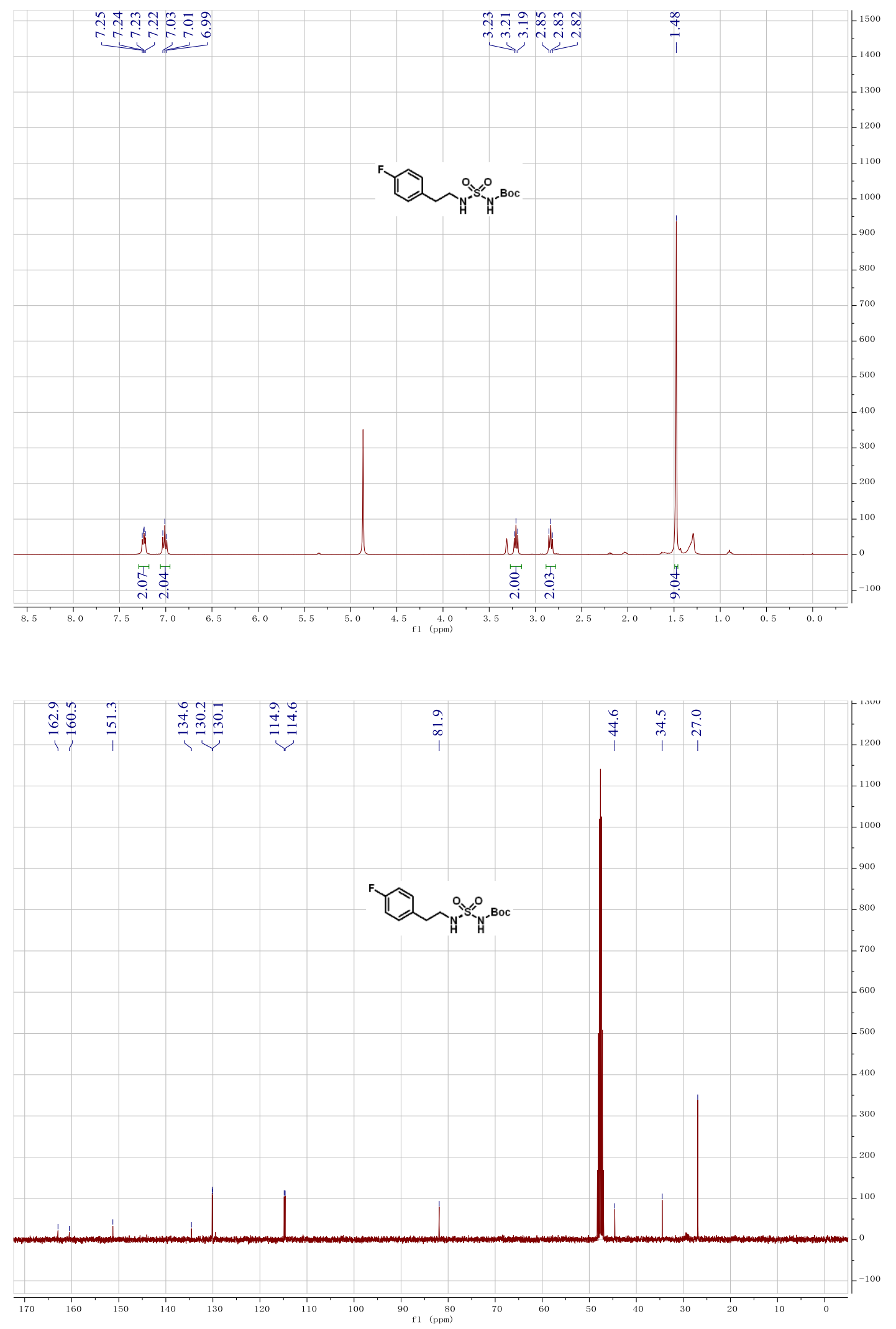

S53 
${ }^{1} \mathrm{H}\left(400 \mathrm{MHz}\right.$, Methanol- $\left.d_{4}\right)$ and ${ }^{13} \mathrm{C}\left(101 \mathrm{MHz}\right.$, Methanol- $\left.d_{4}\right)$ spectra of compound 9a
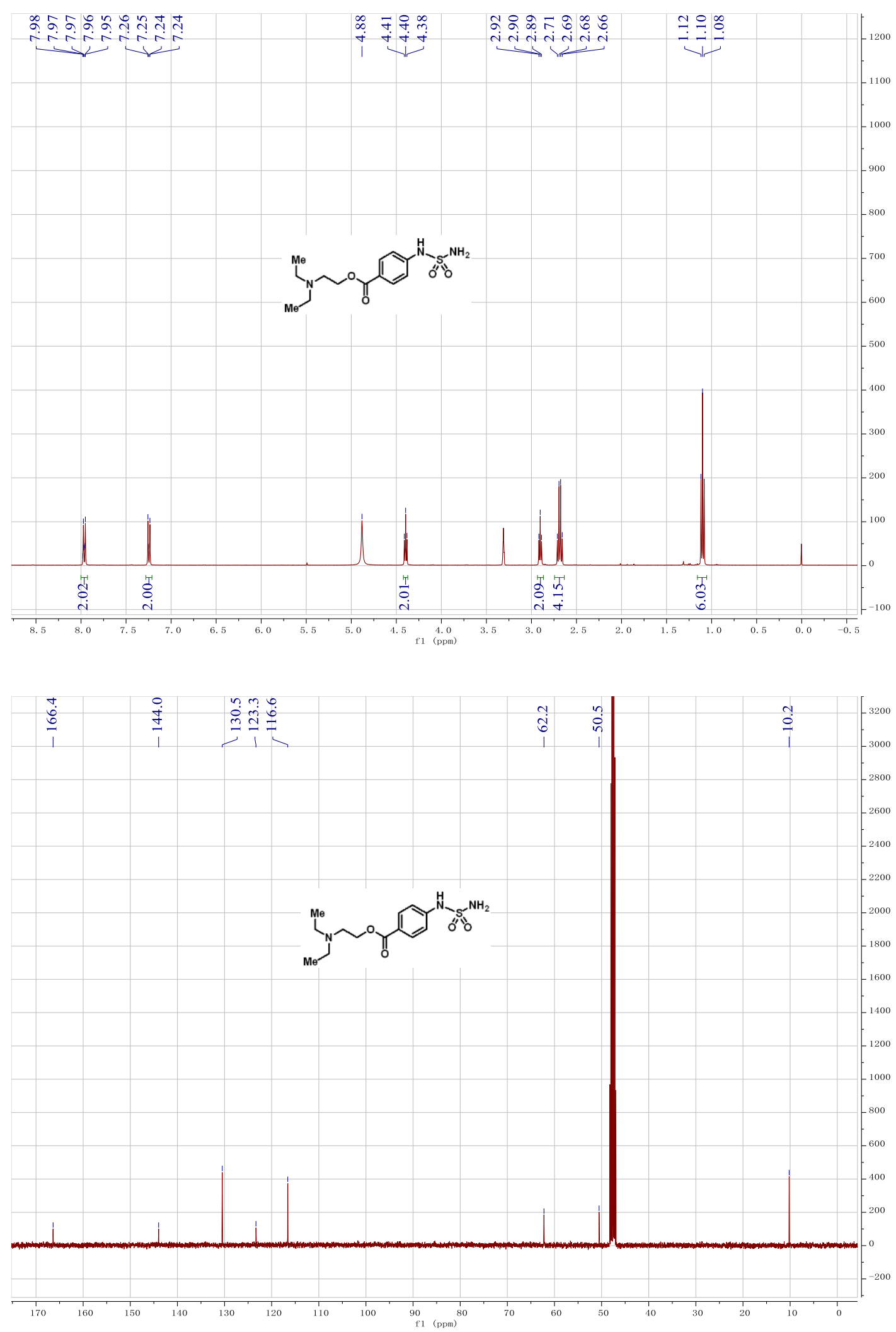
${ }^{1} \mathrm{H}\left(400 \mathrm{MHz}\right.$, Methanol- $\left.d_{4}\right)$ and ${ }^{13} \mathrm{C}\left(101 \mathrm{MHz}\right.$, Methanol- $\left.d_{4}\right)$ spectra of compound 9b
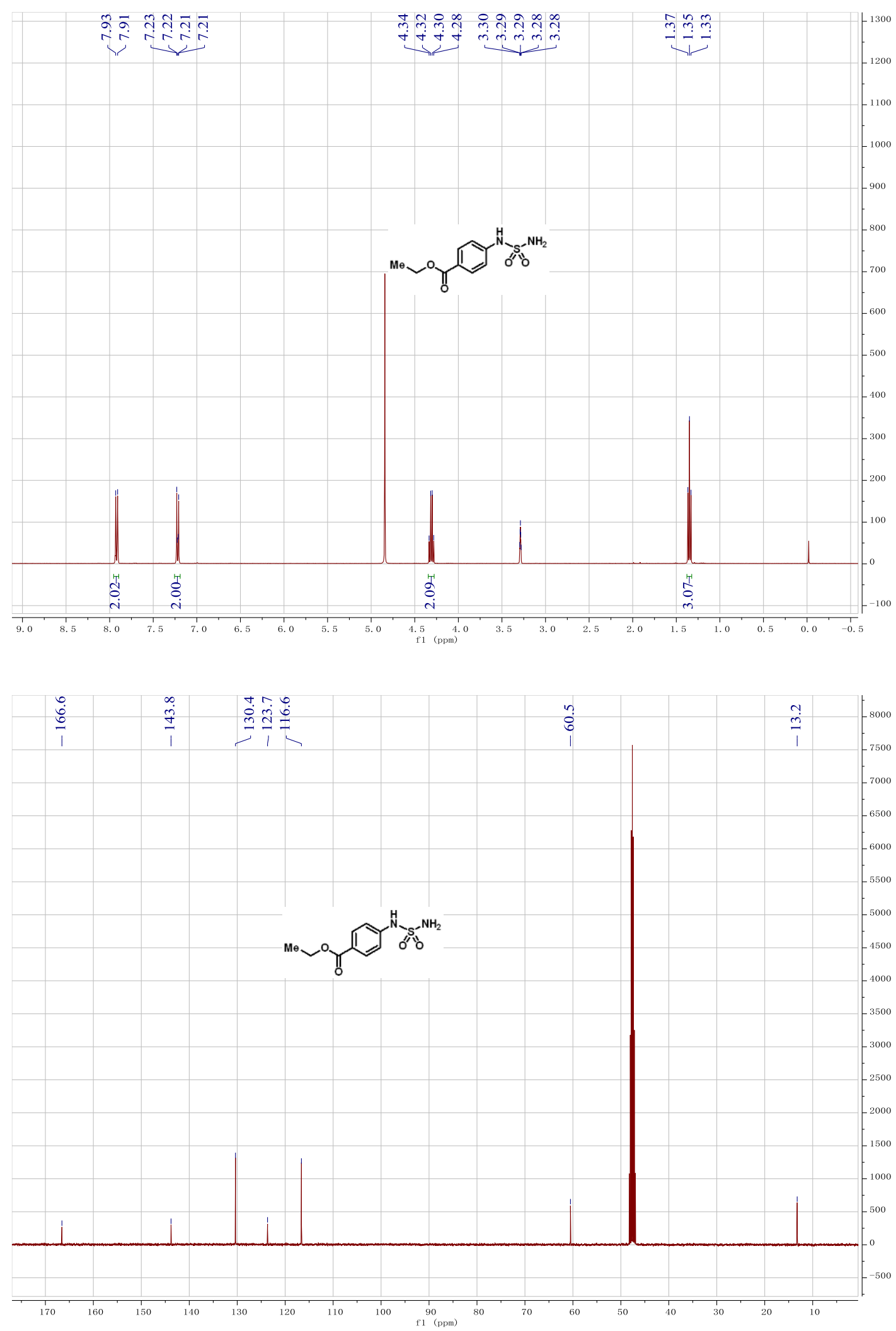
${ }^{1} \mathrm{H}\left(400 \mathrm{MHz}\right.$, Methanol- $\left.d_{4}\right)$ and ${ }^{13} \mathrm{C}\left(101 \mathrm{MHz}\right.$, Methanol- $\left.d_{4}\right)$ spectra of compound 9c
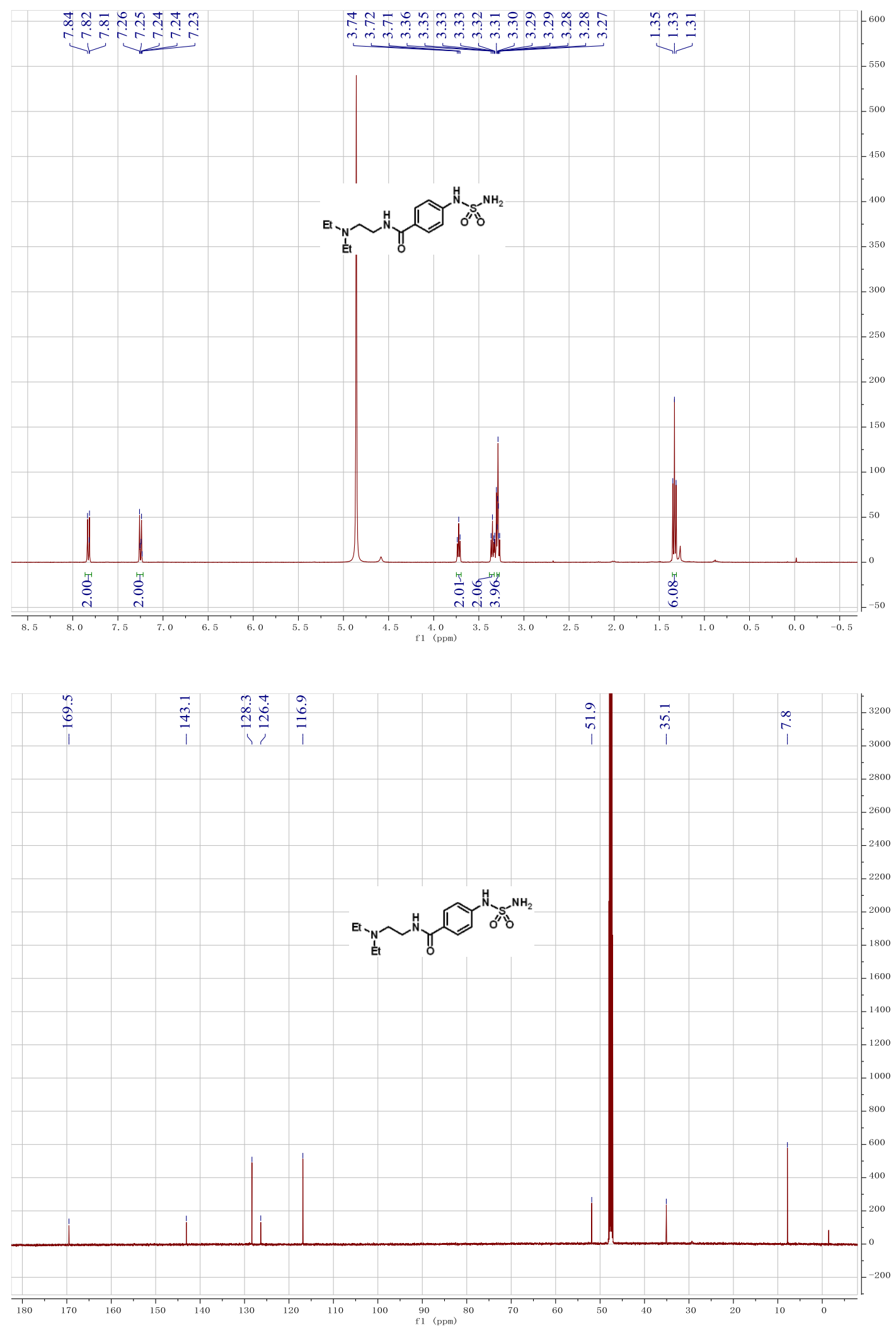
${ }^{1} \mathrm{H}\left(400 \mathrm{MHz}\right.$, Methanol- $\left.d_{4}\right)$ and ${ }^{13} \mathrm{C}\left(101 \mathrm{MHz}\right.$, Methanol- $\left.d_{4}\right)$ spectra of compound 9d

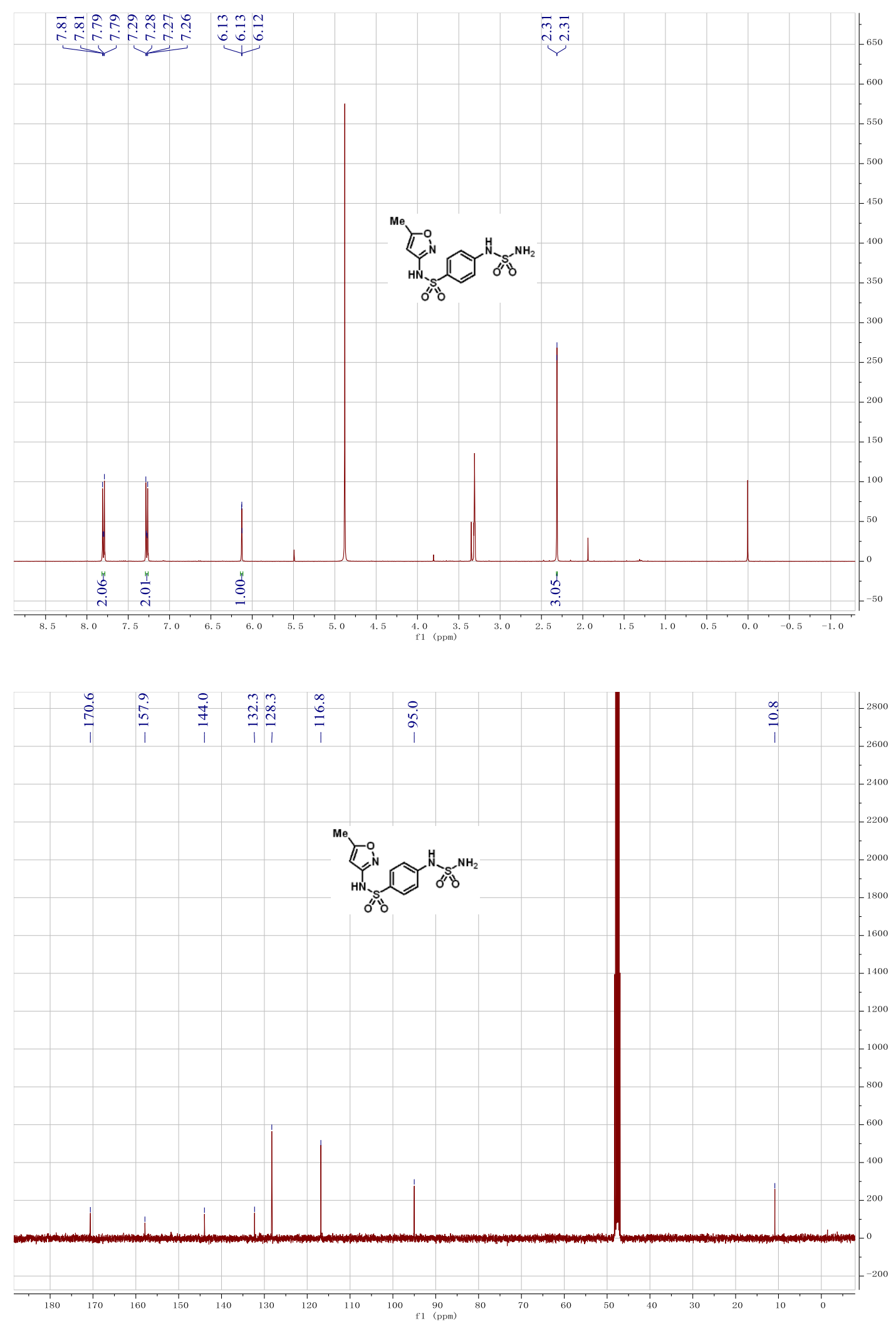


${ }^{1} \mathrm{H}\left(400 \mathrm{MHz}\right.$, Methanol- $\left.d_{4}\right)$ and ${ }^{13} \mathrm{C}\left(101 \mathrm{MHz}\right.$, Methanol- $\left.d_{4}\right)$ spectra of compound ge
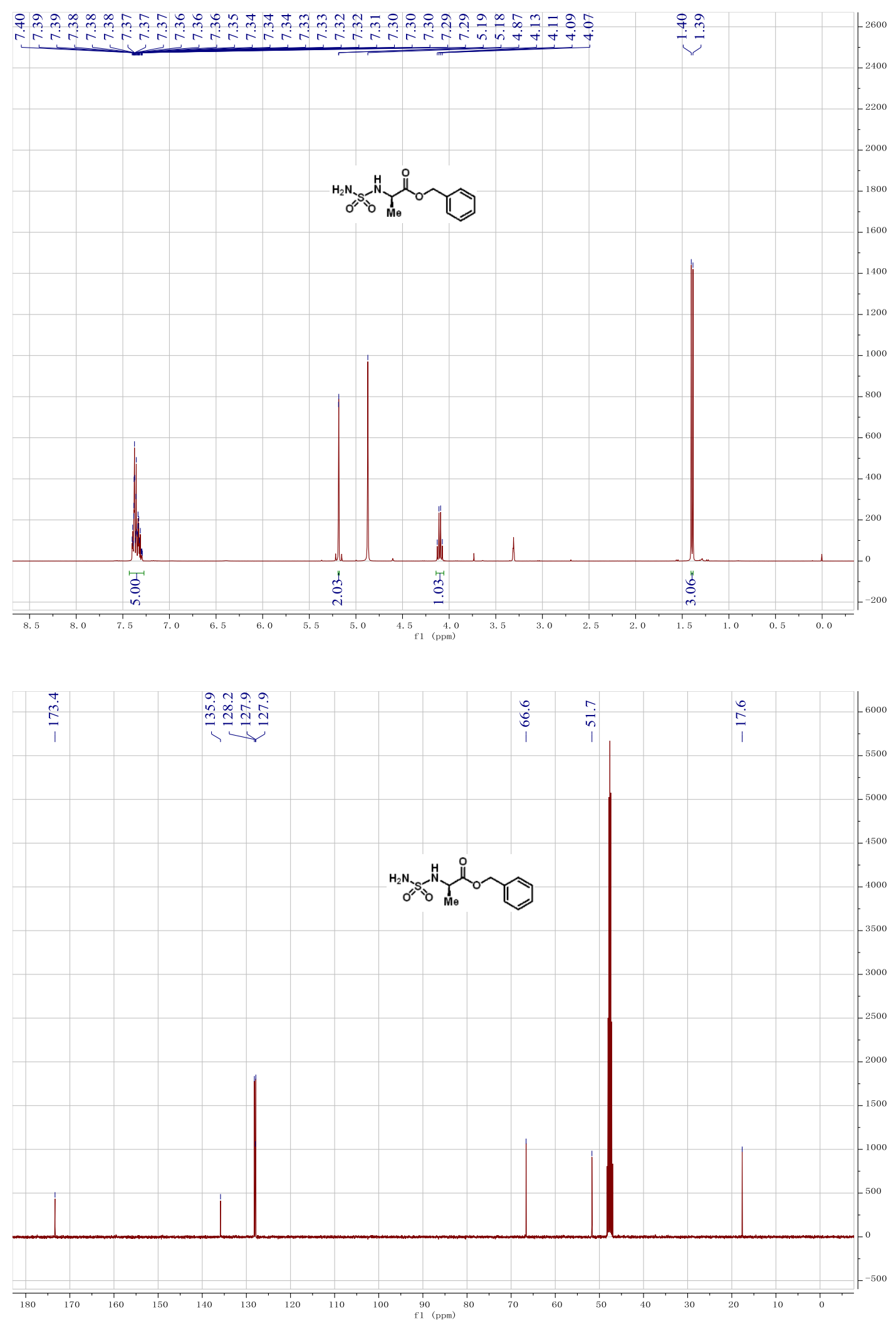

S58 
${ }^{1} \mathrm{H}\left(400 \mathrm{MHz}\right.$, Methanol- $\left.d_{4}\right)$ and ${ }^{13} \mathrm{C}\left(101 \mathrm{MHz}\right.$, Methanol- $\left.d_{4}\right)$ spectra of compound 9f
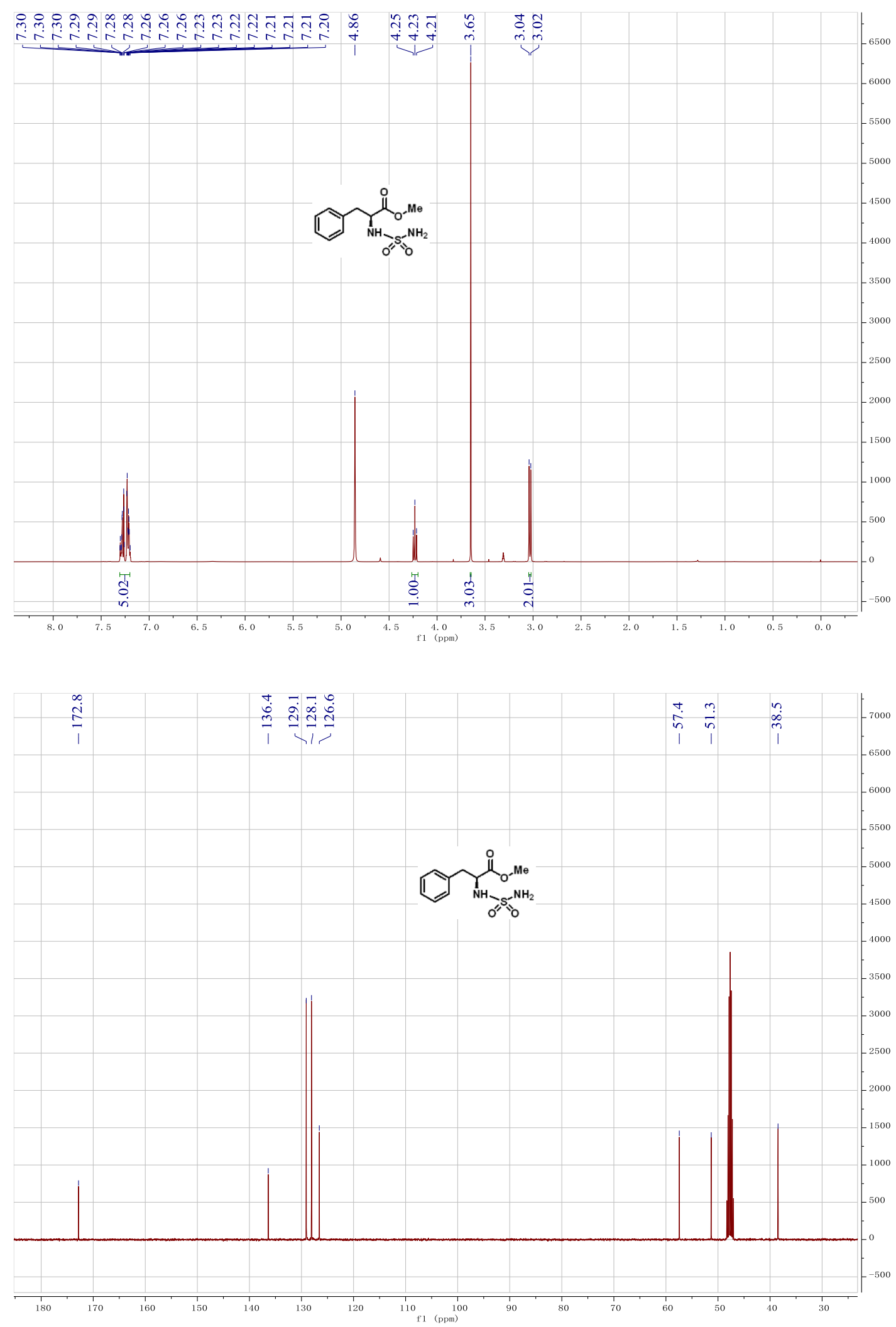
${ }^{1} \mathrm{H}\left(400 \mathrm{MHz}\right.$, Methanol- $\left.d_{4}\right)$ and ${ }^{13} \mathrm{C}\left(101 \mathrm{MHz}\right.$, Methanol- $\left.d_{4}\right)$ spectra of compound 11a
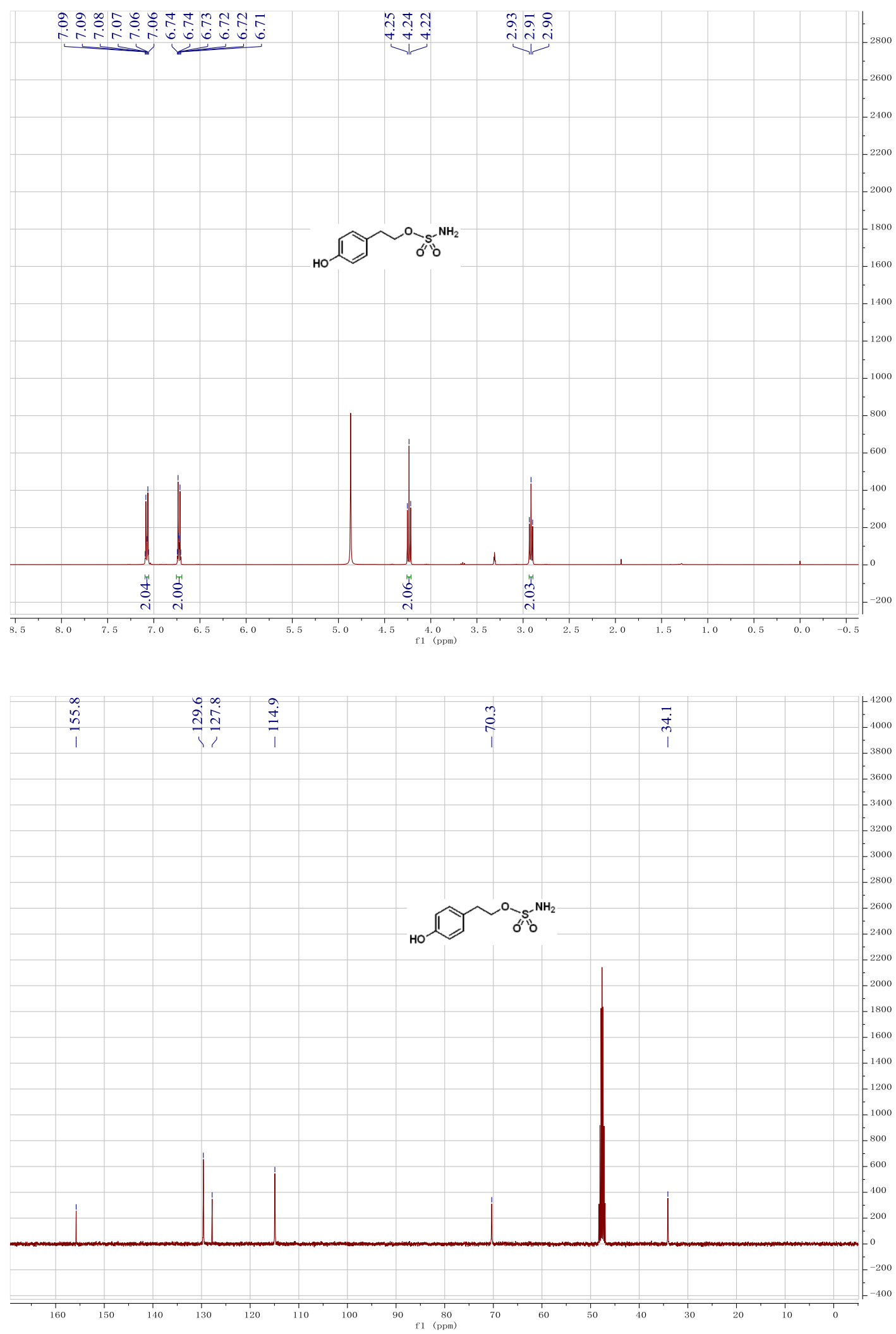
${ }^{1} \mathrm{H}\left(400 \mathrm{MHz}\right.$, Methanol- $\left.d_{4}\right)$ and ${ }^{13} \mathrm{C}\left(101 \mathrm{MHz}\right.$, Methanol- $\left.d_{4}\right)$ spectra of compound $11 b$
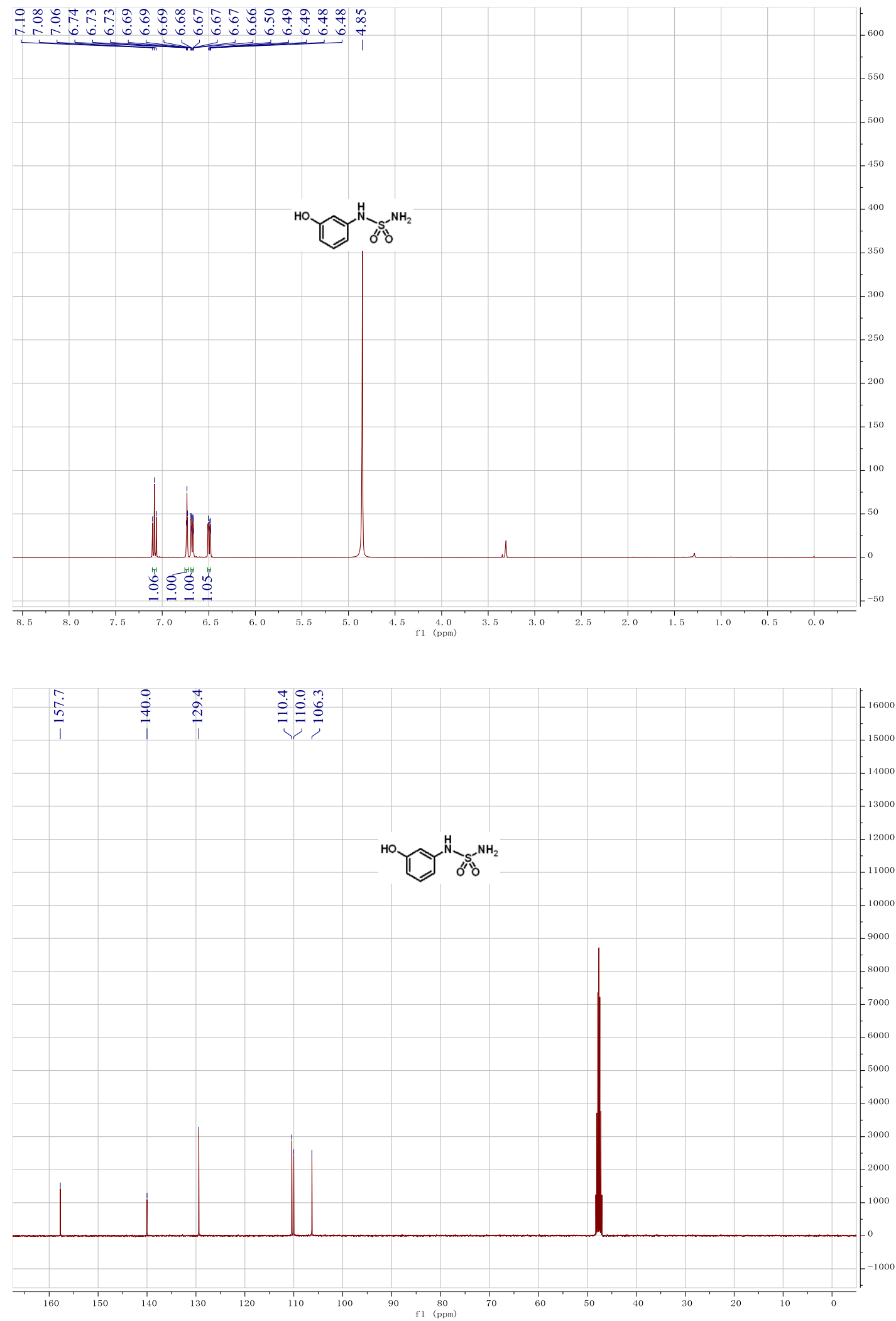
${ }^{1} \mathrm{H}\left(400 \mathrm{MHz}\right.$, Methanol- $\left.d_{4}\right)$ and ${ }^{13} \mathrm{C}\left(101 \mathrm{MHz}\right.$, Methanol- $\left.d_{4}\right)$ spectra of compound 11c
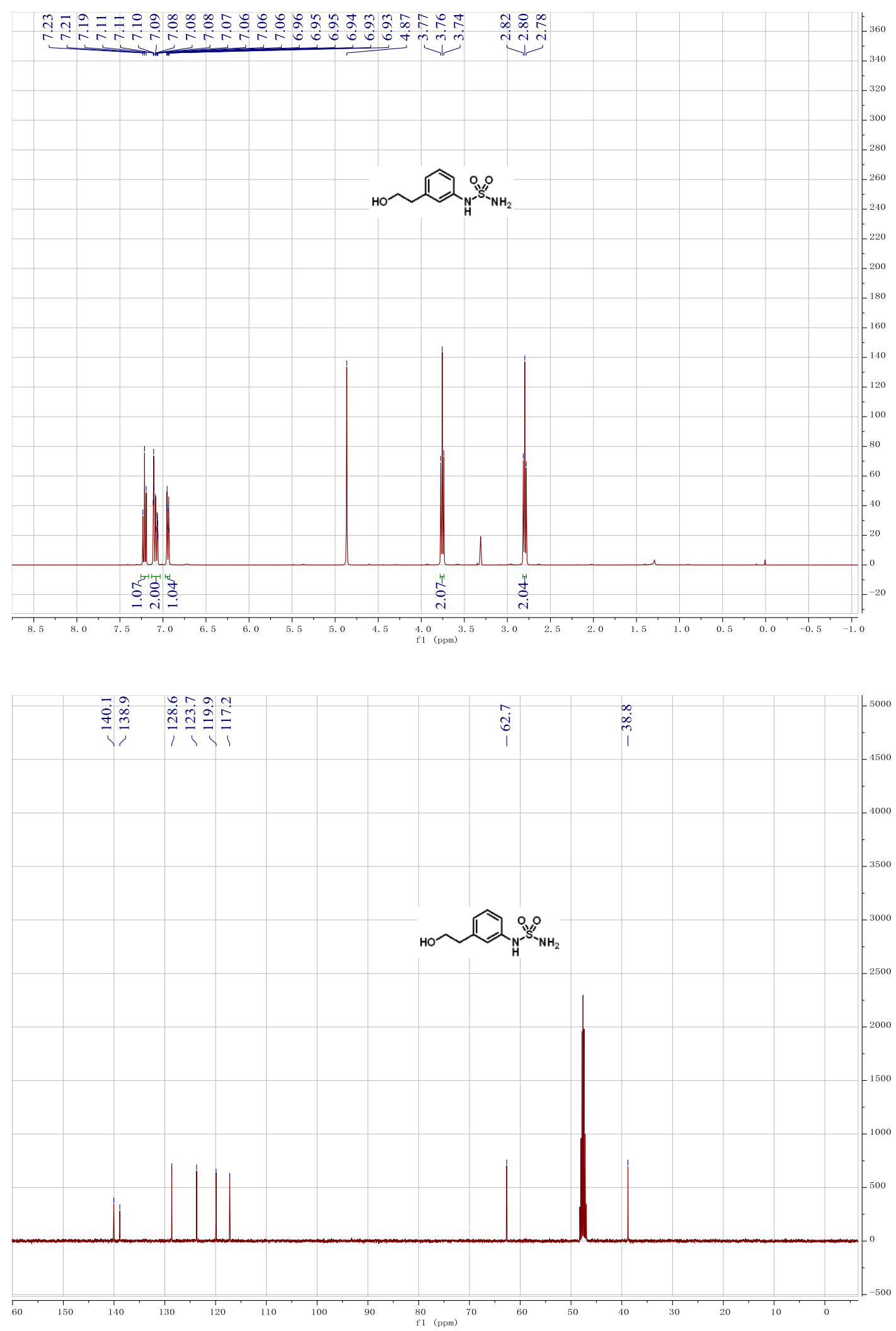
${ }^{1} \mathrm{H}\left(400 \mathrm{MHz}\right.$, Methanol- $\left.d_{4}\right)$ and ${ }^{13} \mathrm{C}\left(101 \mathrm{MHz}\right.$, Methanol- $\left.d_{4}\right)$ spectra of compound 11d
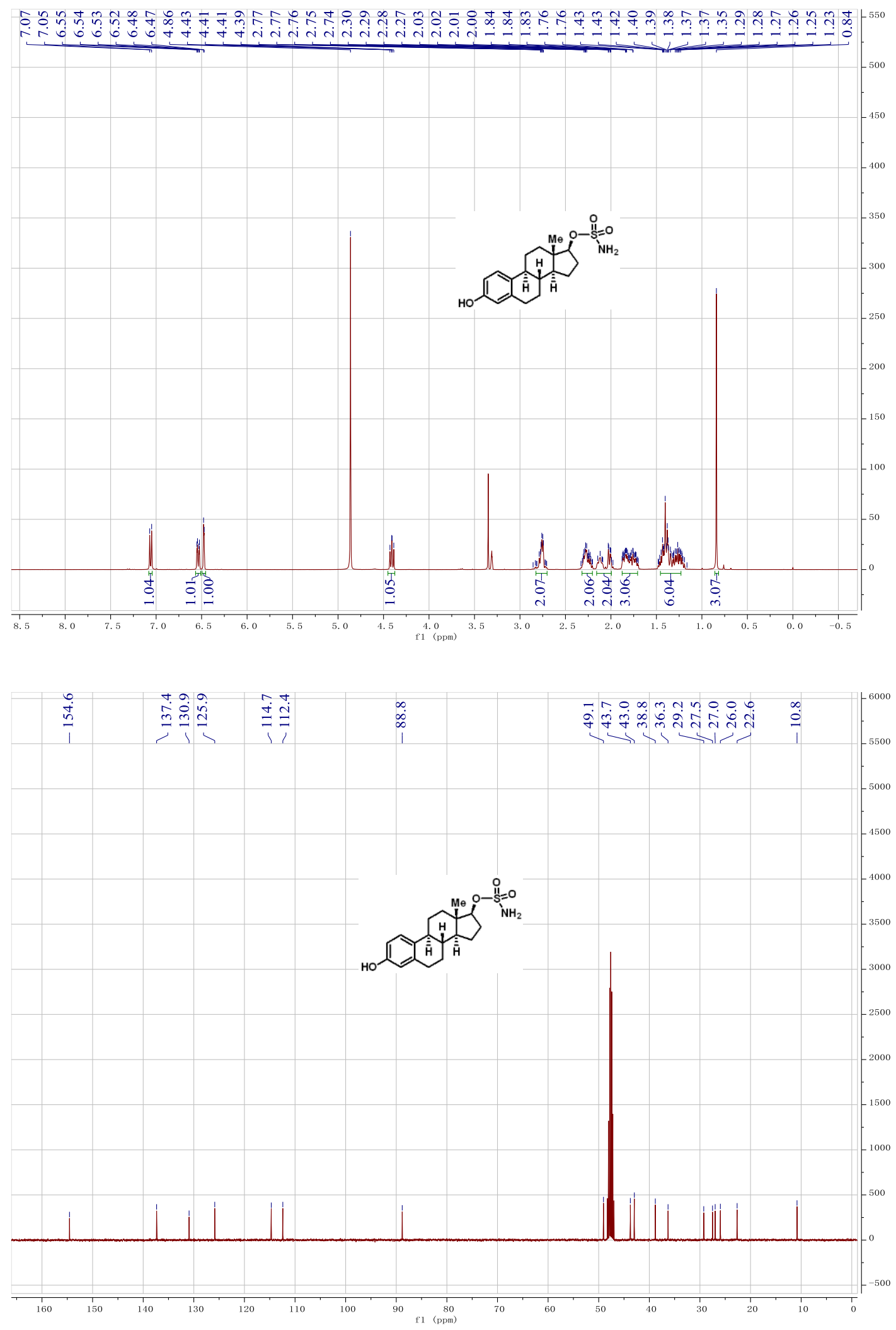
${ }^{1} \mathrm{H}\left(400 \mathrm{MHz}\right.$, Methanol- $\left.d_{4}\right)$ and ${ }^{13} \mathrm{C}\left(101 \mathrm{MHz}\right.$, Methanol- $\left.d_{4}\right)$ spectra of compound 11e
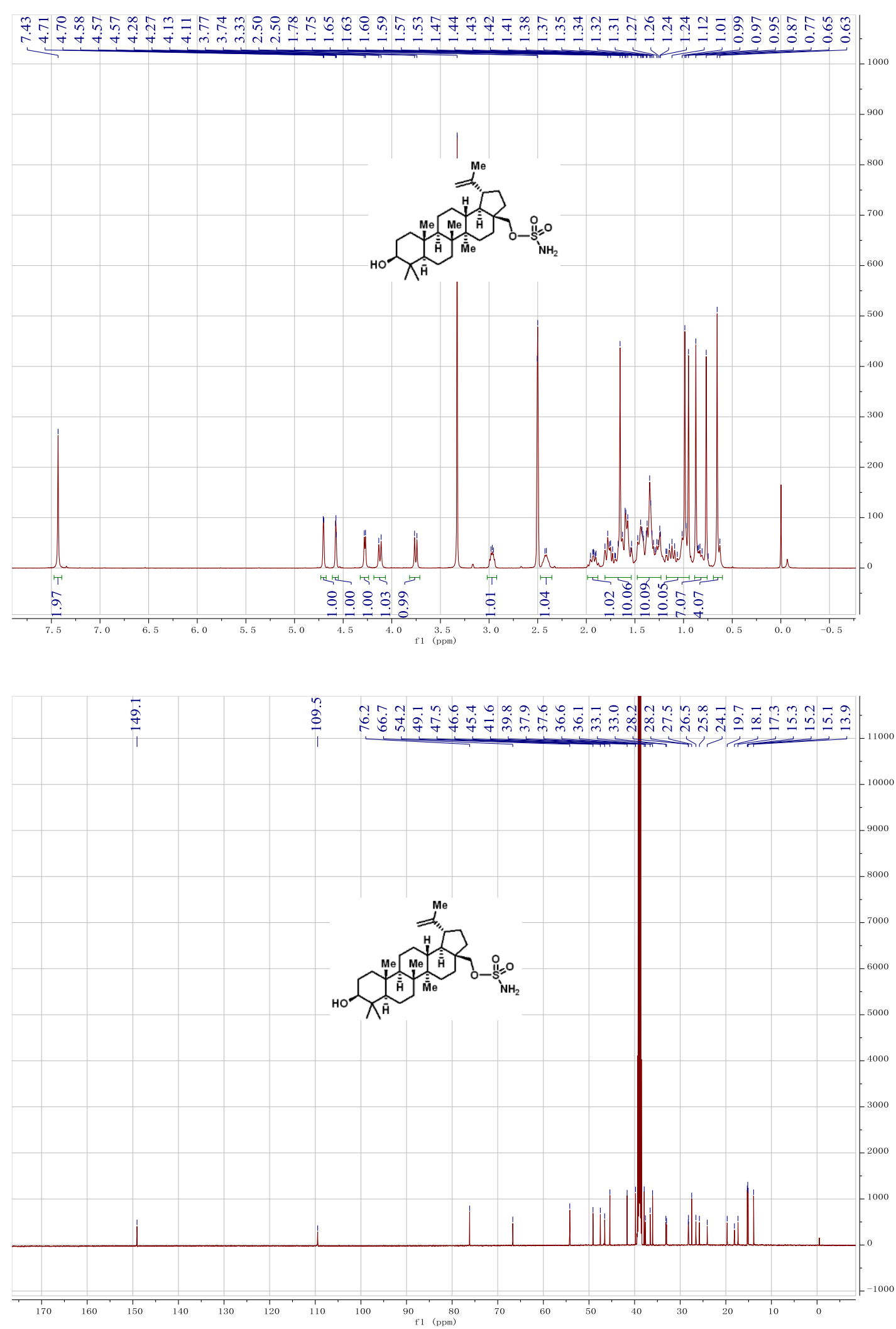
${ }^{1} \mathrm{H}\left(400 \mathrm{MHz}\right.$, Methanol- $\left.d_{4}\right)$ and ${ }^{13} \mathrm{C}\left(101 \mathrm{MHz}\right.$, Methanol- $\left.d_{4}\right)$ spectra of compound $11 f$
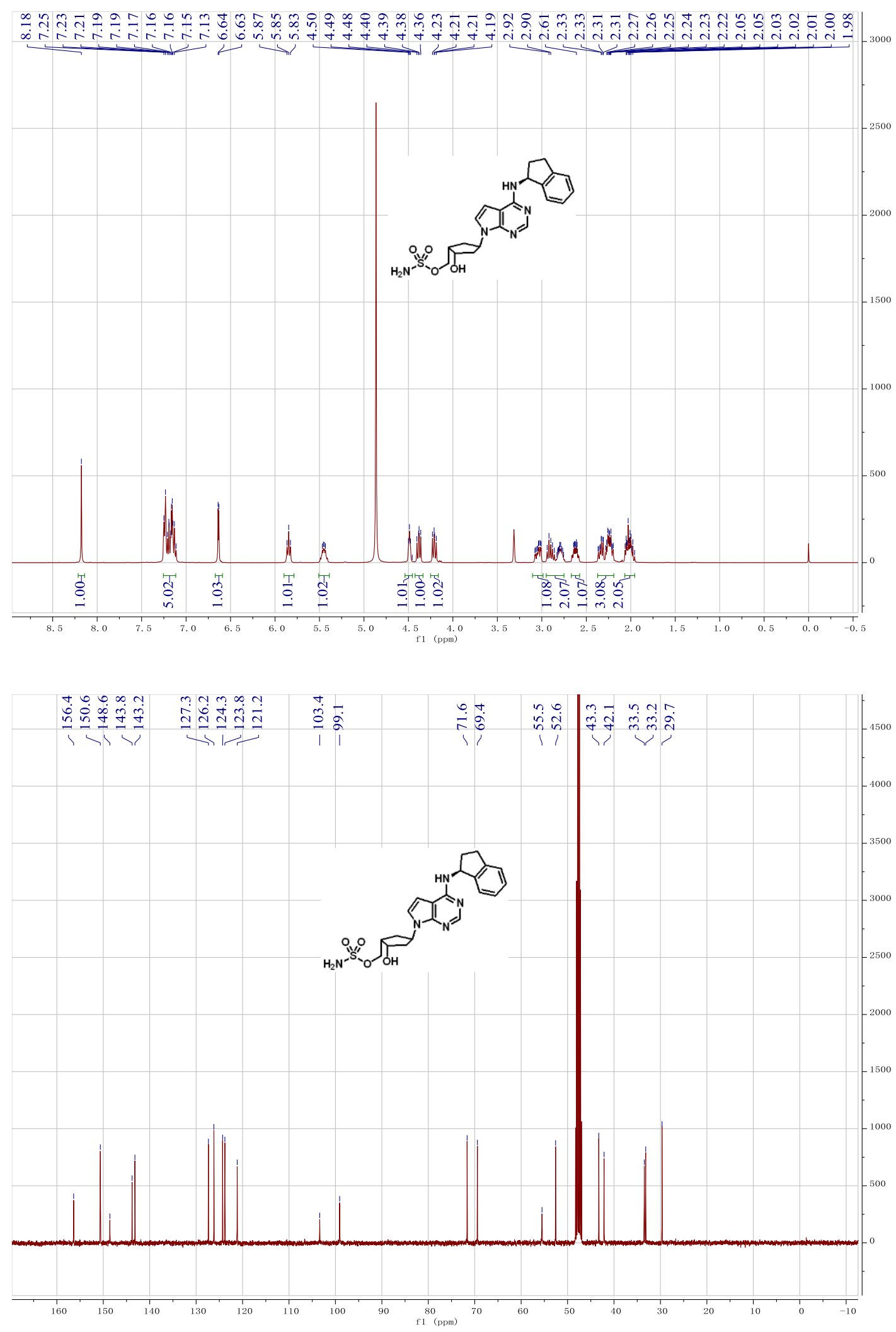

S65 


\section{References}

(1) Soucy, T. A.; Smith, P. G.; Milhollen, M. A.; Berger, A J.; Gavin, J. M.; Adhikari, S.; Brownell, J. E.; Burke, K E.; Cardin, D. P.; Critchley, S.; Cullis, C. A.; Doucette, A.; Garnsey, J. J. Gaulin, J. L.; Gershman, R. E.; Lublinsky, A. R.; McDonald, A.; Mizutani, H.; Narayanan, U.; Olhava, E. J.; Peluso, S.; Rezaei, M.; Sintchak, M. D.; Talreja, T.; Thomas, M. P.; Traore, T.; Vyskocil, S.; Weatherhead, G. S.; Yu, J.; Zhang, J.; Dick, L. R.; Claiborne, C. F.; Rolfe, M.; Bolen, J. B.; Langston, S. P. An inhibitor of NEDD8-activating enzyme as a new approach to treat cancer. Nature. 2009, 458, 732-736. 